Maternal Negative Affectivity and Child-feeding:

Results from the Norwegian Mother and Child Cohort Study.

by

Eivind Ystrøm

Department of Psychosomatics and Health Behavior

Division of Mental Health, Norwegian Institute of Public Health

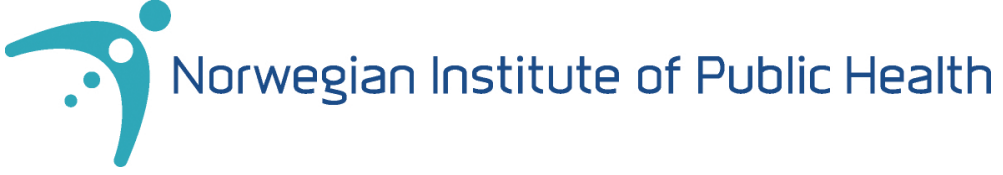

Submitted for the degree of $\mathrm{PhD}$ at the Department of Psychology, Faculty of Social Sciences, University of Oslo

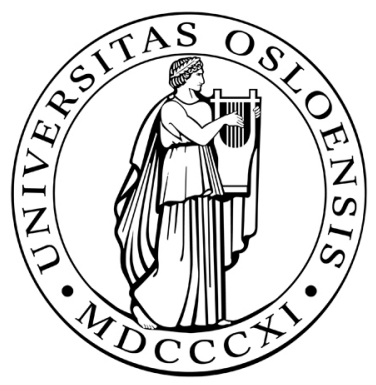


(C) Eivind Ystrøm, 2009

Series of dissertations submitted to the

Faculty of Social Sciences, University of Oslo

No. 160

\section{ISSN 1504-3991}

All rights reserved. No part of this publication may be reproduced or transmitted, in any form or by any means, without permission.

Cover: Inger Sandved Anfinsen.

Printed in Norway: AiT e-dit AS, Oslo, 2009.

Produced in co-operation with Unipub AS.

The thesis is produced by Unipub AS merely in connection with the thesis defence. Kindly direct all inquiries regarding the thesis to the copyright holder or the unit which grants the doctorate.

Unipub AS is owned by

The University Foundation for Student Life (SiO) 


\section{TABLE OF CONTENTS}

ACKNOWLEDGEMENTS V V

$\begin{array}{lll}\text { ABSTRACT } & \text { VII }\end{array}$

LIST OF PAPERS IX

$\begin{array}{ll}\text { INTRODUCTION } & 1\end{array}$

ChILd DieT

COVARIATES OF ChILd Diet 2

MATERNAL PSYCHOLOGICAL DisPositions AND CHILD-FEEDING 2

$\begin{array}{ll}\text { DEFICITS OF PREVIOUS STUDIES } & 7\end{array}$

$\begin{array}{lc}\text { RESEARCH OBJECTIVES } & 8\end{array}$

$\begin{array}{lr}\text { MATERIALS AND METHODS } & 10\end{array}$

$\begin{array}{lr}\text { THE NORWEGIAN MOTHER AND CHILD COHORT STUdy } & 10\end{array}$

MEASURES 11

$\begin{array}{lr}\text { STATISTICAL METHODS } & 15\end{array}$

$\begin{array}{ll}\text { MAIN FINDINGS } & 19\end{array}$

$\begin{array}{ll}\text { DISCUSSION } & 22\end{array}$

$\begin{array}{ll}\text { INTERPRETATION OF THE FINDINGS } & 22\end{array}$

METHODOLOGICAL CONSIDERATIONS 25

$\begin{array}{lr}\text { STRENGTHS OF THE STUDY } & 29\end{array}$

12 ShadES OF Brown: Limitations OF THE StUdy 30

SUGGESTIONS FOR FUTURE RESEARCH

$\begin{array}{lll}\text { CONCLUSION } & 32\end{array}$

REFERENCES

PAPER I-III

APPENDIX I: FACTOR LOADINGS FOR THE MEASUREMENT MODELS APPENDIX II:LATENT VARIABLE CORRELATION MATRIX FOR PAPER III APPENDIX III:QUESTIONNAIRES

1. Questionnaire 1 - 17th WEek OF Gestation

2. QUESTIONNAIRE 4-6 MONTHS POSTPARTUM

3. QUESTIONNAIRE 5-18 MONTHS POSTPARTUM

4. QUESTIONNAIRE 6-36 MONTHS POSTPARTUM 


\section{ACKNOWLEDGEMENTS}

In this thesis I present the results from my three-year doctoral project at the Department of Psychosomatics and Health Behavior at the Norwegian Institute of Public Health (NIPH). During these three years I got advice, guidance, comfort, help, and support along the way from a number of people.

First and foremost I would like to thank my supervisor Margarete Vollrath. It all started with you having a project, but needed a PhD-student. Thank you for always being available, introducing me to the wonderful world of personality research, with never-ending effort and optimism trying to teach me how to write concise, and for always carefully and scrupulously considering my drafts and presentations. My project had a twin project, also supervised by Margarete Vollrath. The student working on this twin-project was Susan Niegel. Thank you Susan for you everyday laughs, conversations, discussions and support. It is less tiring to do a $\mathrm{PhD}$ when you have a companion to give you directions when you're lost, and to help you along the way when you're weary. To find out what we actually were reporting along the way, Susan and I monthly detoured through Knut Hagtvet's 'Quantitative Forum'. Soon enough Knut agreed to join our little family as a supervisor. Thank you Knut for teaching me almost everything I know about structural models, and for never ever giving me the impression that I'm not in trouble when trying to represent reality.

My every-day workplace during these three years has been the Division of Mental Health at the NIPH. I would like to thank Arne Holte and Kari Voll for intentionally constructing this pleasant, motivating, creative, and productive environment. What is more, this environment is filled with an abundance of ambitious, talented, innovative, helpful, and joyful coworkers. Thank you Anne, Anni, Cecilie, Christine, Daniele, Ellen, Evalill, GunMette, Helga, Henrik, Håkon, Karina, Kim, Laila, Leila, Martin, Nikolai, Ragnhild, Stine, and Tilmann for your lunches, seminars, beers, squash matches, and hall-lizarding coffee drinking.

These three years have not only consisted of writing scientific papers, but also of classes and seminars at the Department of Psychology at the University of Oslo. Therefore I would like to thank the Department of Psychology for their PhD program.

The doctoral process has been a lot about me and little about the people around me. I would therefore like to thank my friends for not forgetting me when I was absent writing and my Mother and Sister for telling me to slow down and relax when I was going to fast. 
Lastly I would like to thank my wife, Hilde. The long way to a $\mathrm{PhD}$ is an ego trip. Thank you for your understanding when I was absent, patience when I was absent minded, support when I was tired, and love when I was apathetic.

Eivind Ystrøm, Oslo, September 2008 


\begin{abstract}
In this thesis, I explore the influence of maternal Negative Affectivity on child diet and the mechanisms that mediate this influence. For this purposed I used data from a nationwide birth cohort study of between 15000 and 30000 mother-child dyads.

The main findings of this study were that the children of mothers with a high level of Negative Affectivity to a lesser extent are breastfed during the first 6 months of their life, and have a diet of poorer nutritional value at the age of 18 months and 3 years. Moreover, it is suggested in this thesis a causal link between high levels of Negative Affectivity, external Parental Locus of Control (i.e. believing not to have control over the child), and controloriented child-feeding practices of pressuring the child to eat and restricting the child's food intake. Indeed, external Parental Locus of Control was the most important mechanism, entirely mediating the effect of Negative Affectivity on child feeding practices. What is more, external Parental Locus of Control partially explained the association between the two childfeeding practices. This implicates that believing not to have control over the child, can be viewed as a common etiological factor for control-oriented child feeding.

Child feeding practices showed different associations with child diet. Pressuring the child to eat was associated with a diet of poorer nutritional value. Restricting the child's food intake, in contrast, was associated with a diet of preferable nutritional value.

These findings are important for the understanding of early child-feeding and risk factors for an obesogenic child diet, particularly because belief systems such as Parental Locus of Control are accessible for interventions. Moreover, awareness of these relationships may have clinical relevance for health personnel giving guidance on child-feeding.
\end{abstract}




\section{LIST OF PAPERS}

\section{Paper I}

Ystrom, E., Niegel, S., Klepp, K.-I., \& Vollrath, M. E. (2008). The impact of maternal negative affectivity and general self-efficacy on breast-feeding: The Norwegian Mother and Child Cohort Study. Journal of Pediatrics, 152, 68-72.

Paper II

Ystrom, E., Niegel, S., \& Vollrath, M. E. The impact of maternal negative affectivity on dietary patterns of 18-month-old children in the Norwegian Mother and Child Cohort Study. Maternal and Child Nutrition, (in press).

\section{Paper III}

Ystrom, E., Barker, M., \& Vollrath, M. E. The impact of mothers' negative affectivity, parental locus of control and child-feeding practices on dietary patterns of 3-year old children. The Norwegian Mother and Child Cohort Study. (submitted). 


\section{INTRODUCTION}

\section{Child Diet}

Breast milk promotes sensory and cognitive development, and protects the infant against infectious and chronic diseases (Mortensen, Michaelsen, Sanders, \& Reinisch, 2002). Full breastfeeding reduces infant mortality due to common childhood illnesses such as diarrhea or pneumonia and promotes a quicker recovery during illness (Paricio Talayero et al., 2006). The beneficial effects of breastfeeding have been found in resource-poor and in affluent societies (Kramer et al., 2001). Moreover, breastfeeding is also associated with reduced risk of the sudden infant death syndrome (Ford et al., 1993) and risk of inflammatory bowel disease in adults (Klement, Cohen, Boxman, Joseph, \& Reif, 2004).

In addition, breastfeeding has in meta-studies been associated with a long term reduced risk of atopic disease (Friedman \& Zeiger, 2005), type I and type II diabetes mellitus (Norris \& Scott, 1996; Owen, Martin, Whincup, Smith, \& Cook, 2006), particular forms of childhood cancer (Martin, Gunnell, Owen, \& Smith, 2005), and later weight gain and obesity (Armstrong, Reilly, \& Child Health Information Team, 2002; Dewey, 2003; Owen et al., 2005). The positive and negative effects found in the meta-studies of the health outcomes were in general small after adjusting for confounding variables, and there were indications of possible publication bias. Despite this, the authors advocated the continuance of breastfeeding recommendation.

Currently, the World Health Organization (WHO) recommends as a general policy exclusive breastfeeding during the first 6 months of life, with the caveat that infants must be managed individually in the case of insufficient growth (Kramer \& Kakuma, 2002).

In recent years there have been an explosive growth of childhood obesity in the western world (Wang \& Lobstein, 2006). Intake of fat and refined sugar have been suggested to be partly responsible for this development of obesity in children (Ludwig, Peterson, \& Gortmaker, 2001; Foreyt \& Poston, II, 2002). A frequent intake of sweet foods high in added sugar could lower the overall nutritional value of the diet. In recent years several research groups have studied patterns of early childhood diet from infancy to preschool age in the Western world using exploratory statistical techniques (North \& Emmett, 2000; Northstone \& Emmett, 2005). The number of factors utilized range from three to four, but with two major factors when examining the scree plots: An unhealthy diet (sometimes called "junk"-diet) rich 
in sugar and fat and a wholesome diet (sometimes called "healthy"-, "health conscious-", and "traditional"-diets rich in fiber, vitamins and minerals).

\section{Covariates of Child Diet}

Sustaining breastfeeding for 6 months can be difficult. There are a number of known risk factors that can impede the establishment and sustaining of breastfeeding. Among medical variables, cesarean section and preterm birth are known risk factors (Chapman \& Perez-Escamilla, 1999) Mothers' low level of education, low socioeconomic status, maternal smoking, child in daycare, and early return to work may impede breastfeeding. (Millar \& Littlepage, 1970; Lande et al., 2003; Ong, Yap, Li, \& Choo, 2005; Cooper, Murray, \& Stein, 1993; Wagner et al., 2006). Older mothers and those with several children tend to sustain breastfeeding for longer periods (Venancio \& Monteiro, 2006; Wagner \& Wagner, 1999; Wagner et al., 2006).

The person with the greatest influence on a child's diet is often the mother, and the mother's characteristics in turn, influence her choices. Being young, having lower education attainment, being a smoker, being overweight, and having more than one child increase the likelihood that a mother feeds her child fewer foods from the wholesome pattern and more from the unhealthy pattern (North \& Emmett, 2000; Northstone \& Emmett, 2005).

\section{Maternal Psychological Dispositions and Child-feeding}

\section{General Self-efficacy}

A determinant of health behavior that has received a lot of attention is Self-efficacy, the belief in one's capabilities to cope successfully with future challenges (Bandura, 1977). The original notion of Albert Bandura, the "father" of Self-efficacy, was that efficacy beliefs will fluctuate depending on the situation or skills required and therefore should be operationalized into discrete domains (Bandura, 1997). For the current investigation however, a general trait construct was used: General Self-efficacy. General Self-efficacy is the belief in one's capabilities to cope successfully with a variety of challenging situations (Luszczynska, Scholz, \& Schwarzer, 2005). A high level of General Self-efficacy both improves the goal settings, such as the intention to perform the recommended act of full breastfeeding, but also leads to more persistence in following the goal. General Self-efficacy has been found to be positively associated with active coping with pain ( $r=.33$ corrected for attenuation), with 
domain specific optimistic self-beliefs such as nutrition Self-efficacy ( $r=.27$ corrected for attenuation), and inversely associated with depressive symptoms ( $r=-.45$ corrected for attenuation) (Luszczynska et al., 2005).

Until recently the investigations of Self-efficacy and breastfeeding focused on a situation discrete form of Self-efficacy: breastfeeding Self-efficacy (Dennis, 1999). Breastfeeding Self-efficacy is associated with longer breastfeeding duration (Dennis \& Faux, 1999; Blyth et al., 2002; Blyth et al., 2004). Dennis (1999) suggested that breastfeeding Selfefficacy was due to both previous personal experience, such as having sufficient milk production, or vicarious breastfeeding experience, verbal persuasion from others, and positive emotional states.

\section{Negative Affectivity}

Personality is defined as stable dispositions to think, feel, and behave in consistent ways across situations and time. As personality traits are determinants of behavior, they also affect health-related behaviors. One trait with known effects on health behaviors is Negative Affectivity, a broad trait construct describing the tendency to frequently experience negative emotions, such as anxiousness, depressiveness, and irritability, and to have a negative view of oneself (Watson \& Clark, 1984). Negative Affectivity has been found to be essentially equivalent to the Neuroticism factor, also often called Emotional Stability, in the much applied five factor model of personality (John \& Srivastava, 1999; Clark \& Watson, 1999). To make the overview of findings on the different labels of Neuroticism also known as Emotional Stability also known as Negative Affectivity more readable, will findings from the literature listed in the following text be reported as findings on Negative Affectivity.

\section{Negative Affectivity and Coping}

Coping is the way individuals manage stressful situations (Bolger, 1990). Persons with high levels of Negative Affectivity use dysfunctional strategies to cope with stress. It is a consistent finding in the literature that a high level of Negative Affectivity is associated with passive and inefficient coping strategies; persons with high levels of Negative Affectivity use to a greater extent self-blame, emotional-focused coping, and escape-avoidance and to a lesser extent problem-focused coping, support seeking, and positive reappraisal (McCrae \& Costa, 1986; Smith, Pope, Rhodewalt, \& Poulton, 1989; Bolger, 1990; Watson \& Hubbard, 1996; Vollrath, Torgersen, \& Alnaes, 1998; Vollrath, 2001). 
Negative Affectivity might seem like a highly undesirable trait; it implicates not taking on life. This might not be the case. While one is taking on life it is fortunate to survive; one thing any living person has in common with his or her ancestors is that they survived the dangers of life long enough to become an ancestor. Vigilance, behavioral inhibition and avoidance facilitate survival under threatening situations. In the same manner facilitates affects of fear, distress, and modest self-esteem the motivation to keep out threatening situations even before physically getting in those situations. Anger aids a person to defend his or her resources when threatened. Any person completely lacking these characteristics would expose her or himself to potentially mortal threats.

\section{Mood, Anxiousness, Negative Affectivity and Breastfeeding}

The question whether there is a link between maternal mood, anxiety, and breastfeeding has been discussed in the literature. In several cross-sectional studies during the last decades breastfeeding puerperal women been found to have more positive life events, and lower depression, anxiety and anger scores than formula feeders (Berg-Cross, Berg-Cross, \& McGeehan, 1979; Modhal \& Newton, 1979; Weisenfeld, 1985; Virden, 1988; Cooper et al., 1993; Heck \& Decastro, 1993; Galler, Harrison, Biggs, Ramsey, \& Forde, 1999; Mezzacappa, Guethlein, Vaz, \& Bagiella, 2000; Henderson, Evans, Straton, Priest, \& Hagan, 2003; Groer, 2005; Dunn, Davies, McCleary, Edwards, \& Gaboury, 2006; Sisk, Lovelady, Dillard, \& Gruber, 2006).

In a recent study, post-partum anxiety was related to less breastfeeding confidence but not to breastfeeding knowledge (Britton, 2007). This might imply that the coping due to Negative Affectivity is not related to the potential success of breastfeeding due to actual knowledge, but hampers the follow through. Although performed at a time when the societal view on breastfeeding was different, the conclusion in a pioneering study (1959) describing hospitalized women the first week after birth was that those women who selected breastfeeding rather than bottle feeding were more anxious than those who chose bottle feeding. Moreover, those women who subsequently succeeded with their chosen breastfeeding were more calm than those who failed (Call, 1959). Furthermore, in a study done at about the same time, breastfeeding woman were found to emphasize exchange of positive affection with other people (Brown, Chase, \& Winson, 1961; Newton \& Newton, 1967). This indicates that initial selection of breastfeeding rather than bottle feeding could be 
influenced by extraversion/Positive Affectivity (Clark \& Watson, 1999) related factors, while follow through of breastfeeding is related to Negative Affectivity.

But so far, the picture is not entirely clear. In a study conducted in the late sixties, the authors concluded that both election and duration of breastfeeding was related to less Negative Affectivity measured postnatally (Cornell, 1969). In a study applying Raymond Cattell's 16 Personality Factors it was found that mothers practicing unrestricted breastfeeding (continuously feeding at the child's will) were more suspicious (factor L), more extroverted (factor F), and more open to change (factor Q1) than those who practiced bottle feeding (Chamberlain, 1976). There were no differences on factors semantically at the core of Negative Affectivity.

Wagner and colleagues $(1999,2006)$ applied in two separate studies the five factor model (FFM) of personality (John \& Srivastava, 1999) to investigate personality differences between those who initiated breastfeeding versus those who initiated bottle feeding during their hospitalization 24-96 hours postpartum (Wagner \& Wagner, 1999; Wagner et al., 2006). In the first study, published in 1999, 100 mothers completed the full Revised NEO Personality Inventory (NEO-PI-R), which measures 30 facets of the FFM of personality (John \& Srivastava, 1999). Women who had chosen to initiate breastfeeding had higher scores on facets of extraversion, openness to experience, agreeableness, and one facet of conscientiousness. Mothers who had chosen bottle feeding had higher scores on only one facet; the angry hostility facet of Neuroticism. The construct of anger and hostility are semantically within the domain of Negative Affectivity. In the second study by Wagner et al. (2006), 86 mothers completed the short version of the NEO-PI-R. Mothers who had chosen to initiate breastfeeding were also in this study more extraverted, open to experience, and agreeable. The effect of agreeableness turned redundant when all the five factors in the five factor model predicted breastfeeding in a multiple regression analysis.

While different sub facets of the traits extraversion and openness to experience (John \& Srivastava, 1999) might be related to initiation of breastfeeding, there is in sum quite extensive evidence that Negative Affectivity is to some extent related to both election and especially sustainment of breastfeeding. What is more, since the assessment of Negative Affectivity was done postpartum, one cannot conclude on whether ineffective coping due to Negative Affectivity hampers breastfeeding or whether breastfeeding failure increases the level of Negative Affectivity. 
A mother's decision to breastfeed depends on her situation. The situation of a person can influence the measurement of Negative Affectivity Earlier studies on maternal mood and breastfeeding have only rarely adjusted the results according to the mother's current demographic situation and physical condition.

\section{The role of oxytocin.}

It is well known the public that a sudden shock can stop livestock from producing milk. Case studies of women who have suffered stressing situations document that they have had abrupt cessation of lactation shortly afterwards (Ruvalcaba, 1987). The let down reflex, which starts the secretion of milk, is controlled by the hormone oxytocin. Oxytocin secretion has been found to be inversely associated with trait anxiety and guilt (Uvnäs-Moberg, Widström, Nissen, \& Björvell, 1990; Nissen, Gustavsson, Widström, \& Uvnäs-Moberg, 1998). Given that milk secretion is related to stress (Dewey, 2001; Tu, Lupien, \& Walker, 2005), and persons with high levels of Negative Affectivity have dysfunctional stress coping strategies, it is plausible that the disposition of Negative Affectivity would act as a risk factor for to a greater extent being influenced by neonatal stressors.

\section{Negative Affectivity, Parental Locus of Control and Child-feeding}

Meal times can be emotive for both mother and child. Children often prefer foods with a high fat and sugar content (Hill, 2002). Mothers know that their children should not have too many of such foods. Every parent is familiar with the frustration of trying to feed a child food they are refusing to eat. Such a situation is wearing for most people. Emotionally unstable mothers might be imagined to experience less control over the child (Lovejoy, Verda, \& Hays, 1997) and respond more inconsistently than most (Metsapelto \& Pulkkinen, 2003).

Mothers characterized by levels of Negative Affectivity believe that the behavior and development of their child is not contingent on their parenting, but largely determined by forces external to their parenting such as child temperament and chance (Lovejoy et al., 1997). This belief is described as Parental Locus of Control. Parents who have this belief have been found to compensate by using an authoritarian general parenting style with excessive control (Janssens, 1994). Furthermore, parents with higher levels of Negative Affectivity have also been found to have poor parental control, both exhibiting authoritarian parenting with 
excessive control and permissive parenting with insufficient control (Metsapelto \& Pulkkinen, 2003).

In the study of child diet there has been a focus on maternal child-feeding practices. A commonly used measure for studying child-feeding practices is the Child-feeding Questionnaire (CFQ) (Birch et al., 2001). It is a descriptive approach focusing on parental beliefs and practices related to child's obesity proneness. Of the seven factors in the CFQ, the control oriented factors pressure to eat, i.e. pressuring the child to eat more, and restriction, i.e. keeping attractive foods away from the child, have been given attention in relation to obesogenic diet in children.

Both general parenting styles involving poor parental control and the control-oriented child-feeding practices pressuring a child to eat and restricting a child's food intake, have been found to be predictive of the child consuming a less 'wholesome' diet, i.e. comprising vegetables and fruit, and a more 'unhealthy' diet, comprising sugary and fatty foods (Fisher \& Birch, 1999b; Fisher \& Birch, 1999a; Fisher, Mitchell, Smiciklas-Wright, \& Birch, 2002; Birch, McPhee, Shoba, Pirok, \& Steinberg, 1987; Patrick, Nicklas, Hughes, \& Morales, 2005; De Bourdeaudhuij, 1997; Golan, 2006; Brown, Ogden, Vogele, \& Gibson, 2008).

\section{Deficits of previous studies}

The two main weaknesses in the previous studies of maternal mood, anxiety, and personality in relation to breastfeeding were firstly the predominant use of cross-sectional design, secondly small sample sizes which might have led to a type II error (not finding a true effect).

A major weakness of the previous studies on child dietary patterns was the consistent use of the product-moment correlation matrix. In doing this, one firstly assumes that all the dietary components have equal variance; secondly, and more gravely that the causal factors forming the dietary pattern monotonously influence the intake frequency of all dietary components. This is quite an optimistic assumption. It makes more sense to approach the problem using the polychoric correlation matrix, since it is based on the assumption that the dietary variable observed is only an indicator of an underlying true normally distributed food intake variable and that the thresholds of this underlying variable determine the frequency of each separate dietary component observed.

Previous studies on predictors of breastfeeding behavior, child-feeding, or dietary patterns have by and large not used proper missing data techniques. 


\section{RESEARCH OBJECTIVES}

\section{Paper I}

To investigate the effect of Negative Affectivity and General Self-efficacy on breastfeeding status at six months while controlling for other known risk factors.

\section{Paper II}

To test if mothers high in Negative Affectivity will be less efficient in feeding their child a wholesome diet and less efficient in not feeding an unhealthy diet. This effect will be tested over and beyond known maternal demographic and physical risk factors for unhealthy child eating.

\section{Paper III \\ Hypothesis 1}

The two child dietary patterns of 'wholesome' and 'unhealthy' diet found in this sample of children 18 months after birth will be re-identified when the children are three years of age.

\section{Hypothesis 2}

Since Negative Affectivity relates to external Parental Locus of Control, and the former both relate to excessive control, hypothesis two is that mothers with high levels of Negative Affectivity are more likely to pressure the child to eat and restrict the child's food intake, but that the effect of this personality trait will be mediated through the beliefs of external Parental Locus of Control.

\section{Hypothesis 3}

Higher levels of Negative Affectivity in the mother and external Parental Locus of Control will predict more 'unhealthy' and less 'wholesome' dietary patterns, because mothers will be more likely to use the two forms of control-oriented child-feeding practices of pressuring the child to eat and restricting the child's food. 


\section{Hypothesis 4}

Since it is possible that control-oriented child-feeding practices have an effect on diet in addition to that exerted by mother's personality and general parenting factors, pressuring the child to eat and restricting the child's food intake will have an independent negative effect on the child's 'wholesome' dietary pattern and positive effect on the 'unhealthy' dietary pattern. 


\section{MATERIALS AND METHODS}

\section{The Norwegian Mother and Child Cohort Study}

The data collection was conducted as a part of the Norwegian Mother and Child Cohort Study (MoBa) at the Norwegian Institute of Public Health. The study was launched in 1999 with the aim of studying a wide range of demographic, physical, genetic, and mental health exposure variables and outcomes in mothers and children (Magnus et al., 2006). The study will reach its goal of recruiting 100000 pregnancies within the end of 2008. There are no exclusion criteria, and all maternity units in Norway with more than 100 births annually are included. Mothers are recruited for the study when they undergo their first prenatal ultrasound examination at 17 to 18 weeks gestation. The participation rate in $\mathrm{MoBa}$ is $42.7 \%$. Mothers fill out questionnaires at 17 weeks gestation and 6 months, 18 months, and 3 years after childbirth. Response rates at 17 weeks gestation are 95\%, 87\% at 6 months after birth, $77 \%$ at 18 months, and 62\% at 3 years (Magnus et al., 2006; Magnus, 2007). For the current study the Medical Birth Registry of Norway (MBRN), containing information about all births in Norway (Irgens, 2000) and information from the questionnaires administered at the five assessment points were used.

\section{Sample}

\section{Paper I}

Paper I included 34083 single birth mothers returned the questionnaires at the $17^{\text {th }}$ and $30^{\text {th }}$ week of gestation and 6 months postpartum. The sample was restricted to singletons. The number of cases excluded because of missing data was 6330, and missing information was distributed as follows: maternal age: 1; gestational age of infant: 68; breast milk milk: 2213; Negative Affectivity and General Self-efficacy: 2257; education: 659; maternal smoking: 1005; external daycare: 131. The final sample comprised 27753 mothers.

\section{Paper II}

At the time that paper II was conducted, questionnaires from 28,242 participating mothers with a child that had reached 18 months of age were available. Because of missing data $1.5 \%(n=479)$ of the participants were excluded from the analyses. The final sample consisted of 27763 mothers. The lower fraction of missing cases in paper II and forward was 
due to an increasing awareness during the study of the selection biases that can be produced by list wise deletion of missing cases.

\section{Paper III}

When paper III was written, questionnaires from 15,103 participating mothers with a child that had reached 3 year of age were available. Because of missing data, $6.5 \%(n=981)$ of the participants were excluded. The final sample therefore included 14,122 mothers.

\section{Measures}

\section{Demographical and Physical Characteristics}

Information regarding cesarean section, primiparity, and duration of gestation (based on ultrasound) was retrieved from the MBRN. Maternal self-reports were used as a secondary source where an entry in the MBRN was missing. Mothers completed questionnaires about age, smoking, education, income, marital status (currently single mother or cohabitating/married), current body mass index (BMI), and whether the infant was in daycare. Postpartum maternal smoking was defined as smoking 1 or more cigarettes per day since labor. Preterm birth was defined in accordance with the $10^{\text {th }}$ revision of the International Classification of Diseases (World Health Organization, 2004) as birth before gestation week 37. Level of education and income were measured during pregnancy. Education was defined as number of years of education including college and university studies. To scale income, relative income was defined largely in line with the definition of relative poverty used by the Organization for Economic Cooperation and Development: median income earned by mother and father during pregnancy as 0 and intervals of $\pm 50 \%$ of the median as \pm 1 .

\section{Psychometric Measures}

\section{Paper I}

\section{Negative Affectivity.}

To measured maternal Negative Affectivity, short versions of the Hopkins Symptom Checklist, the SCL-5 were administred (Tambs \& Moum, 1993) at the $17^{\text {th }}$ week of gestation, and the SCL- 8 administered at $30^{\text {th }}$ week of gestation (Strand, Dalgard, Tambs, \& Rognerud, 
2003; Tambs, 2004). The SCL is a self-administered instrument designed to measure psychological distress, particularly anxiousness and depressiveness (Strand et al., 2003). A typical item of the SCL is "Worrying too much about things". The response categories range from 1 to 4 (not bothered, a little bit bothered, quite much bothered and very much bothered). The SCL-5 and SCL- 8 demonstrated internal consistencies of $\alpha=.78$ and $\alpha=.82$, respectively. Although the SCL is designed to measure distress, it has been documented that it can substitute for measures of Negative Affectivity, particular when assessed repeatedly (Watson \& Clark, 1984). Therefore, the SCL-5 at gestation week 17 and the SCL-8 at gestation week 30 were pooled across the time points and computed a mean score. The temporal stability of the SCL-5 and the SCL- 8 was adequate $(r=.57 ; r$ corrected for attenuation $=.71)$.

\section{General Self-efficacy.}

To measure General Self-efficacy at gestation week 30 it was used a 5-item version of the 10-item General Self-efficacy Scale (Luszczynska et al., 2005). A typical item is, "I always manage to solve difficult problems if I try hard enough." Response categories are incorrect (1), partly correct (2), almost correct (3), completely correct (4). The internal consistency of the General Self-efficacy scale was above adequate at $\alpha=.83$.

General Self-efficacy Scale correlated -.23 with SCL-8 at gestation week 30, which corresponds to a correlation of -.28 corrected for attenuation.

\section{Paper II and III}

\section{Negative Affectivity.}

The measurement models for Negative Affectivity were equal in paper II and III. The difference was that in paper II the measurement points at $30^{\text {th }}$ week of gestation, 6 months postpartum, and 18 months postpartum were utilized; while in paper III the measurement points at 6 months, 18 months and 3 years postpartum were used.

A measure of mother's Negative Affectivity from several short scales in the questionnaires was compiled. The 8-item short version of the Hopkins Symptom Checklist (SCL) was used to assess the Anxiousness-Depressiveness component of Negative Affectivity (Strand et al., 2003; Tambs, 2004). To measured the anger component of Negative Affectivity, a 3-item short version of the Anger subscale of the Differential Emotions Scale was used (Izard, Libero, Putnam, \& Haynes, 1993), and the Self-Esteem component of 
Negative Affectivity assessed using a 4-item short version of the Rosenberg Self-Esteem scale (Rosenberg, 1989). By subsuming these short scales into one, a measure of Negative Affectivity with stronger psychometric characteristics was constructed. These components of Negative Affectivity include both time-invariant, dispositional variance and time-specific variance, which reflects a mother's state at the time when she filled out the questionnaire. To subtract the time-invariant dispositional factor, a latent variable across the three assessments was constructed (for details, see the statistics section).

The factor of Negative Affectivity used in paper II and III correlated .92 (without measurement error) with the Neuroticism/Emotional Stability factor in the International Personality Item Pool five factor personality inventory (Gow, Whiteman, Pattie, \& Deary, 2005). This validation was done by utilizing the male partner sample of MoBa, which both included the International Personality Item Pool inventory and the measures of Negative Affectivity.

\section{Parental Locus of Control.}

The degree of external versus internal Parental Locus of Control was assessed at 3 years after childbirth using 5 items (item number 1, 5, 21, 41, and 44) from the Parental Locus of Control Scale (Campis, Lyman, \& Prentice-Dunn, 1986). The Parental Locus of Control scale is a measure of the extent to which parents experience that the behavior of their child is controlled by their internal parenting skills or other events external to their parenting. A high score on the Parental Locus of Control scale indicates an internal Parental Locus of Control, a low score indicates a more external Parental Locus of Control.

\section{Child-feeding practices.}

Two forms of control oriented child-feeding practices, restriction of food intake by the mother and pressure to eat from the mother, were measured at 3 years after childbirth using the Restriction and Pressure to Eat subscales of the Child-feeding Questionnaire (Birch et al., 2001). The Child-feeding Questionnaire is a tool for assessing parents' perceptions, beliefs, attitudes, and practices regarding child-feeding relevant to the development of obesity. A typical question from the pressure to eat subscale is "My child should always eat all of the food on her plate", and a typical question from the restriction subscale is "I have to be sure that my child does not eat to many sweets (candy, ice cream, cake or pastries). The respondents are asked to 'agree' or 'disagree' with each statement on a 5 point scale. 


\section{Child Nutrition}

Paper I

Breastfeeding.

Mothers reported on breastfeeding and bottle feeding sixth month after birth, with detailed reporting for each preceding month. At this time the mothers also reported on feeding of a variety of solid foods; for each food item, they indicated how often, and starting when, the food had been introduced to the infant.

The categorization of breastfeeding was done largely in accordance with the WHO definitions (World Health Organization, 1991), which defines predominant breastfeeding as the case when the infant's predominant source of nutrition has been breast milk. Except for fruit juice and sugar-water, the infant must not have received any other nutrition than breast milk (World Health Organization, 1991). Based on feeding status at 6 months after birth, mothers in our study were classified in 3 feeding groups: predominant breastfeeding, mixed breastfeeding, and bottle feeding. Predominant breastfeeding was breastfeeding without any supplements of formula milk or solid food. Mixed breastfeeding was continued breastfeeding at 6 months, supplemented by milk or solids. Bottle feeding was feeding formula milk by bottle, with possible supplements of solids and no current but possible previous breastfeeding. Although the current WHO recommendation is for exclusive breastfeeding, the current study allowed only predominant breastfeeding to be defined as a category, which is less restrictive. The reason for this is that no information on fluids other than formula the infant might have received up to 6 months postpartum was attainable.

Paper II and III

\section{Child diet.}

Information on the current diet was collected through a maternal reported food frequency questionnaire. The food frequency questionnaires consisted of 36 dietary items at 18 months and 37 items at 3 years, and were on types of foods and drinks such as dairy products, cereal based porridge, and fruit juice. Response categories at 18 months ranged from "never" to "5 or more times a day" for drinks and from "never" to "3 or more times a day" for foods. Response categories at 3 years ranged from "never or less than 1 serving per 
week" to "4 or more servings per day" for foods and drinks, and "once per month or less" to "5 or more times per week" for dinner foods.

\section{Statistical methods}

There was a continuous progression of both awareness of methodological implications and know how throughout the time period of the study. A classical test theory approach was used in paper I. The progression here was an increasing awareness of biases due to list wise deletion. Multiple imputation was therefore sought out in paper I.

In paper II and III, both the measurement and regression models were transferred into Structural Equation Modeling. The reason for this move was that the confidence intervals would be adjusted for the level of uncertainty due to missing data, measurement error could be removed, unidimensional constructs derived from Confirmatory Factor Analysis used, and mediation models applied.

\section{Paper I}

Independent t-tests were conducted to compare mothers excluded from the sample with those included in the analyses on the parametric variables. To compare the excluded with the included group on the dichotomous variables, Chi-square tests with correction for continuity were conducted. To investigate whether the missing data on the personality variables were random, estimates based on multiple imputation with estimates without imputation were compared. As the estimates were similar, we refrained from imputing missing data. A multinomial logistic regression model was done to get the odds ratio of mixed breastfeeding and bottle feeding, contrasted with predominant breastfeeding. The scales on Negative Affectivity and General Self-efficacy were modeled as predictors, adjusted for age, cesarean section, external daycare, primiparity, preterm birth, maternal smoking, and years of education. Variables were entered simultaneously in the multinomial logistic regression. An alpha level of .05 was used across the analyses.

\section{Paper II and III}

Independent t-tests were conducted with the continuous variables and chi-square tests with the categorical variables to compare the characteristics of the mothers included in the analysis and those excluded because of missing data. To perform exploratory factor analysis 
(EFA), the confirmatory factor analyses (CFA), and the structural equation modeling, Mplus 5.1 was used (Muthén \& Muthén, 2007; Muthén \& Muthén, 2008).

\section{Negative Affectivity and Parental Locus of Control}

CFA was used for ordinal data with polychoric correlations to construct the Negative Affectivity components of Anxiousness-Depressiveness, Anger, and Self-Esteem (Flora \& Curran, 2004).

The longitudinal modeling of a time-invariant latent variable of Negative Affectivity was done in accordance with the general framework for latent growth curve analyses with latent indicators based on categorical data described by Bollen \& Curran (Bollen, 2006). Since the aim was to correct personality for time-specific stress, a time-invariant slope was not modeled, but an intercept-only model was used.

To secure syntactically equal measurement, the thresholds of the response categories within each item, the scaling of each item, and the factor structure of each scale was forced to be equal across time points. As a first step, the three Negative Affectivity components at each time point were combined into a latent variable of time-specific Negative Affectivity. Secondy, the factor loadings of the Negative Affectivity measure were forced to be equal across time. In the last step, a cross-time Negative Affectivity latent variable was constructed by setting the factor loadings equal across time. This procedure secured that the time-specific individual deviations were cancelled from the Negative Affectivity variable. The score therefore constitutes the individual characteristic across time.

A CFA for ordinal data of the items from the Parental Locus of Control scale was done to produce a variable of Parental Locus of Control. The items loaded freely on a factor with variance set to 1 . Since the Parental Locus of Control scale can be divided into subdimensions, the items which were from the same sub-dimension were allowed to correlate in the CFA.

\section{Child-feeding practices}

To construct the two variables on child-feeding practices, 'Restriction' and 'Pressure to Eat', CFA for ordinal data with polychoric correlations was used. The items loaded freely on a factor with variance set to 1 . To account for the internal dependencies between the items from the 'Restriction' scale combined in parcels by Birch, et al. (2001), the residual variance of the indicators within each item parcel were allowed to be correlated. 


\section{Dietary patterns}

To identify the dietary pattern factor from the rated dietary items, a polychoric correlation coefficient matrix was produced from the frequency with which each child was reported to eat each food a month. This correlation matrix was then subject to EFA. This is a technique for assessing the factor structure of data measured on an ordinal scale. The scree plot was analyzed, and two dietary pattern factors were identified. In this evaluation, the fewest number of factors that could explain the most multivariate covariance was sought. Varimax rotation was used in paper II, while geomin oblique rotation was used in paper III (Browne, 2001).

\section{Structural equation modeling}

The EFA of child diet, the CFA's of the psychometric measures and the medical and demographic variables was included in a final structural equation model and jointly estimated. Negative Affectivity, the demographic, and the physical variables were defined as independent variables and the two dietary patterns predicted as uncorrelated dependent variables in a multivariate linear regression using structural equation modeling.

When the analyses in paper II were conducted it was not technically possible to include an EFA within structural equation modeling. Therefore, EFA was conducted, and then replicated using the factor loadings in a CFA within the structural equation model. The world of applied statistics fortunately moves forward, so when the work on paper III was done; it was now possible with Mplus version 5.1 to do an EFA within structural equation modeling. When this new option became available in May 2008, paper II was in revision. Therefore the structural equation model for paper II with the new option in Mplus 5.1 was executed. The results were close to identical. Therefore, the model of paper II, then already submitted to the journal, was not changed.

Robust weighted least-squares estimation (robust WLS) was chosen to identify the model (Flora \& Curran, 2004; Muthén \& Muthén, 2007), since CFA using polychoric correlations has proven to be robust to the non-normal distribution typical for behavioral data. Using robust WLS in Mplus 5.1 with covariates included in the model prohibited the estimation of confidence intervals of the standardized.

As a part of the final structural equation model, missing data for dependent variables as a function of the covariates in the model was estimated, and missing data on continuous 
independent variables with the information from continuous covariates was imputed using the expectation-maximization algorithm. Furthermore, cases with missing data on the categorical independent variables from the analyses were excluded., The root mean square error of approximation (RMSEA) was interpreted to evaluate model fit to the data. A point-value on the RMSEA below .06 is considered necessary for a good fit, and the upper rim of the confidence interval of RMSEA below .08 for an adequate fit (Hu \& Bentler, 1998). Using robust WLS, it was not possible to calculate a confidence interval for the RMSEA.

\section{Test of Mediation}

A mediator is the generative mechanism that the independent influences the dependent variable through (Baron \& Kenny, 1986). Baron \& Kenny (1986) specifies four specific steps as the sine qua non of mediation. The independent and dependent variable have to be associated. Secondly, the independent variable has to be related to the mediator. Thirdly, the mediator has to be related to the independent variable. Lastly, the relationship between the independent variable and the dependent variable has to evanesce or be weakened. Complete mediation is achieved when the association between the independent variable vanishes when controlling for the mediator, partial mediation when the association is weakened. Although not a specific criterion for mediation, if there is not an interaction effect between the mediator and the independent variable in relation to the dependent variable there is no possibility for a competing moderator approach.

Baron \& Kenny (1986) envisages a continuum on the last criterion. Furthermore they state that when the association between the independent and the dependent variable is fully accounted for by the mediator, hence is reduced to zero, "we have a strong evidence for a single, dominant mediator. If the residual path is not zero, this indicates the operation of multiple mediating factors." (p 1176). 


\section{MAIN FINDINGS}

\section{Paper I}

The objective of this study was to examine the extent to which maternal personality traits of Negative Affectivity and General Self-efficacy measured during pregnancy predict breastfeeding status at the sixth month postpartum. The adjusting variables maternal smoking, primiparity and cesarean section had a large effect in their own rights on both mixed breastfeeding and bottle feeding compared to predominant breastfeeding. The direction of these associations accords with previous findings and points out the importance of these characteristics (Lande et al., 2003; Chapman \& Perez-Escamilla, 1999).

Negative Affectivity increased the odds for both mixed breastfeeding (Odds ratio $(O R) 1.16$; 95\% Confidence interval $(95 \% C I) 1.03$ - 1.32) and bottle feeding (OR 1.32; 95\% CI 1.14 - 1.53) compared to predominant breastfeeding. General Self-efficacy lowered the odds of bottle feeding (OR 0.90; 95\% CI 0.84 - 0.97) but not mixed breastfeeding (OR 0.98; $95 \%$ CI 0.92 - 1.04) compared to predominant breastfeeding.

\section{Paper II}

The principal finding of this investigation was that mothers with high levels of Negative Affectivity were more likely to feed their children an unhealthy diet (standardized beta (b) 0.09 ; 95\% CI 0.07, 0.10), which is a diet rich in sugar and fat. At the same time, mothers high in Negative Affectivity were neither more nor less likely to feed their child a wholesome diet ( $b-0.00 ; 95 \% C I-0.02,0.02)$, i.e., a diet rich in fibre, vitamins, and minerals. This effect persisted over and beyond earlier found socio-demographic risk factors.

The maternal socio-demographic characteristics were important in several respects, and replicate to large extent earlier findings in pre-school aged children. In terms of effect size the number of children was by far the most important predictor, with more than one-third standard deviation increase $(\beta 0.37 ; 95 \%$ CI $0.35-0.39)$ of unhealthy diet per child. Maternal daily smoking was also a substantial risk factor for feeding the child a less wholesome ( $\beta$-.19; $95 \% C I-0.24--0.15)$ as well as a more unhealthy $\operatorname{diet}(\beta 0.19 ; 95 \% C I 0.15-0.23)$.

These findings are novel in several respects. No previous study has explored the potential relation between mothers' personality characteristics and infant dietary patterns. Beyond that, the findings fit nicely with the findings reported in paper I showing that mothers high in Negative Affectivity were more likely to terminate breastfeeding before the end of the 
recommended period of 6 months. Taken together, this suggests that mothers high in Negative Affectivity show a tendency to feed their child in a less than optimal way.

\section{Paper III}

The key findings of this study were as follows: First, the two child dietary patterns identified in the MoBa-sample at 18 months after birth were corroborated by being identified again at 3 years. Furthermore, they were to a great extent empirically independent of each other: Significantly correlated at -.10; non-significant residual correlation at .04.

Second, mothers with high levels of Negative Affectivity were more inclined to use restriction of diet or to pressure the child to eat, and these behaviors were fully mediated through external Parental Locus of Control (figure 1). Moreover, external Parental Locus of Control explained a part of the association between Pressure to Eat and Restriction $\left(\chi^{2} 16.61\right.$, $1 \mathrm{df}$ ); the reason mothers who pressure the child to eat is likely to also restrict child food intake is their external Parental Locus of Control.

Third, those mothers high in Negative Affectivity and with an external Parental Locus of Control, were more likely to have children with a less 'wholesome' and more 'unhealthy' diet (figure 1). Moreover these effects were partly mediated by the restriction of the child's food intake or pressuring the child to eat.

Fourth, in accordance with the hypotheses, mothers who pressured the child to eat tended not to have children with 'wholesome' diets and were more likely to have children with more 'unhealthy' diets (figure 1). Contrary to the hypotheses, mothers who restricted their children's food intake tended to have children with more 'wholesome' diets and less 'unhealthy' diets (figure 1). The effects of child-feeding practices were largely independent of Negative Affectivity and Parental Locus of Control. The effect of Parental Locus of Control on child-feeding and the effects of Parental Locus of Control and child-feeding on dietary patterns were over and beyond the effect of demographic and physical risk factors adjusted for in the model.

Relationships between the demographic and physical variables and children's diets were in general small, but the in accordance with the general pattern of findings in Paper II and earlier studies on 3-year-old children (North \& Emmett, 2000). Maternal smoking ( $\beta$

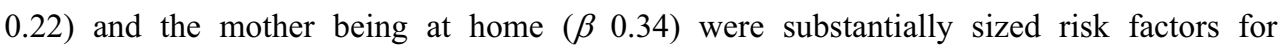
unhealthy eating in 3-year-old children. 


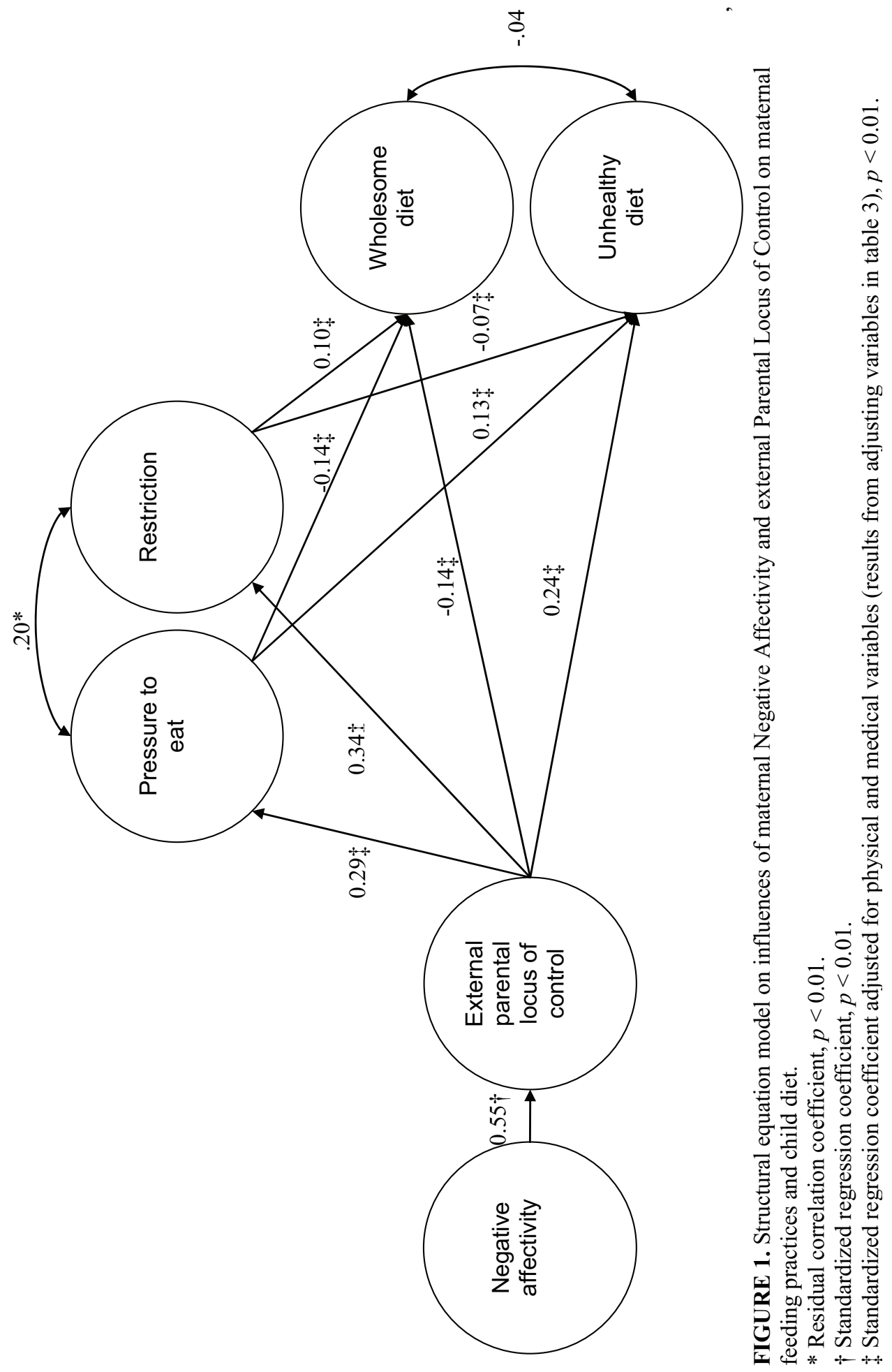




\title{
DISCUSSION
}

\author{
Interpretation of the Findings
}

\section{Maternal Affectivity, Coping, Beliefs and Breastfeeding}

Psychological variables, and particularly personality, have rarely been considered as predictors of breastfeeding. It was shown through the data that the stable personality traits Negative Affectivity and General Self-efficacy, assessed during pregnancy, predict the duration of breastfeeding. This finding is particularly important, because a design where breastfeeding is not present at Time 1 excludes the possibility of reverse causation, which is not the case for most of the earlier studies (Wagner \& Wagner, 1999). From those previous studies it could not be concluded with certainty whether depressiveness or anxiousness or low Self-efficacy were predictors or consequences of difficulties with breastfeeding. Still, the possibility that failure to breastfeed could influence sequential levels of Negative Affectivity is held open.

\section{Negative Affectivity and Breastfeeding}

Several mechanisms might function as mediators of the relationship between Negative Affectivity and less breastfeeding. For example, it is well established that Negative Affectivity is closely linked to stress vulnerability, emotional reactivity, passive coping, and health-related worries (Vollrath, 2001; Friedman, 2000; Oswald et al., 2006). Persons high in Negative Affectivity are prone to give up on their goals when confronted with obstacles (Vollrath et al., 1998). Translated to breastfeeding, this could mean that mothers high in Negative Affectivity could be prone to give up breastfeeding early, if breastfeeding the infant proves difficult. Moreover, persons high in Negative Affectivity are more vigilant with regard to perceiving bodily symptoms (Friedman, 2000). Maternal anxiety has been inversely related to breastfeeding confidence, but not to breastfeeding knowledge (Britton, 2007). Earlier studies have found that mothers who discontinue breastfeeding reported worries that their infant was not receiving enough nutrition (Wagner \& Wagner, 1999). This worry, more than a lack of knowledge on breastfeeding performance, could be a reason why mothers high in NA begin to supplement with solids or formula earlier than other mothers. Finally, maternal stress has been associated with reduced release of oxytocin and impaired lactogenesis (Dewey, 
2001). As high Negative Affectivity increases vulnerability to stress, reduced release of oxytocin could be a consequence.

In the MoBa data almost all the women have at some time during the first week tried to breastfeed their child. This means that almost none of the women in MoBa chose to not initiate breastfeeding at all and go for bottle feeding instead. Previous studies, done in a time and at a place where bottle feeding was more common, investigated differences between those who initially chose to either breastfeed or bottle feed. In 1959, Call found that those who initially decided to solely bottle feed were the least anxious; yet of those who actually put the baby to the breast, it seemed to be the calmer mothers who were most likely to continue. There is therefore little room to interpret such an effect today, since society plausibly has gone from sanctioning bottle feeding to strongly sanctioning breastfeeding. It is possible that the schism where women choose to either breastfeed or bottle feed is to a great extent gone, and that the latter effect described by Call (1959) where women try and fail due to Negative Affectivity is expanded. Moreover, in Wagner and colleagues study (2006) mothers who initiated breastfeeding were found to be more extraverted and open to experience. It seems that such a study of the relation between positive affectivity/extraversion and breastfeeding initiation would be difficult to in Norway when virtually all Norwegian women to some degree initiate breastfeeding during their first week after delivery.

\section{General Self-efficacy and Breastfeeding}

General Self-efficacy, in contrast to Negative Affectivity, is particularly predictive of continuing health-promoting behavior also in the face of obstacles. Therefore, it is not surprising that high scores on the General Self-efficacy scale were found in the predominant breastfeeding group. The findings are therefore in accordance with prior research (Blyth et al., 2002; Blyth et al., 2004) and show that high General Self-efficacy predicts the sustaining of breastfeeding beyond the effect of Negative Affectivity. This can be explained by the fact that General Self-efficacy is construed as an action-related trait that shows its effect even when negative emotions may be present.

A recently published British study corroborates the finding of paper I on Self-efficacy and breastfeeding. The authors found that General Self-efficacy measured antenatally predicted perseverance of breastfeeding from zero to four months postpartum. Furthermore, they found that Breastfeeding Self-efficacy was substantially associated with breastfeeding continuation beyond the effect of General Self-efficacy (Bailey, Clark, \& Shepherd, 2008). 
This finding emphasizes that although General Self-efficacy is applicable in predicting a range of health behaviors, it does not fully cover the range of situation specific coping beliefs.

General Self-efficacy is not conceptually based on unrealistic optimism; it is optimistic beliefs based on various coping experiences (Schwarzer, 1992). In principle multiparas could have more optimistic beliefs about their ability to cope with breastfeeding due to their previous success, or be les optimistic about their ability to cope due to previous failure. Secondly have older age groups been found to have higher levels of General Selfefficacy (Bailey et al., 2008). The results presented in paper I was without these possible confounding effects, since the effect of General Self-efficacy was adjusted for parity and maternal age.

\section{Earlier Findings on Control-oriented Feeding and Child Diet}

To date findings relating control-oriented feeding practices to quality of children's diet have been contradictory. On the one hand, control-oriented feeding practices have been associated with increased preference and intake of an 'unhealthy' diet in children of various ages (Fisher \& Birch, 1999b; Fisher \& Birch, 1999a; Birch et al., 1987; Fisher et al., 2002). On the other hand, parenting characterized by insufficient control has also been associated with intake of an 'unhealthy' and a less 'wholesome' diet in children of various ages (Golan, 2006; De Bourdeaudhuij, 1997). Commonly used scales on feeding-specific parenting practices measure the degree of control over child-eating reported by the parent, whereas scales on general parenting styles measure what the parent believes is essential to do to be in control of their child. An important aspect that lies outside the domain of knowledge with respect to these measures of both feeding specific parental practices and general parenting styles is to what extent the parent finds that her actions are effective in controlling the child, or whether she believes that the child is controlled by factors external to her.

The Art of Defeatism: Negative Affectivity, Parental Control Beliefs and Child-feeding

I interpret the findings on Negative Affectivity, External Parental Locus of Control, child-feeding and diet to be interrelated in the following manner:

Those mothers characterized by high levels of Negative Affectivity tend to have an external Parental Locus of Control (Lovejoy et al., 1997). I interpret this to be because of their ineffective coping skills (Vollrath, 2001). Because they feel they can't control the child's eating behavior they are more likely to compensate by enforcing pressure on the child to eat 
or to restrict the child's food intake. Moreover, the mother's external Parental Locus of Control may have a detrimental effect on the child's diet, because the mother will be less able to cope with the child's demand for sweet and fatty foods and less able to assure that the child eats a wholesome diet. Lastly, mothers with an external Parental Locus of Control are less likely to believe that the child is capable of internal self regulation in the feeding situation; therefore it makes sense to exert control.

The finding that pressuring a child to eat is associated with a less 'wholesome' diet and a more 'unhealthy' diet is in line with earlier findings (Brown et al., 2008; Fisher et al., 2002). The reason is that the children who are pressured to eat wholesome foods tend to build an aversion towards those foods (Fisher et al., 2002). Another control-oriented feeding practice that has been associated with a preference for and intake of an 'unhealthy' diet is restriction (Fisher \& Birch, 1999b; Fisher \& Birch, 1999a). This finding was not replicated, but on the contrary, it was found that restriction was associated with a more 'wholesome' diet and a less 'unhealthy' diet.

The finding that external Parental Locus of Control partially explained the association between Pressure to Eat and Restriction is a novel finding. These two child-feeding practices have in another study, together with the practice of monitoring, been subsumed under a common factor (Birch \& Fisher, 2000). This study implicates that if Pressure to Eat and Restriction is constructed as caused by one common factor, the factor could be confounded with the parent's belief of being efficiently in control.

While Pressure to Eat has been described as an overt form of child-feeding, hence perceivable to the child, Restriction has on the other hand been described as a covert form of child-feeding (Ogden, Reynolds, \& Smith, 2006). While the overt form has been related to more unhealthy snacking and less fruit and vegetable intakes, other have found the covert form to relate to the opposite (Brown et al., 2008). It could be that when a mother attempts to restrict her child's food intake, it is less obvious than pressuring the child to eat, and therefore the child does not react negatively to what the mother is trying to achieve.

\section{Methodological considerations}

\section{Reliability}

Reliability is consistency of measurement. Imagine doing an interview study on being for or against the European Union. To be sure whether one has tapped into a persons true 
standing, one asks him or her 100 times “are you for or against the European Union?". Assuming that the fluctuations in answers are due to random influences such as noise atmospheric changes, they will cancel each other out, and the person's score will to a greater extent reflect his or her true standing. Since humans remember that they have just been asked that very same question, and this would possibly influence their true score; to conform with the assumptions of Classical Test Theory one would have to brainwash the respondents after each question (Lord \& Novick, 1968) (pp 29-30). Although the implicated demands of entirely conforming to classical test theory are serious enough for quantitative psychology, reliability was tested in the current study using several approaches.

In paper I an internal consistency reliability coefficient, also known as Cronbach's alpha, was calculated for the SCL-5, SCL-8, and General Self-efficacy scale. The alphas were $.78, .82$, and .83 respectively. The reliability coefficient indicates the share of true variance in a measure. The Cronbach's alpha is an expression of the average split-half correlation and is an indication of how well the measure measures one single uni-dimensional factor; given that the measure actually measures only one single factor. For the purpose of paper I, the measures all had acceptable internal consistencies.

The pooling of measures over time done in Paper I could be thought of as a second form of reliability testing: Test-retest reliability. The correlation between the SCL-5 at week 17 and SCL-8 at week 30 was .57 . Beyond this being a below adequate score, there are several problems in using this form of reliability. First, if a correlation between two measures is to be seen as an expression of reliability, the true score must have perfect stability. It could be that the true level of Negative Affectivity changed during the 3.5 months between measurement points. Second, to interpret the pooling of SCL-5 and SCL-8 as an attempt to investigate reliability, the measures should have been identical. They were not; SCL- 8 has 3 items more than SCL-5.

The concept of reliability differs somewhat between classical test theory and latent variables. Reliability within latent variables is the squared correlation of a measure and it's latent variable (Bollen, 1989). The factor loadings for Negative Affectivity were adequate; even when taking in consideration that the current study used a measurement model with second order factors across time. The factor loadings for Parental Locus of Control and childfeeding practices varied more, but were in general adequate. 


\section{Construct Validity}

\section{Negative Affectivity}

The psychometrical derivation of the theoretical implications of a concept is construct validation (Cronbach \& Meehl, 1955). To establish construct validity there should be convergence over different methods and discriminability in relation to other constructs (Campbell \& Fiske, 1959). Although arguably a limit which should be set in specific relation to each nomological connection, a rule of thumb for deciding on discriminant validity between measures, is that they should not correlate above .80 without measurement error (John \& Benet-Martinez, 2000). In paper II and III an approximation of Negative Affectivity was attempted by converging measures of anxiousness/depressiveness, anger, and low self esteem, which have content semantically defined within Negative Affectivity; (Watson \& Clark, 1984). Watson, Clark et al. concludes that the facets of Negative Affectivity have convergent and discriminant validity (Watson et al., 1995)). So was the case in the current study; anxiousness/depressiveness correlated .59 with anger and .61 with low self-esteem, and anger .53 with low self-esteem (from time point at 18 months postpartum; all correlations reported concerning validity are without measurement error). So far, so good. In the introduction it was stated that Negative Affectivity and Neuroticism/Emotional Stability from the five factor model are not discriminable with a correlation reported in the literature of .83 (Clark \& Watson, 1999). So after the measure of Negative Affectivity was compiled for this study it was correlated with a measure of Neuroticism/Emotional Stability, utilizing the sample of fathers in MoBa. The correlation was at .92. This implies that the semantical aim for Negative Affectivity was by all means good, but that it possibly was set a little bit too high and towards Neuroticism/Emotional Stability.

The Nomological Relationship Between Negative Affectivity, General Self-efficacy, and Parental Locus of Control

General Self-efficacy does not conform to Bandura's conceptualization of context discrete self-efficacies. General Self-efficacy has no clear cut status as a trait, but is perhaps better conceptualized as a lower order trait. In the five factor model, Self-efficacy is regarded as a facet of the trait Conscientiousness (sometimes called C1 - Competence) (John \& Srivastava, 1999). Although advocates of Self-efficacy as a prime factor would claim that low Self-efficacy is proneness to failure and therefore states of Negative Affect (Bandura, 1997), 
it is here claimed that General Self-efficacy is not within the semantical heart of Negative Affectivity. There is discriminant validity between the two measures, with a correlation corrected for attenuation of -.28 (Negative Affectivity as measured in Paper I).

In their examination of convergent and discriminant validity of parental efficacy Lovejoy et al. concludes that measures of parental efficacy might reflect distress rather than specific beliefs about parenting. Their conclusion is flawed. First, the mean correlation between Negative Affectivity and Parental Locus of Control is at .64 corrected for attenuation; hence sharing $41 \%$ variance. The measures of the two concepts correlated .55 (30\% shared variance) in the current study. This supports, as opposed to the conclusion by Lovejoy et al., discriminant validity. Second, content overlap in the range of psychological questionnaire measurement taken in consideration; measures of Negative Affectivity taps internal states of affects, while measures of parental efficacy taps specific beliefs in a specific parent-child relationship.

\section{Short Scales}

Several short form versions of scales were used in the current study. The SCL-5, SCL8, and the Rosenberg Self-esteem scale were all shortened using stepwise regression; sequentially picking out those items who explain the most variance in the full version score (Tambs \& Moum, 1993; Tambs, 2004). The SCL-5 and SCL-8 explain 84\% and 89\% of the SCL-25 respectively, and the 4-item version of Rosenberg Self-esteem scale explains $90 \%$ of the variance in the full 10-item scale (all not corrected for measurement error) (Tambs, 2004). The 5-items on General-self efficacy were selected by selecting the items with highest factor loadings.

These two approaches to short-form creation have their differences. While with the regression approach one seeks to make a short form of a scale, with the factor analysis approach one seeks to find the best indicators of measuring a construct. Since a scale formed by subsuming several questions can have multiple dimensions, one risk, by using the regression approach, to select items representing small sub-dimensions within a scale (e.g. panic attacks). This possibly makes sense when operating on operationalistic terms (i.e. representing a scale), but not when seeking construct validity (i.e. finding the best psychometric approach to a concept). It is my opinion that the uni-dimensional factor analytic approach makes by far more sense, if one believes that the responses on the items are actually due to (in a causal sense) a characteristic within the responding. 
This problem has been remedied in paper II and III by using factor analysis on the regression derived short-forms.

\section{The Content Validity of the Parental Locus of Control Measure}

The items used to measure Parental Locus of Control was sampled neither by regression nor factor analysis. The items were selected for the MoBa study on face value. The measure of Parental Locus of Control can be applied both as divided in to sub factors defined by Campis et al. (1986) or subsumed into one scale of internal versus external Parental Locus of Control. On one hand the items were not selected with any sound statistical method, on the other were they selected to best semantically reflect Parental Locus of Control. Still there is uncertainty whether all aspects of Parental Locus of Control are covered well enough.

\section{Strengths of the Study}

First, a major strength of this study is that it is a population based cohort study where nearly all members of the population are invited. This makes to some extent the prevalence findings, but especially the association based findings generalizable to the Norwegian population.

Second, earlier studies on psychological determinants of breastfeeding have largely been done post partum. In using measures of the respondents psychological characteristics before the investigated behavior has been initiated strengthens the findings.

This is to the best of knowledge the second study to use polychoric correlations as a basis for studying dietary patterns (Togo, Heitmann, Sorensen, \& Osler, 2003) and the first study to apply this methodology on child data. The assumption is that there are several normally distributed etiological factors influencing diet. It does not make sense that the actual frequency in different specific nutritional intakes should be the same. The use of polychoric correlations, where one assumes that the observed association to be caused by normally distributed latent variables follows this assumption to a greater extent than utilizing the much used product-moment correlation matrix in studying dietary patterns.

By using measures of Negative Affectivity across several time points, time specific stress other biases are attenuated.

The definition of data as ordinals (ordered categories) rather than intervals and including this within a latent variable framework does conform syntactically with the notion 
of persons having inner characteristics which is manifested in specific responses contingent on their respective level of that characteristic.

\section{Shades of Brown: Limitations of the Study}

When generalizing the findings, several limitations must be kept in mind.

1. The SCL used to operationalize Negative Affectivity in paper I is less sensitive to normal variations in personality traits and shows a skewed distribution of scores. As a result, the effect sizes might have been either overestimated or underestimated.

2. In paper I Negative Affectivity was operationalized only through anxiousness and depressiveness. It can be argued, however, that Negative Affectivity includes other emotions and affects as well, such as anger, guilt and low self-esteem. At the same time, the measurement models from paper II and III showed that the SCL was a very good proxy of Negative Affectivity.

3. A further limitation in the previous vein is that in paper I a mean score across the items was used, while in paper II and III factor analysis was used. Within a composite score there could be several dimensions influencing the outcome differentially; within a factor score there can be only one dimension, making the association less ambiguous.

4. The full range of personality traits that is relevant in the context of health-behaviors was not assessed. However, space restrictions in the questionnaires did not allow for a full personality assessment questionnaire.

5. Persons with a high level of Negative Affectivity have more health complaints. This could pull the maternal report on child diet in a negativistic direction.

6. The range and numbers of indicators for the dietary patterns was limited, but it could be argued that children under three years of age have a limited diet and it was sought to find only a modest dietary pattern.

7. Although the same size or larger than several known risk factors, the effect size of Negative Affectivity on the unhealthy eating was small. Still, child diet has probably a wide range of etiological factors, so a very large effect size from only one maternal personality trait was not expected.

8. Unlike in the study of dietary patterns in this sample at 18 months after birth, marital status and age were not controlled for parity. Since parity could be related to marital status and age, the effect of those two former variables could therefore be partly due to number of children in the household. 
9. An important maternal characteristic was not applied in the models used in paper II and III: maternal diet. On one hand maternal diet could be thought of as a mediating factor between Negative Affectivity and child diet. On the other hand, there is no room for this interpretation; since external Parental Locus of Control, which relates to a specific mother-child relationship, completely mediated the association between Negative Affectivity and child diet.

10. The studies on child-feeding, paper II and paper III, was done using maternal characteristics as predictors of child-feeding and diet. Although the mother plausibly has a large influence in early childhood years, I did not look into paternal or child related predictors. One thing is that by including these factors more variance in child diet would be explained. Another more severe point is that paternal and child characteristics could possibly function as moderators of the maternal influence.

11. Although the main characteristic of interest, Negative Affectivity, was measured before the parenting and dietetic outcomes, in paper III Parental Locus of Control, child-feeding practices and child diet was measured without a time lag.

12. The former limitation leads us onto the last limitation, which is of a more philosophical character; a multiple regression model reflects only one form of thinking. Other competing models with rearranged or even novel variables could therefore be specified indefinitely.

\section{Suggestions for Future Research}

Future studies ought to focus on the normal variations of personality traits and assess their entire spectrum as represented by the Big Five trait taxonomy (John \& Srivastava, 1999). More specifically have breastfeeding initiation, as opposed to choosing not to breastfeed, been associated with personality traits related to extraversion (Chamberlain, 1976; Wagner et al., 2006). Moreover did the breastfeeding mothers in Chamberlain's (1976) study report that they would like their children to "become noisy and excited at all times". Future studies should investigate the possible relation between extraversion, sensation seeking, and approach motivation as predictors of breastfeeding behavior. Furthermore, it could be important to examine the impact of Conscientiousness, a trait predicting a wide spectrum of health behaviors (Bogg \& Roberts, 2004), on both breastfeeding initiation and follow through.

The finding that mothers with higher levels of Negative Affectivity to a lesser extent breastfed was interpreted as due to inefficient coping. Since lactogenesis and hormonal 
control of the let down reflex of breast milk is influenced by maternal stress, future studies should look into specific interactions between Negative Affectivity and breastfeeding problems. E.g. measured or experienced insufficient milk production, or nipple pain during feeding.

Since the much used Child-feeding Questionnaire (Birch et al., 2001), measuring child-feeding practices, is not theoretically derived; should future studies look into the role of personality, parenting strategies, and parenting beliefs in explaining the covariation between different forms of child-feeding practices. In the same vein should the factor structure of the widely established Child-feeding Questionnaire be questioned and reexamined.

\section{CONCLUSION}

The overall conclusion is that the children of mothers with a high level of Negative Affectivity to a lesser extent are breastfed and have a diet of poorer nutritional value beyond that of previous findings on maternal demographic and physical risk factors. Moreover, this thesis indicates a link between high levels of Negative Affectivity, not believing to be in control of the child, and harsher control in child-feeding. This link is corroborated by the findings that the impact of maternal Negative Affectivity on child-feeding and child diet is completely mediated by external Parental Locus of Control. These findings are important for future research on risk factors for obesogenic child diet, and awareness of these relationships may have clinical relevance for health personnel giving guidance on child-feeding. 


\section{REFERENCES}

Armstrong, J., Reilly, J. J., \& Child Health Information Team (2002). Breastfeeding and lowering the risk of childhood obesity. Lancet, 359, 2003-2004.

Bailey, J., Clark, M., \& Shepherd, R. (2008). Duration of breastfeeding in young women: psychological influences. British Journal of Midwifery, 16, 172-178.

Bandura, A. (1977). Self-efficacy: toward a unifying theory of behavioral change. Psychological Review, 84, 191-215.

Bandura, A. (1997). Self-efficacy: The exercise of control. New York: Freeman \& co.

Baron, R. M. \& Kenny, D. A. (1986). The moderator-mediator variable distinction in social psychological research: Conceptual, strategic, and statistical considerations. Journal of Personality and Social Psychology, 51, 1173-1182.

Berg-Cross, L., Berg-Cross, G., \& McGeehan, D. (1979). Experience and personality differences among breast- and bottle-feeding mothers. Psychology of Women Quarterly, 3, 344-356.

Birch, L. L. \& Fisher, J. O. (2000). Mothers' child-feeding practices influence daughters' eating and weight. American Journal of Clinical Nutrition, 71, 1054-1061.

Birch, L. L., Fisher, J. O., Grimm-Thomas, K., Markey, C. N., Sawyer, R., \& Johnson, S. L. (2001). Confirmatory factor analysis of the Child Feeding Questionnaire: a measure of parental attitudes, beliefs and practices about child feeding and obesity proneness. Appetite, 36, 201-210.

Birch, L. L., McPhee, L., Shoba, B. C., Pirok, E., \& Steinberg, L. (1987). What kind of exposure reduces children's food neophobia? Looking vs. tasting. Appetite, 9, 171-178.

Blyth, R., Creedy, D. K., Dennis, C. L., Moyle, W., Pratt, J., \& De Vries, S. M. (2002). Effect of maternal confidence on breastfeeding duration: an application of breastfeeding self-efficacy theory. Birth, 29, 278-284.

Blyth, R. J., Creedy, D. K., Dennis, C. L., Moyle, W., Pratt, J., De Vries, S. M. et al. (2004). Breastfeeding duration in an Australian population: the influence of modifiable antenatal factors. Journal of Human Lactation, 20, 30-38.

Bogg, T. \& Roberts, B. W. (2004). Conscientiousness and health-related behaviors: a meta-analysis of the leading behavioral contributors to mortality. Psychological Bulletin, 130, 887-919.

Bolger, N. (1990). Coping as a personality process: A prospective study. Journal of Personality and Social Psychology, 59, 525-537.

Bollen, K. A. (1989). Structural equations with latent variables. (1989).xiv, 514 pp.Oxford, England: John Wiley \& Sons., 514.

Bollen, K. A. (2006). Latent curve models : a structural equation perspective. Hoboken, N.J.: Wiley-Interscience. 
Britton, J. R. (2007). Postpartum anxiety and breast feeding. Journal of Reproductive Medicine, 52, 689-695.

Brown, F., Chase, J., \& Winson, J. (1961). Studies in infant feeding choices of primiparae: II. Comparison of Rorschach determinants of accepters and rejecters of breast feeding. Journal of Projective Techniques, 25, 412-421.

Brown, K. A., Ogden, J., Vogele, C., \& Gibson, E. L. (2008). The role of parental control practices in explaining children's diet and BMI. Appetite, 50, 252-259.

Browne, M. W. (2001). An overview of analytic rotation in exploratory factor analysis. Multivariate Behavioral Research, 36, 111-150.

Call, J. D. (1959). Emotional factors favoring successful breast feeding of infants. Journal of Pediatrics, 55, 485-496.

Campbell, D. T. \& Fiske, D. W. (1959). Convergent and discriminant validation by the multitrait-multimethod matrix. Psychological Bulletin, 56, 81-105.

Campis, L. K., Lyman, R. D., \& Prentice-Dunn, S. (1986). The Parental Locus of Control Scale: Development and validation. Journal of Clinical Child Psychology, 15, 260 267.

Chamberlain, R. E. (1976). Some personality differences between breast and bottle feeding mothers. Birth \& the Family Journal, 3, 31-34.

Chapman, D. J. \& Perez-Escamilla, R. (1999). Identification of risk factors for delayed onset of lactation. Journal of the American Dietetic Association, 99, 450-454.

Clark, L. A. \& Watson, D. (1999). Temperament: A new paradigm for trait psychology. In L.A.Pervin \& O. P. John (Eds.), Handbook of Personality: Theory and Research (2nd ed ed., pp. 399-423). New York: Guilford Press.

Cooper, P. J., Murray, L., \& Stein, A. (1993). Psychosocial factors associated with the early termination of breast-feeding. Journal of Psychosomatic Research, 37, 171-176.

Cornell, M. M. (1969). Psychological variables in the mother related to infant feeding patterns. Dissertation Abstracts International, 29, 3479.

Cronbach, L. J. \& Meehl, P. E. (1955). Construct validity in psychological tests. Psychological Bulletin, 52, 281-302.

De Bourdeaudhuij, I. (1997). Family food rules and healthy eating in adolescents. Journal of Health Psychology, 2, 45-56.

Dennis, C. L. (1999). Theoretical underpinnings of breastfeeding confidence: a selfefficacy framework. Journal of Human Lactation, 15, 195-201.

Dennis, C. L. \& Faux, S. (1999). Development and psychometric testing of the Breastfeeding Self-Efficacy Scale. Research in Nursing \& Health, 22, 399-409. 
Dewey, K. G. (2001). Maternal and fetal stress are associated with impaired lactogenesis in humans. Journal of Nutrition, 131, 3012S-3015S.

Dewey, K. G. (2003). Is breastfeeding protective against child obesity? Journal of Human Lactation, 19, 9-18.

Dunn, S., Davies, B., McCleary, L., Edwards, N., \& Gaboury, I. (2006). The relationship between vulnerability factors and breastfeeding outcome. Jognn-Journal of Obstetric Gynecologic and Neonatal Nursing, 35, 87-97.

Fisher, J. O. \& Birch, L. L. (1999a). Restricting access to foods and children's eating. Appetite, 32, 405-419.

Fisher, J. O. \& Birch, L. L. (1999b). Restricting access to palatable foods affects children's behavioral response, food selection, and intake. American Journal of Clinical Nutrition, 69, 1264-1272.

Fisher, J. O., Mitchell, D. C., Smiciklas-Wright, H., \& Birch, L. L. (2002). Parental influences on young girls' fruit and vegetable, micronutrient, and fat intakes. Journal of the American Dietetic Association, 102, 58-64.

Flora, D. B. \& Curran, P. J. (2004). An empirical evaluation of alternative methods of estimation for confirmatory factor analysis with ordinal data. Psychological Methods, 9, 466491.

Ford, R. P. K., Taylor, B. J., Mitchell, E. A., Enright, S. A., Stewart, A. W., Becroft, D. M. O. et al. (1993). Breast-feeding and the risk of sudden-infant-death-syndrome. International Journal of Epidemiology, 22, 885-890.

Foreyt, J. P. \& Poston, W. S. C., II (2002). Consensus view on the role of dietary fat and obesity. American Journal of Medicine, 113, Suppl-62S.

Friedman, H. S. (2000). Long-term relations of personality and health: dynamism, mechanisms, tropisms. Journal of Personality, 68, 1089-1107.

Friedman, N. J. \& Zeiger, R. S. (2005). The role of breast-feeding in the development of allergies and asthma. Journal of Allergy \& Clinical Immunology, 115, 1238-1248.

Galler, J. R., Harrison, R. H., Biggs, M. A., Ramsey, F., \& Forde, V. (1999). Maternal moods predict breastfeeding in Barbados. Journal of Developmental and Behavioral Pediatrics, 20, 80-87.

Golan, M. (2006). Parents as agents of change in childhood obesity - from research to practice. International Journal of Pediatric Obesity, 1, 66-76.

Gow, A. J., Whiteman, M. C., Pattie, A., \& Deary, I. J. (2005). Goldberg's 'IPIP' BigFive factor markers: Internal consistency and concurrent validation in Scotland. Personality and Individual Differences, 39, 317-329.

Groer, M. W. (2005). Differences between exclusive breastfeeders, formula-feeders, and controls: A study of stress, mood, and endocrine variables. Biological Research For Nursing, 7, 106. 
Heck, H. \& Decastro, J. M. (1993). The caloric demand of lactation does not alter spontaneous meal patterns, nutrient intakes, or moods of women. Physiology \& Behavior, 54, 641-648

Henderson, J. J., Evans, S. F., Straton, J. A. Y., Priest, S. R., \& Hagan, R. (2003). Impact of postnatal depression on breastfeeding duration. Birth, 30, 175-180.

Hill, A. J. (2002). Developmental issues in attitudes to food and diet. Proceedings of the Nutrition Society, 61, 259-266.

Hu, L. T. \& Bentler, P. M. (1998). Fit indices in covariance structure modeling: Sensitivity to underparameterized model misspecification. Psychological Methods, 3, 424453.

Irgens, L. M. (2000). The Medical Birth Registry of Norway. Epidemiological research and surveillance throughout 30 years. Acta Obstetricia et Gynecologica Scandinavica, 79, 435-439.

Izard, C. E., Libero, D. Z., Putnam, P., \& Haynes, O. M. (1993). Stability of emotion experiences and their relations to traits of personality. Journal of Personality and Social Psychology, 64, 847-860.

Janssens, J. M. A. M. (1994). Authoritarian child-rearing, parental locus of control, and the childs behavior style. International Journal of Behavioral Development, 17, 485-501.

John, O. P. \& Benet-Martinez, V. (2000). Measurement: Reliability, construct validation, and scale construction. In H.T.Reis \& C. M. Judd (Eds.), Handbook of research methods in social and personality psychology (pp. 339-369). New York: Cambridge University Press.

John, O. P. \& Srivastava, S. (1999). The Big Five Trait taxonomy: History, measurement, and theoretical perspectives. In L.A.Pervin \& O. P. John (Eds.), Handbook of personality: Theory and research (2nd ed., pp. 102-138). New York: Guilford Press.

Klement, E., Cohen, R. V., Boxman, J., Joseph, A., \& Reif, S. (2004). Breastfeeding and risk of inflammatory bowel disease: a systematic review with meta-analysis. American Journal of Clinical Nutrition, 80, 1342-1352.

Kramer, M. S., Chalmers, B., Hodnett, E. D., Sevkovskaya, Z., Dzikovich, I., Shapiro, S. et al. (2001). Promotion of breastfeeding intervention trial (PROBIT) - a randomized trial in the Republic of Belarus. JAMA: Journal of the American Medical Association, 285, 413420 .

Kramer, M. S. \& Kakuma, R. (2002). The optimal duration of exclusive breastfeeding. A systematic review. (WHO/NHD/01.08 ed.) Geneva: World Health Organization.

Lande, B., Andersen, L. F., Baerug, A., Trygg, K. U., Lund-Larsen, K., Veierod, M. B. et al. (2003). Infant feeding practices and associated factors in the first six months of life: the Norwegian infant nutrition survey. Acta Paediatrica, 92, 152-161. 
Lord, F. M. \& Novick, M. R. (1968). Statistical theories of mental test scores. Reading, Mass: Addison-Wesley.

Lovejoy, M. C., Verda, M. R., \& Hays, C. E. (1997). Convergent and discriminant validity of measures of parenting efficacy and control. Journal of Clinical Child Psychology, 26, 366-376.

Ludwig, D. S., Peterson, K. E., \& Gortmaker, S. L. (2001). Relation between consumption of sugar-sweetened drinks and childhood obesity: a prospective, observational analysis. Lancet, 357, 505-508.

Luszczynska, A., Scholz, U., \& Schwarzer, R. (2005). The general self-efficacy scale: multicultural validation studies. Journal of Psychology: Interdisciplinary and Applied, 139, 439-457.

Magnus, P. (2007). The Norwegian Mother and Child Cohort Study (MoBa) - new research possibilities. Norwegian Journal of Epidemiology, 17, 107-110.

Magnus, P., Irgens, L. M., Haug, K., Nystad, W., Stoltenberg, C., \& The MoBa Study Group (2006). The Norwegian Mother and Child Cohort Study. International Journal of Epidemiology, 35, 1146-1150.

Martin, R. M., Gunnell, D., Owen, C. G., \& Smith, G. D. (2005). Breast-feeding and childhood cancer: A systematic review with metaanalysis. International Journal of Cancer, $117,1020-1031$.

McCrae, R. R. \& Costa, P. T. (1986). Personality, coping, and coping effectiveness in an adult sample. Journal of Personality, 54, 385-405.

Metsapelto, R. L. \& Pulkkinen, L. (2003). Personality traits and parenting: Neuroticism, extraversion, and openness to experience as discriminative factors. European Journal of Personality, 17, 59-78.

Mezzacappa, E. S., Guethlein, W., Vaz, N., \& Bagiella, E. (2000). A preliminary study of breast-feeding and maternal symptomatology. Annals of Behavioral Medicine, 22, 71-79.

Millar, D. G. \& Littlepage, B. N. (1970). Puerperal thromboembolism. Lancet, 1, 887.

Modhal, C. \& Newton, N. (1979). Mood state difference between breast and bottle feeding mothers. In L.Caranzeta \& L. Zinchella (Eds.), Emotion and reproduction: Proceedings of the Serano Symposium: Vol 20B (pp. 819-822). New York: Academic Press.

Mortensen, E. L., Michaelsen, K. F., Sanders, S. A., \& Reinisch, J. M. (2002). The association between duration of breastfeeding and adult intelligence. JAMA: Journal of the American Medical Association, 287, 2365-2371.

Muthén, L. K. \& Muthén, B. O. (2007). Mplus user's guide. (5th ed.) Los Angeles, CA: Muthén \& Muthén.

Muthén, L. K. \& Muthén, B. O. (2008). Version 5.1: Mplus language addendum. Los Angeles, CA: Muthén \& Muthén. 
Newton, N. \& Newton, M. (1967). Psychologic aspects of lactation. New England Journal of Medicine, 277, 1179-1188.

Nissen, E., Gustavsson, P., Widström, A. M., \& Uvnäs-Moberg, K. (1998). Oxytocin, prolactin, milk production and their relationship with personality traits in women after vaginal delivery or cesarean section. Journal of Psychosomatic Obstetrics and Gynecology, 19, 49-58.

Norris, J. M. \& Scott, F. W. (1996). A meta-analysis of infant diet and insulindependent diabetes mellitus: do biases play a role? Epidemiology, 7, 87-92.

North, K. \& Emmett, P. (2000). Multivariate analysis of diet among three-year-old children and associations with socio-demographic characteristics. European Journal of Clinical Nutrition, 54, 73-80.

Northstone, K. \& Emmett, P. (2005). Multivariate analysis of diet in children at four and seven years of age and associations with socio-demographic characteristics. European Journal of Clinical Nutrition, 59, 751-760.

Ogden, J., Reynolds, R., \& Smith, A. (2006). Expanding the concept of parental control: A role for overt and covert control in children's snacking behaviour? Appetite, 47, $100-106$

Ong, G., Yap, M., Li, F. L., \& Choo, T. B. (2005). Impact of working status on breastfeeding in Singapore: evidence from the National Breastfeeding Survey 2001. European Journal of Public Health, 15, 424-430.

Oswald, L. M., Zandi, P., Nestadt, G., Potash, J. B., Kalaydjian, A. E., \& Wand, G. S. (2006). Relationship between cortisol responses to stress and personality.

Neuropsychopharmacology, 31, 1583-1591.

Owen, C. G., Martin, R. M., Whincup, P. H., Davey-Smith, G., Gillman, M. W., \& Cook, D. G. (2005). The effect of breastfeeding on mean body mass index throughout life: a quantitative review of published and unpublished observational evidence. American Journal of Clinical Nutrition, 82, 1298-1307.

Owen, C. G., Martin, R. M., Whincup, P. H., Smith, G. D., \& Cook, D. G. (2006). Does breastfeeding influence risk of type 2 diabetes in later life? A quantitative analysis of published evidence. American Journal of Clinical Nutrition, 84, 1043-1054.

Paricio Talayero, J. M., Lizan-Garcia, M., Otero, P. A., Benlloch Muncharaz, M. J., Beseler, S. B., Sanchez-Palomares, M. et al. (2006). Full breastfeeding and hospitalization as a result of infections in the first year of life. Pediatrics, 118, e92-e99.

Patrick, H., Nicklas, T. A., Hughes, S. O., \& Morales, M. (2005). The benefits of authoritative feeding style: caregiver feeding styles and children's food consumption patterns. Appetite, 44, 243-249.

Rosenberg, M. (1989). Society and the adolescent self-image. (Rev. ed.) Middletown, CT: Wesleyan University Press. 
Ruvalcaba, R. H. (1987). Stress-induced cessation of lactation. Western Journal of Medicine, 146, 228-230.

Schwarzer, R. (1992). Self-Efficacy: Thought control of action. Washington: Hemisphere.

Sisk, P. M., Lovelady, C. A., Dillard, R. G., \& Gruber, K. J. (2006). Lactation counseling for mothers of very low birth weight infants: Effect on maternal anxiety and infant intake of human milk. Pediatrics, 117, E67-E75.

Smith, T. W., Pope, M. K., Rhodewalt, F., \& Poulton, J. L. (1989). Optimism, neuroticism, coping, and symptom reports: An alternative interpretation of the Life Orientation Test. Journal of Personality and Social Psychology, 56, 640-648.

Strand, B. H., Dalgard, O. S., Tambs, K., \& Rognerud, M. (2003). Measuring the mental health status of the Norwegian population: A comparison of the instruments SCL-25, SCL-10, SCL-5 and MHI-5 (SF-36). Nordic Journal of Psychiatry, 57, 113-118.

Tambs, K. \& Moum, T. (1993). How well can a few questionnaire items indicate anxiety and depression? Acta Psychiatrica Scandinavica, 87, 364-367.

Tambs, K. (2004). Valg av spørsmål til kortversjoner av etablerte psykometriske instrumenter. Forslag til framgangsmåte og noen eksempler. In I.Sandanger \& T. Sørensen (Eds.), Ubevisst sjeleliv og bevisst samfunnsliv: psykisk helse $i$ en sammenheng : festskrift til Tom Sørensen på hans 60-årsdag ( Nittedal: Nordkyst psykiatri.

Togo, P., Heitmann, B. L., Sorensen, T. I. A., \& Osler, M. (2003). Consistency of food intake factors by different dietary assessment methods and population groups. British Journal of Nutrition, 90, 667-678.

Tu, M. T., Lupien, S. J., \& Walker, C. D. (2005). Measuring stress responses in postpartum mothers: Perspectives from studies in human and animal populations. Stress: The International Journal on the Biology of Stress, 8, 19-34.

Uvnäs-Moberg, K., Widström, A. M., Nissen, E., \& Björvell, H. (1990). Personality traits in women 4 days postpartum and their correlation with plasma levels of oxytocin and prolactin. Journal of Psychosomatic Obstetrics \& Gynecology, 11, 261-273.

Venancio, S. I. \& Monteiro, C. A. (2006). Individual and contextual determinants of exclusive breast-feeding in Sao Paulo, Brazil: a multilevel analysis. Public Health Nutrition, $9,40-46$.

Virden, S. F. (1988). The relationship between infant-feeding method and maternal role adjustment. Journal of Nurse-Midwifery, 33, 31-35. 335-347.

Vollrath, M. (2001). Personality and stress. Scandinavian Journal of Psychology, 42,

Vollrath, M., Torgersen, S., \& Alnaes, R. (1998). Neuroticism, coping and change in MCMI-II clinical syndromes: Test of a mediator model. Scandinavian Journal of Psychology, $39,15-24$ 
Wagner, C. L. \& Wagner, M. T. (1999). The breast or the bottle? Determinants of infant feeding behaviors. Clinics in Perinatology, 26, 505-525.

Wagner, C. L., Wagner, M. T., Ebeling, M., Chatman, K. G., Cohen, M., \& Hulsey, T. C. (2006). The role of personality and other factors in a mother's decision to initiate breastfeeding. Journal of Human Lactation, 22, 16-26.

Wang, Y. \& Lobstein, T. (2006). Worldwide trends in childhood overweight and obesity. International Journal of Pediatric Obesity, 1, 11-25.

Watson, D., Clark, L. A., Weber, K., Assenheimer, J. S., Strauss, M. E., \& Mccormick, R. A. (1995). Testing a tripartite model: I. Evaluating the convergent and discriminant validity of anxiety and depression symptom scales. Journal of Abnormal Psychology, 104, 3-14.

Watson, D. \& Clark, L. A. (1984). Negative affectivity: the disposition to experience aversive emotional states. Psychological Bulletin, 96, 465-490.

Watson, D. \& Hubbard, B. (1996). Adaptational style and dispositional structure: Coping in the context of the five-factor model. Journal of Personality, 64, 737-774.

Weisenfeld, A. R. (1985). Psychophysiological response of breast- and bottle-feeding mothers to their infants' signals. Psychophysiology, 22, 79-86.

World Health Organization (1991). Indicators for assessing breastfeeding practices. (WHO/CDD/SER/91.14 ed.) Geneva: World Health Organization.

World Health Organization (2004). International statistical classification of diseases and related health problems (ICD-10): 10th Rev. (2 ed.) Geneva: World Health Organization. 
I 
Ystrom, E., Niegel, S., Klepp, K.-I., \& Vollrath, M. E. (2008). The impact of maternal negative affectivity and general self-efficacy on breast-feeding: The Norwegian Mother and Child Cohort Study. Journal of Pediatrics, 152, 68-72.

The article is removed from the dissertation. The original publication is available at $\underline{\mathrm{http}: / / \mathrm{x}-}$ port-sfx.uio.no/sfx_ubo?rft_id=info:doi/10.1016/j.jpeds.2007.06.005

Access to the published version may require journal subscription.

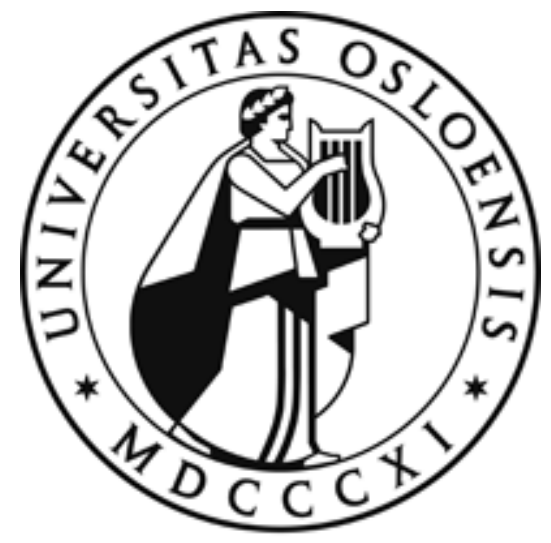




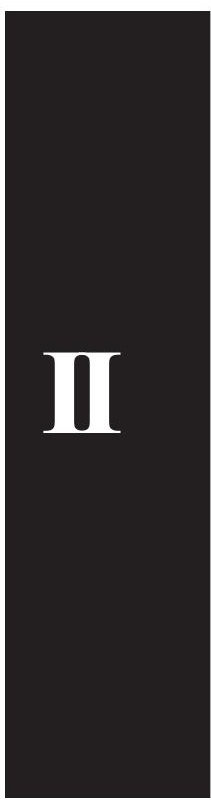


Ystrom, E., Niegel, S., \& Vollrath, M. E. The impact of maternal negative affectivity on dietary patterns of 18-month-old children in the Norwegian Mother and Child Cohort Study. Maternal and Child Nutrition, (in press).

Published in Maternal \& Child Nutrition, Early View, Date: March 2009.

This article is removed from the dissertation.

The original publication is available at Wiley InterScience http://www3.interscience.wiley.com/

Access to the published version may require journal subscription.

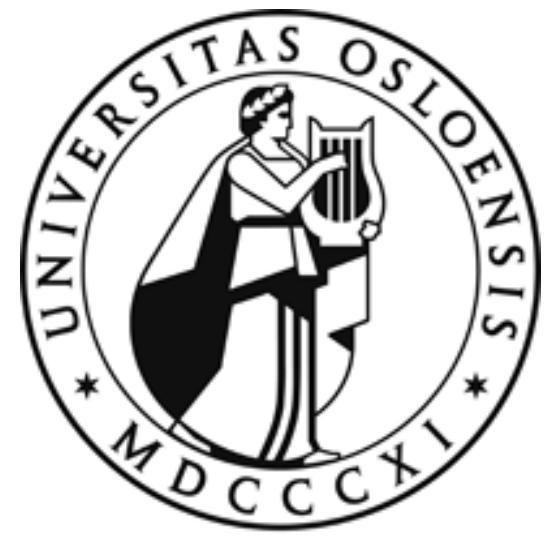




\begin{abstract}
Early dietary habits are formative for dietary habits later in life. Maternal personality might be an important factor in unhealthy feeding of children. The currents study aim to assess the degree to which the personality trait of Negative Affectivity in mothers predicts their child's diet at age 18 months. This study is a part of the Norwegian Mother and Child Cohort Study conducted at the Norwegian Institute of Public Health. A total of 27763 mothers completed 3 repeated assessments of Negative Affectivity before and after childbirth and of the child's diet when the child was 18 months old. Exploratory factor analysis was used to identify the dietary patterns, and structural equation modeling was used to investigate the relationship with Negative Affectivity adjusted for socio-demographical variables. Exploratory factor analysis of a foods frequency questionnaire revealed two dietary patterns in the child, labeled unhealthy diet and healthy diet. The unhealthy diet comprised foods rich in sugar and fat; the healthy diet comprised foods rich in fiber, vitamins and minerals. Mothers high in Negative Affectivity were more inclined to feed their child an unhealthy diet. The results were adjusted for maternal age, years of education, relative income, marital status, number of children, having the child in daycare, maternal smoking, maternal body mass index, and child gender. This study shows that a maternal personality trait, Negative Affectivity, is related to feeding the child an unhealthy diet after controlling for key sociodemographic variables.
\end{abstract}

Keywords: cohort, diet, infant, mothers, parenting, personality 


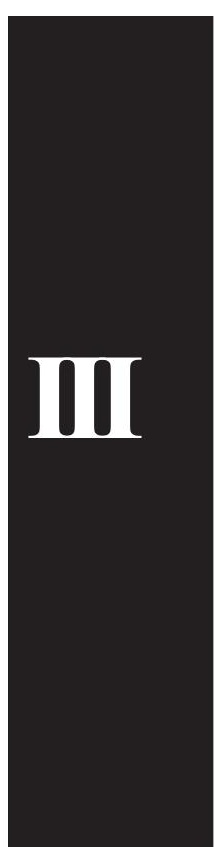


Ystrom, E., Barker, M., \& Vollrath, M. E. The impact of mothers' negative affectivity, parental locus of control and child-feeding practices on dietary patterns of 3-year old children. The Norwegian Mother and Child Cohort Study. (submitted to Appetite).

This is an author produced version of the article. The original publication is available at Elsevier ScienceDirect http://www.sciencedirect.com/science/journal/01956663

Access to the published version may require journal subscription.

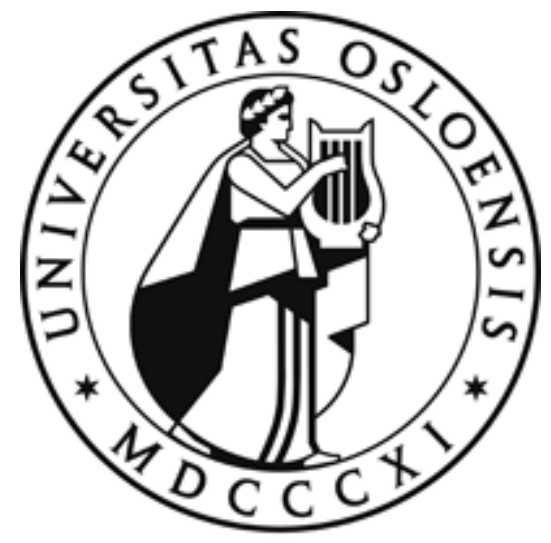


1 The impact of mothers' negative affectivity, parental locus of control, and child-feeding

22 Short running head: Maternal affectivity, parenting, and child diet

23 Word Count (text only): 5594

24 Number of Tables: 3
Eivind Ystrom, cand.psychol. (EY); Mary Barker, $\mathrm{PhD}(\mathrm{MB})$;

Margarete E. Vollrath, PhD (MEV)
Author affiliations: EY MEV Department of Psychosomatics and Health Behavior, Norwegian Institute of Public Health

MB MRC Epidemiology Resource Centre, University of Southampton, Southampton General Hospital, Southampton SO16 6YD, UK MEV Department of Psychology, University of Oslo, Norway

Author responsible for correspondence and reprints:

Eivind Ystrom

Norwegian Institute of Public Health, Department of Psychosomatics and Health Behavior

Postbox 4404, Nydalen

0403 Oslo, Norway

(Tel) + 47234083 34; (Fax) + 4723408101

(E-mail) eivind.ystrom@fhi.no

\author{
Number of Tables: 3
}

Number of Figures: 2 


\section{ABSTRACT}

27 Background: Both the maternal personality trait of Negative Affectivity (NA) and controloriented child-feeding are related to a low-quality child diet. There is no knowledge on the possible mechanisms for these findings

Objective: First, to identify dietary patterns in 3-year-old children. Second to investigate the extent to which NA, Parental Locus of Control (PLOC), and child-feeding practices (pressure to eat and restriction) relate to these dietary patterns. Third, examine to what extent PLOC and child-feeding practices serve as mediators for these effects.

34 Design: This study is part of the Norwegian Mother and Child Cohort Study, comprising 14,122 mothers completing assessments at 6 months, 18 months and 3 years postpartum.

36 Results: Factor analysis of the children's diet identified two weakly correlated dietary patterns, labeled 'unhealthy' and 'wholesome', respectively. Mothers high in NA perceived little control over their child's behavior, which in turn was associated with both pressuring their child to eat or to restrict the child's food intake, and a less 'wholesome' and a more 'unhealthy' diet in the child. Pressuring the child to eat was associated with a less?

41 'wholesome' and a more 'unhealthy' diet. Restricting the child's diet was associated with a more 'wholesome' and a less 'unhealthy' diet. These findings held after controlling for maternal smoking, education, age, BMI, marital status, homemaker status, and child gender.

44 Conclusion: Unhealthy and wholesome eating in 3-year-old children is weakly correlated. Mothers higher in NA perceive less control over their children, use more control-oriented child-feeding, and have children who have a lower-quality diet. 


\section{INTRODUCTION}

The epidemic increase in childhood obesity has lead to childhood diet becoming the focus of much research interest in recent years(1). Earlier studies of dietary patterns in preschool children have identified two main patterns(2;3); one pattern describes the consumption of 'unhealthy' foods, such as soda, chocolate, and sweets, and the other describes the consumption of 'wholesome' foods, such as beans, fruit, and fish.

The person with the greatest influence on a child's diet is arguably the mother, and the mother's characteristics, in turn, influence her food choices on behalf of her child. Being young, overweight, a smoker, or having lower educational attainment or more than one child increases the likelihood that a mother feeds her child less wholesome foods and more unhealthy ones(2;3).

Meal times can be emotive for both mother and child. Children often prefer foods with a high fat and sugar content(4). However, mothers know that their children should not eat too much of these foods, and that they instead should make them eat healthier alternatives. This can result in a situation familiar to most parents: the frustration of trying to feed a child foods he or she refuses to eat. Such a situation is stressful for most mothers. It might be especially so for emotionally unstable mothers, who could be susceptible to experiencing less control over their child(5) and to responding to him or her more inconsistently(6). Emotional instability, frequently called Negative Affectivity (NA), is a fundamental personality trait that embraces an innate inclination to emotional variability; frequent experience of negative affects such as anxiety, anger, and sadness; and a negative view of one's own self(7).

In previous studies we have shown that mothers characterized by high levels of NA were less likely to breastfeed exclusively throughout the baby's first six months(8) and more likely to feed their children an 'unhealthy' diet at 18 months of age(3). Persons characterized by high levels of NA believe that the behavior and development of their child is not contingent 
on their parenting, but is largely determined by external forces such as child temperament and chance(5). This belief is captured by the construct of external parental locus of control (PLOC). Parents perceiving to have little control over their child tend to compensate by an authoritarian parenting style characterized by excessive control(9). Likewise, parents with higher levels of NA have been found to have poor parental control, both exhibiting authoritarian parenting with excessive control and permissive parenting with insufficient control(6).

Both general parenting and the parents' feeding practices have come into focus as a risk factor for child obesity in recent years(10). Commonly used scales on feeding-specific parenting practices measure the degree of control reported by the parent, whereas scales on general parenting styles measure what the parent believes is essential to do to be in control of their child. Findings show that authoritarian parenting, permissive parenting, and controloriented child-feeding practices, such as pressuring a child to eat and restricting a child's food intake predict that the child consumes fewer 'wholesome' and more 'unhealthy' foods(11-18). In this study we firstly aim to re-identify at three years the two child dietary patterns of 'wholesome' and 'unhealthy' diet found in this sample of children 18 months after birth(3) (hypothesis 1).

Secondly, because NA relates to external PLOC, and both NA and PLOC relate to excessive control, we hypothesize that mothers with high levels of NA are more likely to pressure the child to eat and restrict the child's food intake, but that the effect of this personality trait will be mediated through external PLOC (hypothesis 2; figure 1).

Thirdly, we hypothesize that higher levels of NA in the mother and external PLOC will predict more 'unhealthy' and less 'wholesome' dietary patterns, because mothers will be more likely to use the two forms of control-oriented child-feeding practices of pressuring the child to eat and restricting the child's food intake (hypothesis 3; figure 1). 
Because it is possible that control-oriented child-feeding practices affect diet over and above the effects of maternal personality and general parenting, we fourthly hypothesize that pressuring the child to eat and restricting the child's food intake will have an independent negative effect on the child's 'wholesome' dietary pattern and a positive effect on the 'unhealthy' dietary pattern (hypothesis 4; figure 1).

We aim to test these hypotheses using data from the Norwegian Mother and Child Cohort Study and to control for key demographic and physical variables.

\section{SUBJECTS AND METHODS}

\section{Study population}

The data collection was conducted as a part of the Norwegian Mother and Child Cohort Study (MoBa) at the Norwegian Institute of Public Health. The study was launched in 1999 with the purpose of finding causes of serious diseases among mothers and children(19). There are no exclusion criteria, and all maternity units in Norway with more than 100 births annually are included. Mothers are recruited for the study when they undergo their first prenatal ultrasound examination at 17 to 18 weeks gestation. The participation rate in MoBa is $42.7 \%$. Mothers fill out questionnaires at 17 weeks gestation and child age 6 months, 18 months, and 3 years after childbirth. Response rates are $95 \%$ at during pregnancy, while after birth they are $87 \%$ at 6 months, $77 \%$ at 18 months, and $62 \%$ at 3 years(19;20). For our study, we used information from the questionnaires administered at the aforementioned assessment points. In addition we used the Medical Birth Registry of Norway, which contains information about all births in Norway(21).

The study was approved by the appropriate regional committees for ethics in medical research and the Norwegian National Data Inspectorate. 
121 At the time that we conducted this study, questionnaires from 15,103 participating mothers

122 with a child that had reached 3 years of age were available. We excluded 6.5 percent $(n=981)$

123 of the participants because of missing data. The final sample therefore consisted of 14,122

124 mothers.

125 Demographic and physical risk factors

126 We gathered information on child gender and maternal age from the Medical Birth Registry

127 of Norway. We retrieved information on the mothers' smoking status (current regular smoker

128 or non-smoker), education (years attained), current homemaker vs. working status, current

129 body mass index (BMI) and current marital status (single or cohabiting/married) from the

130 MoBa questionnaires.

131 Negative Affectivity

132 A measure of mother's NA was compiled from several short scales in the

133 questionnaires(3). Using an 8-item short version of the Hopkins Symptom Checklist (SCL),

134 we assessed the Anxiety-Depression component of NA(22). We measured the anger

135 component of NA using 3 items from the Anger subscale of the Differential Emotions

136 Scale(23), and the Self-Esteem component of NA using a 4-item short version of the

137 Rosenberg Self-Esteem scale(24). By subsuming these short scales into one, we constructed a

138 measure of NA with stronger psychometric characteristics. The assessment points for the NA

139 components were at child age 6 months, 18 months, and 3 years. These components of NA

140 include both time-invariant, dispositional variance and time-specific variance, which reflects

141 the mother's state at the time when she filled out the questionnaire. We constructed a latent

142 variable across the three assessments, to subtract the time-invariant dispositional factor (for

143 details, see the statistics section).

144 The MoBa cohort study also includes an assessment of the child's father at the 17th week

145 of gestation(19). In this assessment, the items used for modeling NA among mothers were 
146 included together with a measure of Emotional Stability/Neuroticism from the International

147 Personality Item Pool(25). The construct of Emotional Stability/Neuroticism is equivalent to

$148 \mathrm{NA}(26)$. When correlating a latent NA variable construed in the fathers' data with a latent

149 variable of Neuroticism/Emotional Stability from the same dataset, we found a correlation of

$150 r=0.92$, suggesting an excellent validity of the NA-measure used our study.

151 Parental locus of control

152 The degree of external versus internal PLOC was assessed at child age 3 years using 5

153 items from the Parental Locus of Control Scale (item number 1, 5, 21, 41, and 44)(27). The

154 PLOC scale is a measure of the extent to which parents believe that the behavior of their child

155 is controlled by their own parenting skills or by other events external to their parenting. A

156 high score on the PLOC scale indicates an internal PLOC, a low score indicates a more

157 external PLOC.

158 Child-feeding practices

159 Two forms of control-oriented child-feeding practices, restriction of child food intake, and

160 pressuring the child to eat were measured at child age 3 using the 'restriction' and 'pressure to

161 eat' subscales of the Child-feeding Questionnaire(10). The Child-feeding Questionnaire is a

162 tool for assessing parents' perceptions, beliefs, attitudes, and practices regarding child-feeding

163 relevant to the development of obesity. A typical question from the pressure to eat subscale is

164 "My child should always eat all of the food on her plate", and a typical question from the

165 restriction subscale is "I have to be sure that my child does not eat too many sweets (candy,

166 ice cream, cake or pastries)." The respondents are asked to 'agree' or 'disagree' with each

167 statement on a five-point scale.

168 Child's diet

169 We collected information on the current diet of the 3-year-old children from their mothers,

170 who filled out a 37-item food frequency questionnaire addressing how often the child 
171 consumed foods and drinks such as bread, vegetables, snacks, and dairy products in an

172 average month. Response categories ranged from "never or less than one serving per week"

173 to "four or more servings per day" for non-dinner foods and drinks, and "once per month or

174 less" to "five or more times per week" for dinner foods.

\section{Statistical analysis}

176 We conducted independent t-tests with the continuous variables and chi-square tests with the

177 categorical variables to compare the characteristics of the mothers included in the analysis and 178 those excluded because of missing data. To perform exploratory factor analysis (EFA), the

179 confirmatory factor analyses (CFA), and the structural equation modeling (SEM), we used

180 Mplus 5.1(28).

181 Dietary patterns

182 To identify dietary patterns from the 37 dietary items, we produced a polychoric correlation 183 coefficient matrix from the frequency with which each child was said to eat each food in a 184 month. This correlation matrix was then subject to EFA. The combination of the polychoric 185 correlation matrix and EFA comprise a technique for assessing the multivariate factor

186 structure of data measured on an ordinal scale. To rotate the factor solution, we used the

187 geomin oblique rotation(29). We analyzed the scree plot and identified the first two dietary188 pattern factors. In this evaluation we sought to find the smallest number of factors that could 189 explain the most multivariate covariance.

190 Negative Affectivity and Parental Locus of Control

191 We used CFA for ordinal data with polychoric correlations to construct the NA

192 components of Anxiety-Depression, Anger, and Self-Esteem(30). By forcing the thresholds of

193 the response categories within each item, the scaling of each item, and the factor structure of

194 each scale to be equal across time points, we secured syntactically equal measurement. As a

195 first step, we combined the 3 NA components at each time point into a latent variable of time- 
196 specific NA. Secondly, we forced the factor loadings of the NA measure to be equal across

197 time. In the last step, we constructed a cross-time NA latent variable by setting the factor

198 loadings equal across time. This procedure secured that the time-specific individual deviations

199 were removed from the NA variable. The score therefore constitutes the individual

200 characteristic across time.

201 To produce a variable of PLOC, we did a CFA for ordinal data of the items from the PLOC

202 scale. The items loaded freely on a factor with variance set to 1 . Since the PLOC scale can be

203 divided into sub-dimensions, we let the items which were from the same sub-dimension

204 correlate in the CFA.

205 Child-feeding practices

206 To construct the variables on child-feeding practices, 'restriction' and 'pressure to eat,' we

207 used CFA for ordinal data with polychoric correlations. The items loaded freely on a factor

208 with variance set to 1 . To account for the internal dependencies between the items from the

209 'restriction' scale combined in parcels by Birch, et al.(10), the residual variance of the

210 indicators within each item parcel was allowed to be correlated.

\section{Mediation analysis}

212 A mediator is the generative mechanism that the independent influences the dependent

213 variable through(31). Baron \& Kenny (1986) specifies four specific steps as the sine qua non

214 of mediation. The independent and dependent variable have to be associated. Secondly, the

215 independent variable has to be related to the mediator. Thirdly, the mediator has to be related

216 to the independent variable. Lastly, the relationship between the independent variable and the

217 dependent variable has to disappear or be weakened. Complete mediation is achieved when

218 the association between the independent variable vanishes when controlling for the mediator,

219 partial mediation when the association is weakened. Although not a specific criterion for

220 mediation, if there is not an interaction effect between the mediator and the independent 
221 variable in relation to the dependent variable there is no possibility for a competing moderator

222 approach.

223

224

225

226

227

228

229

230

231

232

233

234

235

\section{Structural equation modeling}

The EFA of child diet, the CFA's of the psychometric measures, and the medical and demographic variables were included in a final SEM model and jointly estimated. We defined NA, the demographic, and the physical variables as independent variables, PLOC and childfeeding practices as independent or mediation variables, and the two dietary patterns predicted as correlated dependent variables in a multivariate linear regression using SEM.

We chose robust weighted least-squares estimation (robust WLS) to identify the model(28;30), since CFA using polychoric correlations has proven to be robust to the nonnormal distribution typical for behavioral data. Using robust WLS in Mplus 5.1 with covariates included in the model prohibited us from estimating confidence intervals of the standardized coefficients. The unstandardized coefficients and confidence intervals are available upon request.

As a part of the final SEM model, we estimated missing data for dependent variables as a function of the covariates in the model. We imputed missing data on continuous independent variables with the information from continuous covariates using the expectationmaximization algorithm. Furthermore, we excluded cases with missing data on categorical independent variables from the analyses. To evaluate model fit to the data, we interpreted the root mean square of approximation, where a point-value below .06 is considered necessary for a good fit(32). Using robust WLS, it was not possible for us to calculate a confidence interval for the RMSEA.

\section{RESULTS}

\section{Participants}


Compared to participants, a greater proportion of the mothers excluded because of missing

247 data were single. There was no other significant difference in demographic and physical variables between participating mothers and those excluded because of missing data (Table $1)$.

\section{Identification of dietary patterns (hypothesis 1)}

From the EFA, we extracted two dietary patterns for the child. Since the factors were nearly identical to the patterns found at child age 18 months the same sample, we labeled the first factor 'unhealthy' and the second factor 'wholesome'. In summing the indicators with factor loadings above .30, the 'unhealthy' factor describes a pattern of eating characterized by consumption of chips, buns, cakes, waffles, chocolate, cookies, sweets, soda, ice cream, popsicles, bread with jam or honey, pizza, and soda with artificial sweeteners (Table 2). The 'wholesome' factor describes a pattern characterized by consumption of lean fish, oily fish, boiled vegetables, raw vegetables, fruit, bread with fish products, egg, bread with meat, Norwegian brown cheese, and fish products (table 2). $C I-.09$ to -.12). The residual correlation, after adjusting for NA, PLOC, child-feeding, and medical and demographic characteristics, was non-significant ( $r=-.04 ; 95 \% C I-.08$ to .00$)$.

\section{CFA of mother's Negative Affectivity, Parental Locus of Control and child-feeding} practices

The factor structure and loadings from the CFA for ordinal data on mother's personality was meaningful and reproduced the SCL, Anger and Rosenberg Self-Esteem scales. The

267 median item factor loadings for these scales were $.79, .79$, and .78 , respectively. The median

268 factor loading of the time-specific NA variables was .74. For the cross-time NA variable, the median factor loading was .86. The CFA on the items from the PLOC scale returned a below adequate median factor loading of .41 . The factor loadings for the two scales measuring child- 
271 feeding practices were less coherent. The 'pressure to eat' and the 'restriction' scales showed

272 median factor loadings of .70 and .47 , respectively.

273 Test of mediation of Negative Affectivity through Parental Locus of control on child

274 dietary patterns and child-feeding practices.

275 To investigate whether there was no, partial or full mediation of NA through PLOC on the

276 dietary patterns, we firstly identified the statistically significant associations between NA and

277 the dietary patterns. Subsequently we determined the significant association between both NA

278 and PLOC, and PLOC and the dietary patterns. The criteria, as described in the statistics

279 section, for mediation was met, since all associations between independent, mediator and

280 dependent variable were significant and there were no interaction effects between the

281 independent and mediation variable(31). When we allowed for mediation of NA through

282 PLOC on the dietary patterns, the mediation was complete, meaning that the entire effect of

283 NA on diet went through PLOC.

284 In the same manner, we tested the extent of mediation of NA through PLOC on the two 285 child-feeding practices. There was a positive association between NA, PLOC and both child286 feeding practices, and no interaction effects. When we tested for mediation, the entire effect 287 of NA on both Pressure to Eat and Restriction was completely mediated by PLOC.

Mediation of Negative Affectivity and Parental Locus of Control through child-feeding practices on child dietary patterns.

290 Likewise, we sought out to investigate whether the effect of PLOC on diet was mediated

291 through feeding practices. A small portion of the effect of both PLOC and the indirect effect

292 of NA were partially mediated through both Pressure to Eat and Restriction to both

293 'wholesome' and 'unhealthy' diet. The mediation was only partial, and most of the effect of

294 child-feeding on child diet was independent to that of NA and PLOC. 


\section{Child-feeding practices predicted by Negative Affectivity mediated through Parental}

\section{Locus of Control}

297

The results clearly showed that those mothers who had an external PLOC were more likely

to both pressure their children to eat and to restrict their diets (Figure 2). An equally clear pressure the child to eat or restrict her child's food intake (Figure 2).

An additional finding was that external PLOC significantly explained part of the single were less likely to pressure their child to eat. Mothers who were homemakers were more likely to pressure their child to eat. Mothers who were homemakers, had more years of education, or who had a boy were more likely to restrict their children's food intake, unlike mothers who were older or had a higher BMI who were less likely. In terms of impact on

310 child-feeding, external PLOC, several years of education, and being a homemaker were all

311 strongly associated with pressuring the child to eat. The mothers' level of external PLOC was

312 the only strong predictor of restricting the child's food intake.

313 Child dietary patterns predicted by negative affectivity mediated through parental locus

\section{4 of control and child-feeding practices (hypothesis 3)}

315 In the SEM analysis, both the mother's level of NA, external PLOC and child-feeding

316 practices were associated with the child's diet (figure 2). A higher score of NA in the mothers

317 was associated with external PLOC, which was associated with both a more 'unhealthy' and

318 less 'wholesome' diet in the child. Furthermore, only a minor part of the effect of NA and

319 PLOC was mediated through child-feeding practices (figure 2). Mothers with a high level of 
320 NA and an external PLOC were more inclined to both pressure their child to eat and restrict

321 their child's diet (figure 2). The children of those mothers were therefore more likely to have

322 a less 'wholesome' and more 'unhealthy' diet due to pressuring their child to eat and at the

323 same time more likely to have a 'wholesome' diet due to restricting their child's diet and not

324 pressuring their child to eat. When combined, these two small opposite indirect effects of high

325 NA and external PLOC on 'wholesome' diet fully cancel each other and partially cancel each

326 other on 'unhealthy' diet, with the effect through pressure to eat being somewhat stronger.

\section{Independent effect of child-feeding practices (hypothesis 4)}

328 Most of the effect of the two control-oriented child-feeding practices on diet were

329 independent of NA and PLOC. Mothers who pressured their child to eat had children with a

330 less 'wholesome' and more 'unhealthy' diets (figure 2). Restriction had the opposite effect on

331 diet; mothers who restricted their children's diets had children with more 'wholesome' diets

332 and less 'unhealthy' diets.

333 Association between demographic and physical variables and dietary patterns.

334 Demographic and physical variables were associated with children's diet in several ways

335 (table 3). The effects of the continuous variables in Table 3, i.e. maternal education, age, and

336 BMI, are given as incremental change per interval. For example; a three-year increase in

337 maternal education should be interpreted as a threefold incremental difference in standard

338 deviation on the dependent variable. Mothers who were regular smokers, had a higher BMI,

339 or who had boys were less likely to have children with a 'wholesome' diet. Mothers with

340 more years of education, who were homemakers, or older tended to have children with more

341 'wholesome' diets. Mothers who had more years of education or were single tended not to

342 have children with an 'unhealthy' diet. Mothers who were regular smokers, homemakers,

343 older, or had a higher BMI were more likely to have children with an 'unhealthy' diet. 
344 The SEM analysis, which simultaneously included all the CFA's and the multiple regression

345 analysis, had a good fit to the covariance matrix (root mean square error of approximation of $346.03)$.

\section{DISCUSSION}

349 The key findings of this study are as follows: First, the two child dietary patterns identified 350 in the MoBa-sample at 18 months after birth were corroborated by being identified again at 3 351 years. Unhealthy and wholesome diet was only modestly associated, and furthermore nonsignificantly associated after adjusting for other variables. This means that a child's intake of

353 chocolate, chips, and soda at 3-years of age is only weakly related to his or her intake of

354 vegetables, fish, and fruit. Second, mothers with high levels of NA were more inclined to

355 restrict their child's diet or to pressure the child to eat, and these behaviors were fully

356 mediated through external PLOC. Moreover, external PLOC explained a part of the

357 association between Pressure to Eat and Restriction; mothers' external PLOC could therefore

358 be interpreted as a common etiological factor for the mother's tendency to pressure the child

359 to eat and to restrict the child's food intake. Third, mothers high in NA and with an external

360 PLOC were more likely to have a child eating a less 'wholesome' and more 'unhealthy' diet.

361 Further, these effects were partly mediated by the restriction of the child's food intake or

362 pressuring the child to eat. Fourth, in accordance with our hypotheses, mothers who pressured

363 the child to eat tended not to have a child with 'wholesome' diets and were more likely to

364 have children with more 'unhealthy' diets. Contrary to our hypotheses, mothers who restricted

365 their children's food intake tended to have a child with more 'wholesome' diets and less

366 'unhealthy' diets. The effects of child feeding practices were largely independent of NA and 367 PLOC. 
Relationships between the demographic and physical variables and children's diets were in accordance with earlier studies on 18 -months-old and three-year-old children $(2 ; 3)$.

Maternal smoking and the mother being a homemaker were substantial risk factors for unhealthy eating in the children.

To date, findings relating control-oriented feeding practices to quality of children's diet have been contradictory. On the one hand, control-oriented feeding practices have been associated with a preference for and consumption of an 'unhealthy' diet in children of various ages(11-14). On the other hand, parenting characterized by insufficient control has been also been associated with intake of an 'unhealthy' and less 'wholesome' diet in children of various $\operatorname{ages}(16 ; 17)$.

Mothers characterized by high levels of NA will tend to have an external PLOC because of their ineffective general coping skills $(5 ; 33)$. Perceiving that they have little control over the child's eating behavior, such mothers will tend to enforce control by using pressure and restriction as feeding strategies. At the same time, mothers perceiving little control will be less able to cope with the child's demand for sweet and fatty foods and less able to ensure that the child eats a wholesome diet. Lastly, mothers perceiving little control tend to believe that the child is capable of internal self regulation in the feeding situation; therefore it makes sense for them to exert control.

The finding that pressuring a child to eat is associated with a less 'wholesome' diet and a more 'unhealthy' diet is in line with earlier research $(13 ; 18)$. Children that are pressured to eat

388 certain foods are at risk to build an aversion towards just these foods(13). In a similar vein,

389 the control-oriented feeding practice of restriction appears to be related to a preference for and

390 the intake of an 'unhealthy' $\operatorname{diet}(11 ; 12)$. Our results did not replicate this finding; on the

391 contrary, we found restriction to be associated with the opposite dietary pattern, a more

392 'wholesome' diet and a less 'unhealthy' diet. 
The finding that external PLOC partially explained the association between Pressure to Eat and Restriction is novel. This study implicates that if Pressure to Eat and Restriction is conceptualized as caused by a common factor of control-oriented child-feeding, this factor could be confounded with the parent's belief of being efficiently in control.

While pressure to eat has been related to an overt form of child-feeding, hence perceivable

to the child, restriction has on the other hand been described as a covert form of child-

399 feeding(34). While the overt form of child-feeding has been related to more unhealthy snacking and less fruit and vegetable intakes, the covert form of child-feeding relates to less snacking and fruit and vegetable intake(18). It could be that when a mother attempts to restrict her child's food intake, it is less obvious than pressuring the child to eat, and therefore the child does not react negatively to the mother's control efforts.

There are some limitations to the current study that should be addressed. Firstly, the foodfrequency questionnaire was limited in range of foods. Then again, three-year-olds have a limited diet. Secondly, the mediated effect of NA on diet was small. Yet it was arguably the same size or larger than the effects of some demographic and physical factors commonly

408 deemed important, such as maternal age and maternal BMI,. Thirdly, unlike in the study of 409 dietary patterns in this sample at 18 months after birth, marital status and age were not 410 controlled for parity. Since parity may be related to marital status and age, the effect of those 411 two former variables could therefore be partly due to number of children in the household.

412 The fourth limitation is of a more philosophical character; a multiple regression model

413 reflects only one form of thinking, and the parental variables were measured at the same time 414 as the dietary information. Other competing models with rearranged or even novel variables 415 could therefore be specified.

416 We suggest that the clinical implications of our findings relates firstly to the form of 417 dietary recommendations and advice given by health professionals. NA manifests as readily 
418 recognizable anxiousness, insecurity, and helplessness. Health professionals who meet

419 mothers showing these signs may prevent child-feeding problems by asking whether these

420 mothers feel that they have control of the feeding situation. Secondly, the finding that the

421 unhealthy and the wholesome diets were only weakly correlated implicates that to the

422 promotion of healthy eating in pre-school-aged children must target both dietary patterns

423 separately. Reducing the intake of sweet foods will not automatically increase the intake of

424 wholesome foods (e.g. fruit and vegetables).

425 Since PLOC partially explained the association between Pressure to Eat and Restriction,

426 future studies should investigate the role of personality and parenting in explaining the

427 covariation between child-feeding practices. Second, since the effect of external PLOC was

428 largely independent of the two control-oriented-child-feeding practices, future research ought

429 to assess a range of child-feeding practices and aspects of parenting other than those directly

430 related to feeding. Furthermore, a full spectrum or personality traits should be included to

431 relate both child-feeding and diet to different forms of stress coping(33). 


\section{ACKNOWLEDGMENTS}

433 EY conceived the design of this study, performed all data analysis, and drafted and finalized

434 the manuscript. MEV designed the study and participated in strategic decisions concerning

435 the analysis and interpretation of data. MB participated in interpretation of the data and

436 writing of the manuscript. All of the authors reviewed the manuscript for important content

437 and approved the final manuscript. None of the authors had a conflict of interest. 


\section{REFERENCES}

1. Wang Y, Lobstein T. Worldwide trends in childhood overweight and obesity. Int J Pediatr Obes 2006;1:11-25.

2. North K, Emmett P. Multivariate analysis of diet among three-year-old children and associations with socio-demographic characteristics. Eur J Clin Nutr 2000;54:73-80.

3. Ystrom E, Niegel S, Vollrath ME. The impact of maternal negative affectivity on dietary patterns of 18-month-old children in the Norwegian Mother and Child Cohort Study. Matern Child Nutr 2008.

4. Hill AJ. Developmental issues in attitudes to food and diet. Proc Nutr Soc 2002;61:259-66.

5. Lovejoy MC, Verda MR, Hays CE. Convergent and discriminant validity of measures of parenting efficacy and control. J Clin Child Psychol 1997;26:366-76.

6. Metsapelto RL, Pulkkinen L. Personality traits and parenting: Neuroticism, extraversion, and openness to experience as discriminative factors. Eur J Pers 2003;17:59-78.

7. Watson D, Clark LA. Negative affectivity: the disposition to experience aversive emotional states. Psychol Bull 1984;96:465-90.

8. Ystrom E, Niegel S, Klepp K-I, Vollrath ME. The impact of maternal negative affectivity and general self-efficacy on breast-feeding: The Norwegian Mother and Child Cohort Study. J Pediatr 2008;152:68-72.

9. Janssens JMAM. Authoritarian child-rearing, parental locus of control, and the childs behavior style. Int J Behav Dev 1994;17:485-501.

10. Birch LL, Fisher JO, Grimm-Thomas K, Markey CN, Sawyer R, Johnson SL. Confirmatory factor analysis of the Child Feeding Questionnaire: a measure of 
parental attitudes, beliefs and practices about child feeding and obesity proneness. Appetite 2001;36:201-10.

11. Fisher JO, Birch LL. Restricting access to palatable foods affects children's behavioral response, food selection, and intake. Am J Clin Nutr 1999;69:1264-72.

12. Fisher JO, Birch LL. Restricting access to foods and children's eating. Appetite 1999;32:405-19.

13. Fisher JO, Mitchell DC, Smiciklas-Wright H, Birch LL. Parental influences on young girls' fruit and vegetable, micronutrient, and fat intakes. J Am Diet Assoc 2002;102:58-64.

14. Birch LL, McPhee L, Shoba BC, Pirok E, Steinberg L. What kind of exposure reduces children's food neophobia? Looking vs. tasting. Appetite 1987;9:171-8.

15. Patrick H, Nicklas TA, Hughes SO, Morales M. The benefits of authoritative feeding style: caregiver feeding styles and children's food consumption patterns. Appetite 2005;44:243-9.

16. De Bourdeaudhuij I. Family food rules and healthy eating in adolescents. J Health Psychol 1997;2:45-56.

17. Golan M. Parents as agents of change in childhood obesity - from research to practice. Int J Pediatr Obes 2006;1:66-76.

18. Brown KA, Ogden J, Vogele C, Gibson EL. The role of parental control practices in explaining children's diet and BMI. Appetite 2008;50:252-9.

19. Magnus P, Irgens LM, Haug K, Nystad W, Stoltenberg C, The MoBa Study Group. The Norwegian Mother and Child Cohort Study. Int J Epidemiol 2006;35:1146-50.

484 20. Magnus P. The Norwegian Mother and Child Cohort Study (MoBa) - new research possibilities. Nor J Epidemiol 2007;17:107-10. 
21. Irgens LM. The Medical Birth Registry of Norway. Epidemiological research and surveillance throughout 30 years. Acta Obstet Gynecol Scand 2000;79:435-9.

22. Strand BH, Dalgard OS, Tambs K, Rognerud M. Measuring the mental health status of the Norwegian population: A comparison of the instruments SCL-25, SCL-10, SCL-5 and MHI-5 (SF-36). Nord J Psychiatry 2003;57:113-8.

23. Izard CE, Libero DZ, Putnam P, Haynes OM. Stability of emotion experiences and their relations to traits of personality. J Pers Soc Psychol 1993;64:847-60.

24. Rosenberg M. Society and the adolescent self-image. Middletown, CT: Wesleyan University Press, 1989.

25. Gow AJ, Whiteman MC, Pattie A, Deary IJ. Goldberg's 'IPIP' Big-Five factor markers: Internal consistency and concurrent validation in Scotland. Pers Individ Dif

26. Clark LA, Watson D. Temperament: A new paradigm for trait psychology. In: Pervin LA, John OP, eds. Handbook of Personality: Theory and Research. New York: Guilford Press 1999:399-423.

27. Campis LK, Lyman RD, Prentice-Dunn S. The Parental Locus of Control Scale: Development and validation. J Clin Child Psychol 1986;15:260-7.

28. Muthén LK, Muthén BO. Mplus user's guide. Los Angeles, CA: Muthén \& Muthén, 2007.

29. Browne MW. An overview of analytic rotation in exploratory factor analysis. Multivariate Behav Res 2001;36:111-50.

30. Flora DB, Curran PJ. An empirical evaluation of alternative methods of estimation for confirmatory factor analysis with ordinal data. Psychol Methods 2004;9:466-91. 
509 31. Baron RM, Kenny DA. The moderator-mediator variable distinction in social

510 psychological research: Conceptual, strategic, and statistical considerations. J Pers Soc Psychol 1986;51:1173-82.

512 32. Hu LT, Bentler PM. Fit indices in covariance structure modeling: Sensitivity to

513 underparameterized model misspecification. Psychol Methods 1998;3:424-53.

514 33. Vollrath M. Personality and stress. Scand J Psychol 2001;42:335-47.

515 34. Ogden J, Reynolds R, Smith A. Expanding the concept of parental control: A role for 516 overt and covert control in children's snacking behaviour? Appetite 2006;47:100-6. 
Table 1. Characteristics of the mothers included and those excluded because of missing data*

\begin{tabular}{lcc}
\hline & Included $(\mathrm{n}=14,122)$ & Excluded $(\mathrm{n}=981)$ \\
\hline Child gender boy (\%) & 51.2 & $48.9[978]$ \\
Daily smoking (\%) & 11.0 & $23.1[26]$ \\
Education (y) & $14.4 \pm 2.4 \dagger$ & $14.4 \pm 2.4$ \\
Homemaker (\%) & 30.2 & $27.6[261]$ \\
Maternal age (y) & $33.0 \pm 4.6$ & $32.9 \pm 4.5$ \\
Maternal BMI§ & $24.8 \pm 4.4$ & $24.7 \pm 3.8$ \\
Single marital status $(\%)$ & 6.0 & $10.1[238] \ddagger$ \\
\hline
\end{tabular}

*Number of cases in brackets.

$\dagger$ Mean \pm standard deviation (all such values).

$\ddagger$ Significantly different from the included cases $\left(\chi^{2}\right.$ test $): P<.05$.

$\S$ Body mass index 
Table 2. Standardized rotated factor loadings of various dietary items in the two dietary factors identified in 3 year old children based on the food frequency questionnaire (loadings above 0.3 are shown in bold).

Unhealthy

Chocolate

Chips

Sweets

Buns, cakes, and waffles

Ice cream

Cookies

Popsicle

Soda

Bread with jam or honey

Pizza

Soda with artificial sweeteners

Pancakes

Juice

Meat, sausage, and meatballs

Slices per day of fiber rich bread

Flavored yogurt

Bread slices per day

Skimmed and semi-skimmed milk

Boiled vegetables

Lean fish

Oily fish

.62

.56

.56

.54

.54

.54

.51

.08

.48

$-.07$

.33

$-.02$

.30

.02

.30

$-.15$

.21

.03

.18

.11

.16

.08

$-.14$

.09

.13

.04

$-.11$

.07

$-.07$

.00

$-.10$

.50

$-.04$

.50

$-.08$

.05

10

.02

8

.07


Raw vegetables

Fruit

Bread with fish products

Egg

Potatoes

Bread with cheese

Soup

Fish products

Raisins

Bread with meat

Rice

Plain yogurt

Norwegian brown cheese

Soured milk with LGG

Pasta

Full-cream milk
$-.06$ .17

$-.03$ .17

$-.07$ .16

.09 .15

.08 


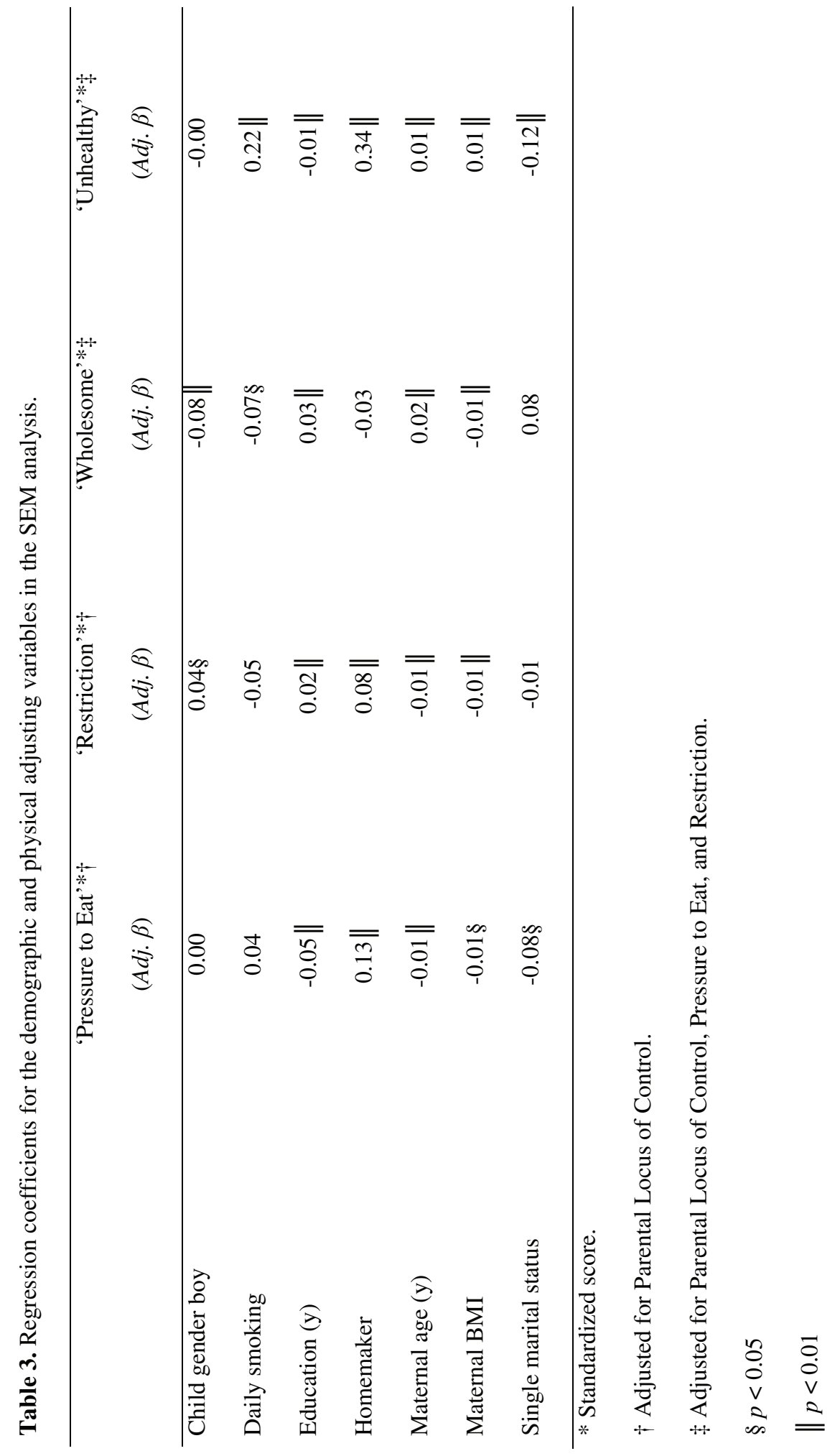




\section{LEGEND FOR FIGURES}

FIGURE 1. Conceptual model of the interrelation between maternal Negative Affectivity, external Parental Locus of Control, child-feeding practices, and child diet.

FIGURE 2. Structural equation model on influences of maternal Negative Affectivity and external Parental Locus of Control on child-feeding practices and child diet.

* Residual correlation coefficient, $p<0.01$.

$\dagger$ Standardized regression coefficient, $p<0.01$.

$\ddagger$ Standardized regression coefficient adjusted for physical and medical variables (results from adjusting variables in table 3$), p<0.01$. 


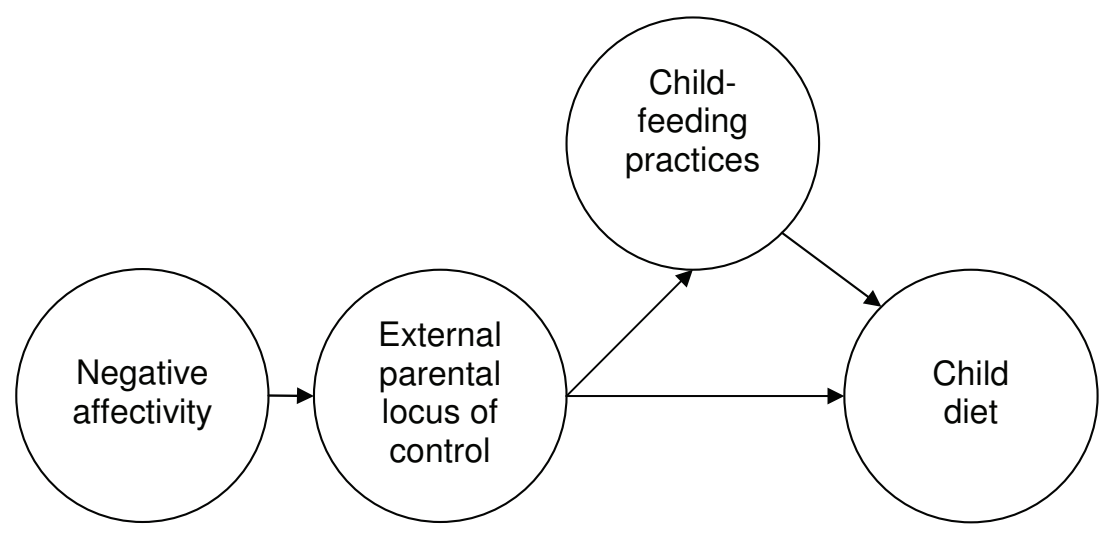




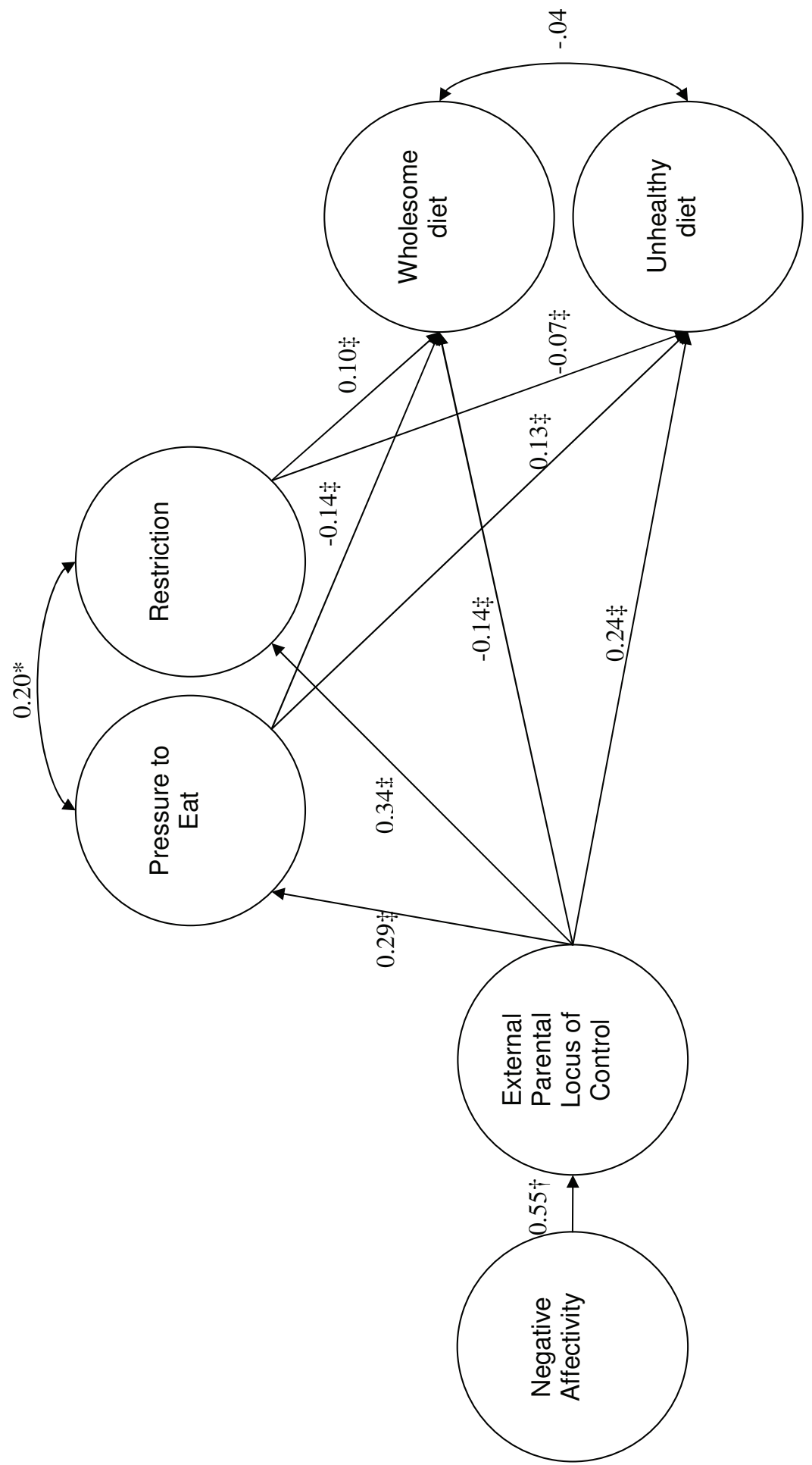


APPENDIX I - III 

APPENDIX I

Standardized Factor Loadings From the Measurement Models in Paper III

Negative Affectivity at 3 years postpartum: Subscales, items and factor loadings

Hopkins Symptom Checklist (SCL-8)

Feeling fearful .81

Nervousness or shakiness inside .85

Feeling hopeless about the future .83

Feeling blue .86

Worrying too much about things .84

Feeling everything is an effort .76

Feeling tense or keyed up .76

Suddenly scared for no reason .79

Rosenberg Self-esteem scale

I take a positive attitude toward myself $-.84$

I certainly feel useless at times .85

I feel I do not have much to be proud of .73

I feel that I'm person of worth, at least on an equal plane with others

Anger subscale of Differential Emotions Scale

Feel like screaming at somebody or banging or something .78

Feel angry, irritated, annoyed

Feel mad at somebody

*NA Negative Affectivity 
Factor loadings for the latent Parental Locus of Control variable used in

\begin{tabular}{|c|c|c|}
\hline & $\begin{array}{c}\text { Item\# in } \\
\text { PLOC-scale }\end{array}$ & Factor loading \\
\hline What I do has little effect on my child's behavior & 1 & .39 \\
\hline My child usually ends up getting his/her way, so why try & 5 & .50 \\
\hline My life is chiefly controlled by my child & 21 & .52 \\
\hline $\begin{array}{l}\text { It is often easier to let my child have his/her way than to } \\
\text { put up with a tantrum }\end{array}$ & 41 & .50 \\
\hline $\begin{array}{l}\text { Sometimes when I'm tired I let my children do things I } \\
\text { normally wouldn't }\end{array}$ & 44 & .48 \\
\hline
\end{tabular}


Factor loadings for the latent variables of the Restriction and Pressure to Eat subscales of Child Feeding Questionnaire.

Factor

loading

\section{Restriction}

1. I have to be sure that my child does not eat too many sweets (candy, ice cream, cake or pastries)

2. I have to be sure that my child does not eat too many high fat foods

3. I have to be sure that my child does not eat too much of his/her favorite foods

4. I intentionally keep some foods out of my child's reach

5. I offer sweets (candy, ice cream, cake, pastries) to my child as a reward for good behavior

6. I offer my child his/her favorite food as a reward for good behavior

7. If I did not regulate my child's eating he/she would eat too much unhealthy food

8. If I did not guide or regulate my child's eating he/she would eat too much of his/her favorite foods

\section{Pressure to Eat}

9. My child should always eat all the food on her plate

10. I have to be especially careful to make sure my child eats enough

11. If my child says "I'm not hungry", I try him/her to eat anyway

12. If I did not regulate my child's eating, she would eat much less than she should 



\section{APPENDIX II}

Correlations of latent variable used in paper III.

\begin{tabular}{lcccccc}
\hline & 1 & 2 & 3 & 4 & 5 & 6 \\
\hline Negative Affectivity & 1 & & & & & \\
External Parental Locus of Control & .55 & 1 & & & & \\
Pressure to Eat & .16 & .29 & 1 & & \\
Restriction & .19 & .34 & .28 & 1 & & \\
Unhealthy & .14 & .26 & .20 & .05 & 1 & \\
Wholesome & -.08 & -.15 & -.18 & .02 & -.11 & 1 \\
\hline
\end{tabular}

Note. $\mathrm{N}=14122$; only those variables used in the structural mediation model are given, not those which only were a part of the measurement model. 



\section{APPENDIX III}

\section{Questionnaires}

1. Questionnaire $1-17^{\text {th }}$ week of gestation

2. Questionnaire 4-6 months postpartum

3. Questionnaire 5-18 months postpartum

4. Questionnaire 6-36 months postpartum 


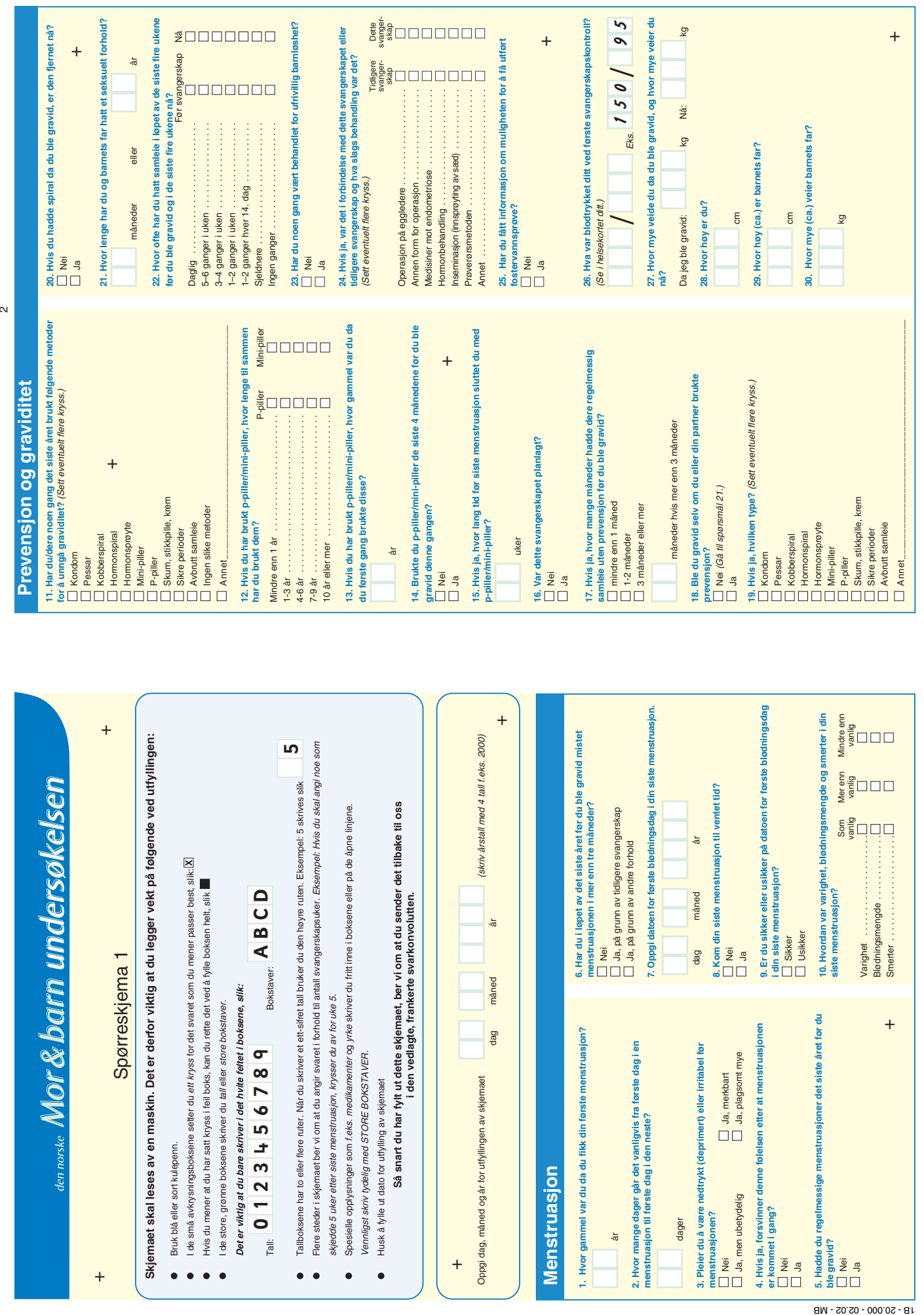

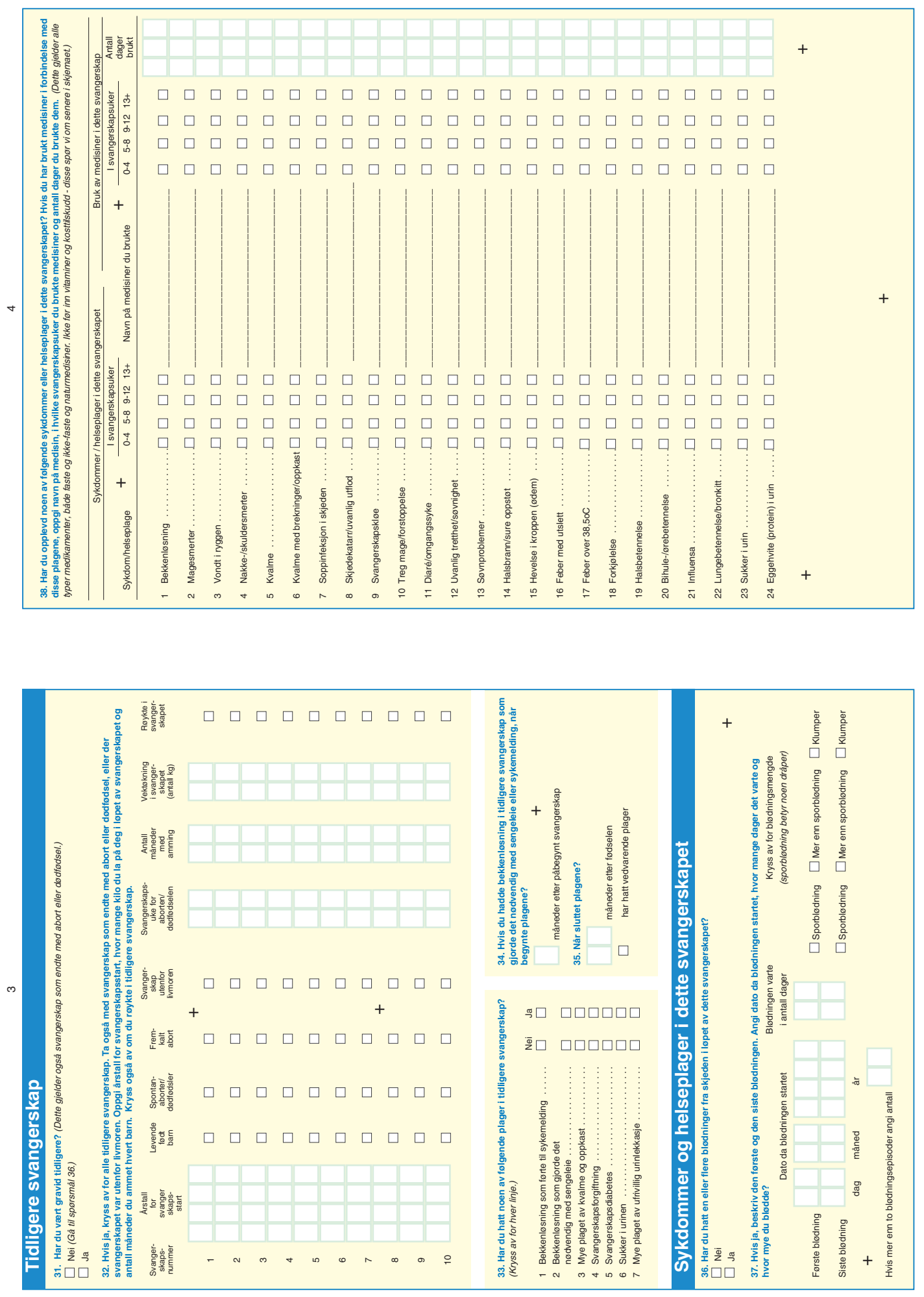

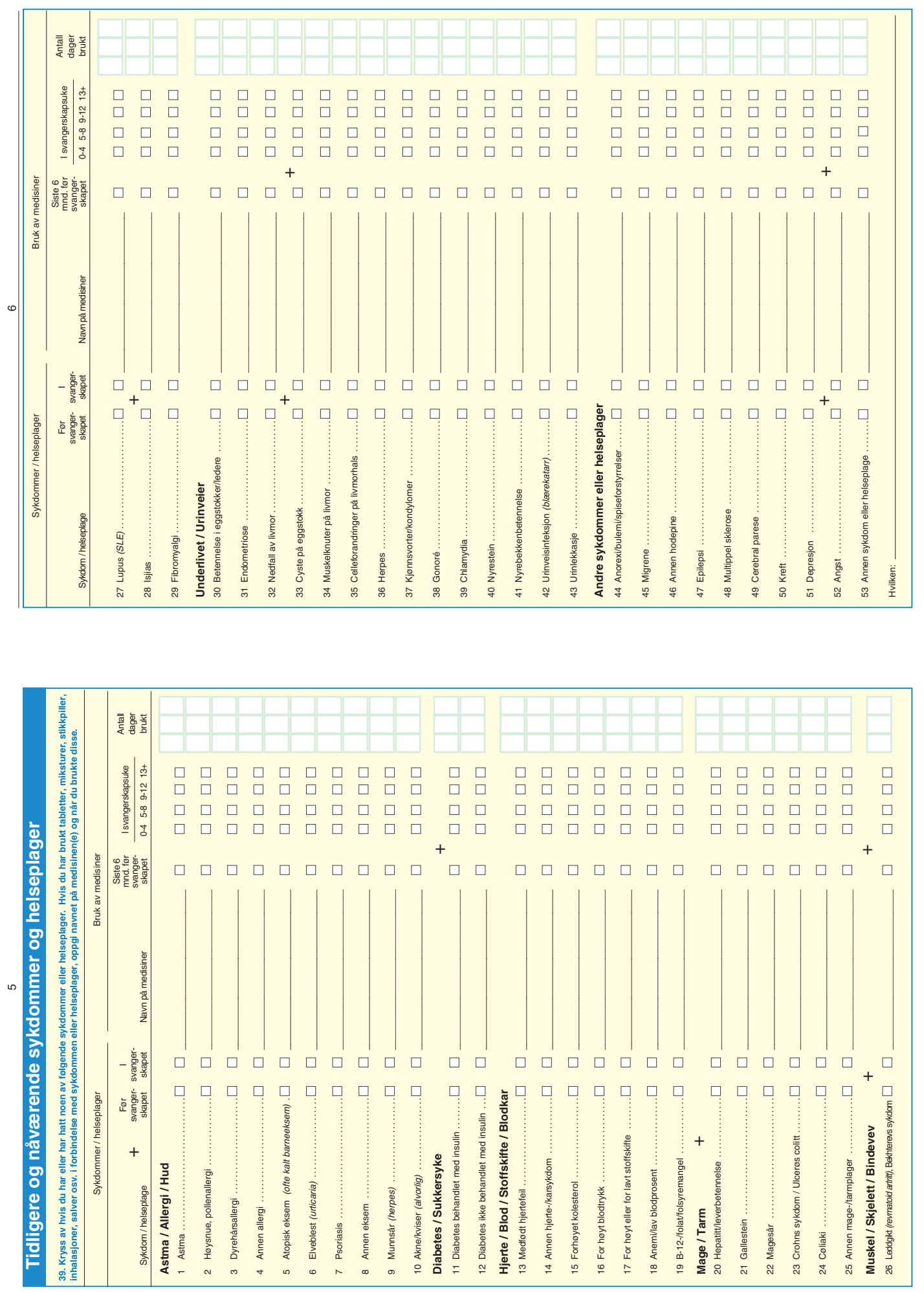

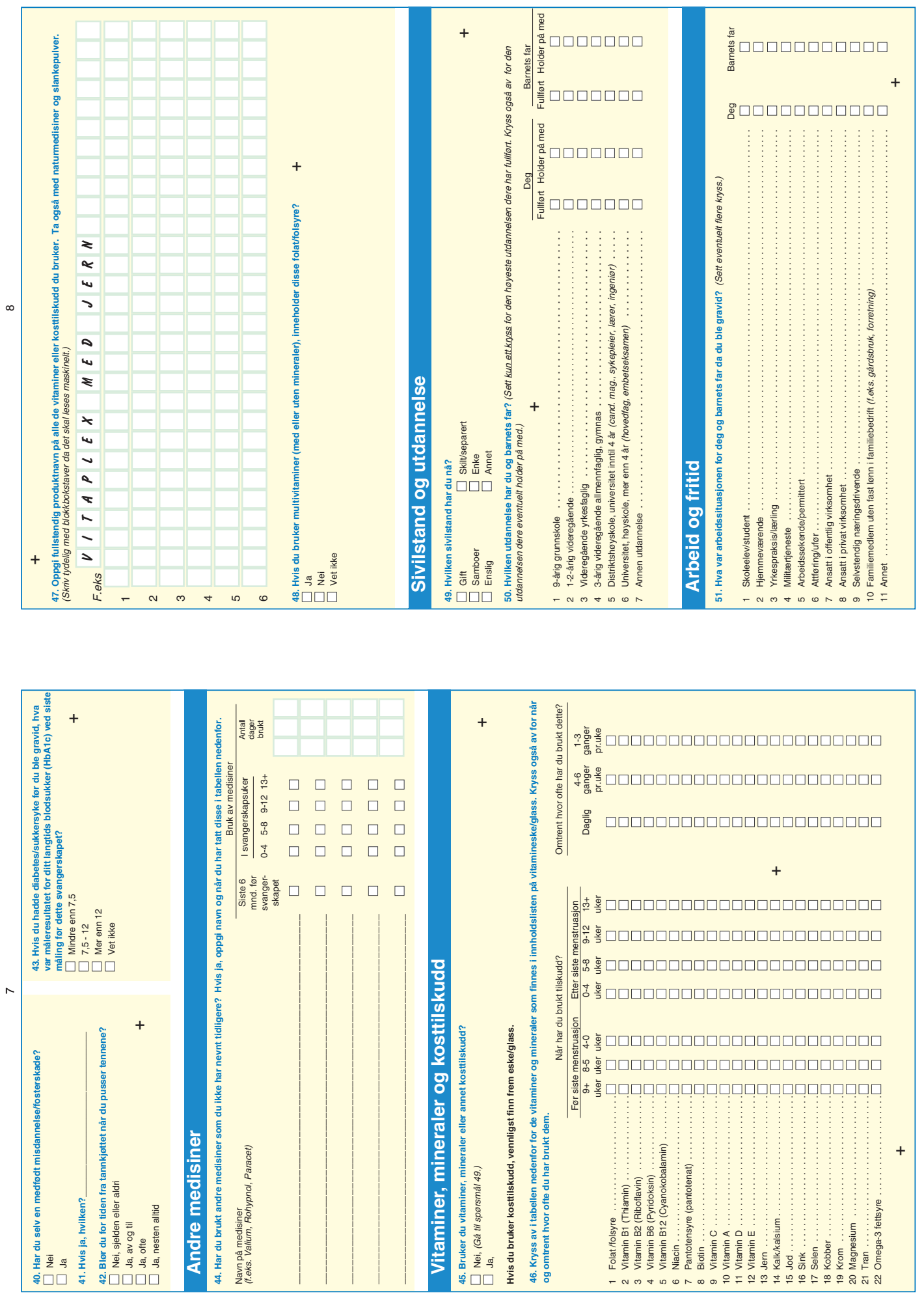

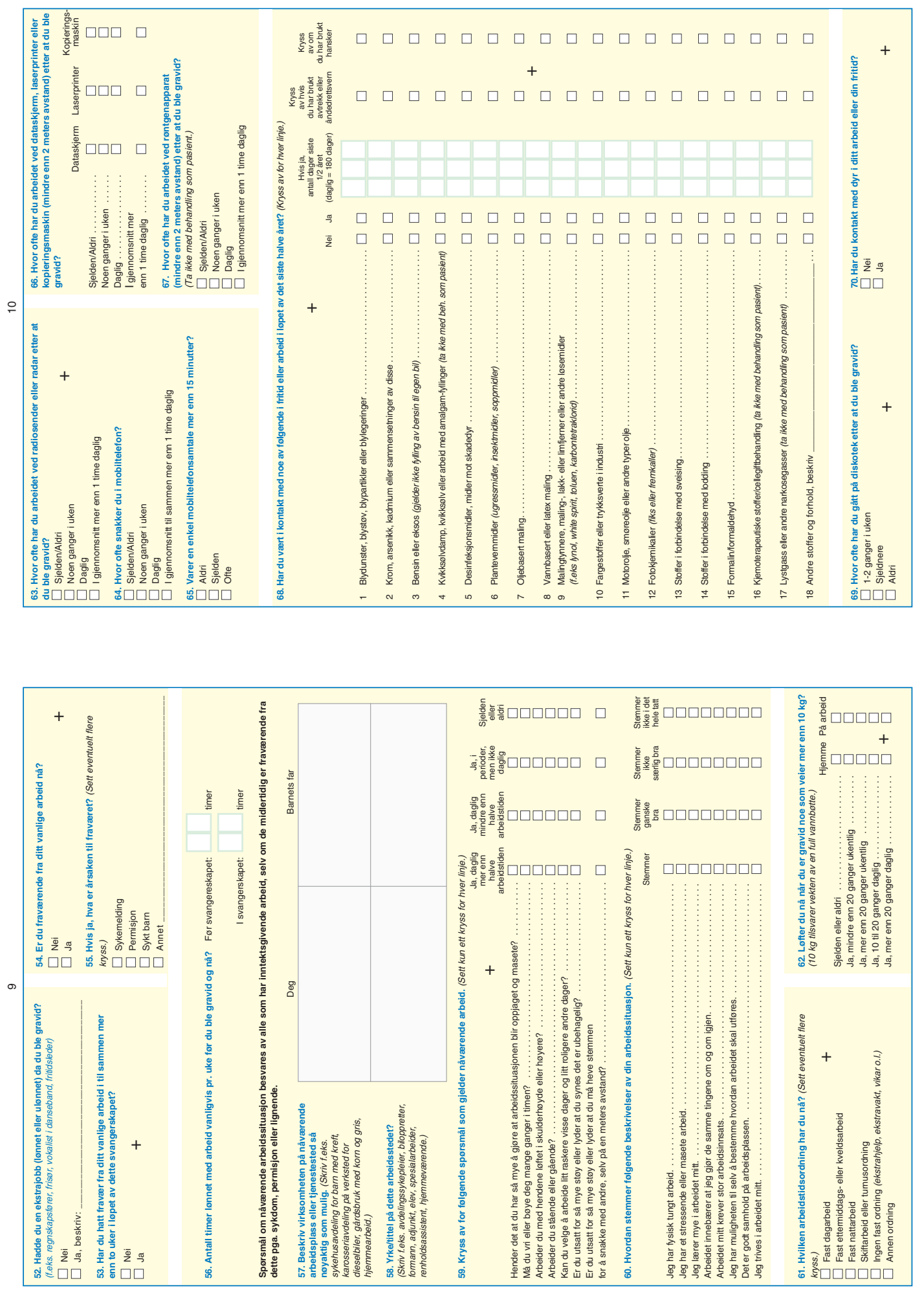

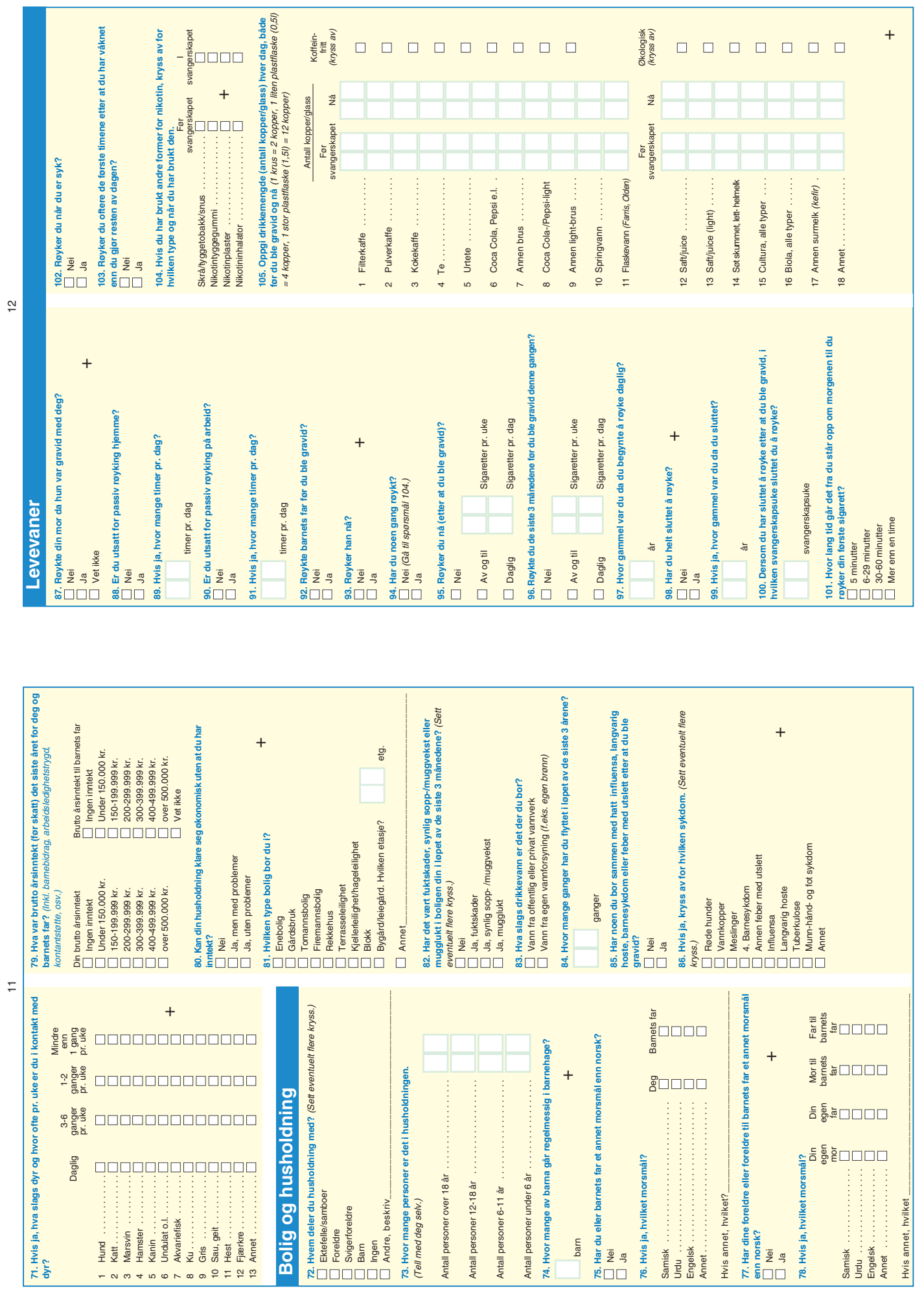

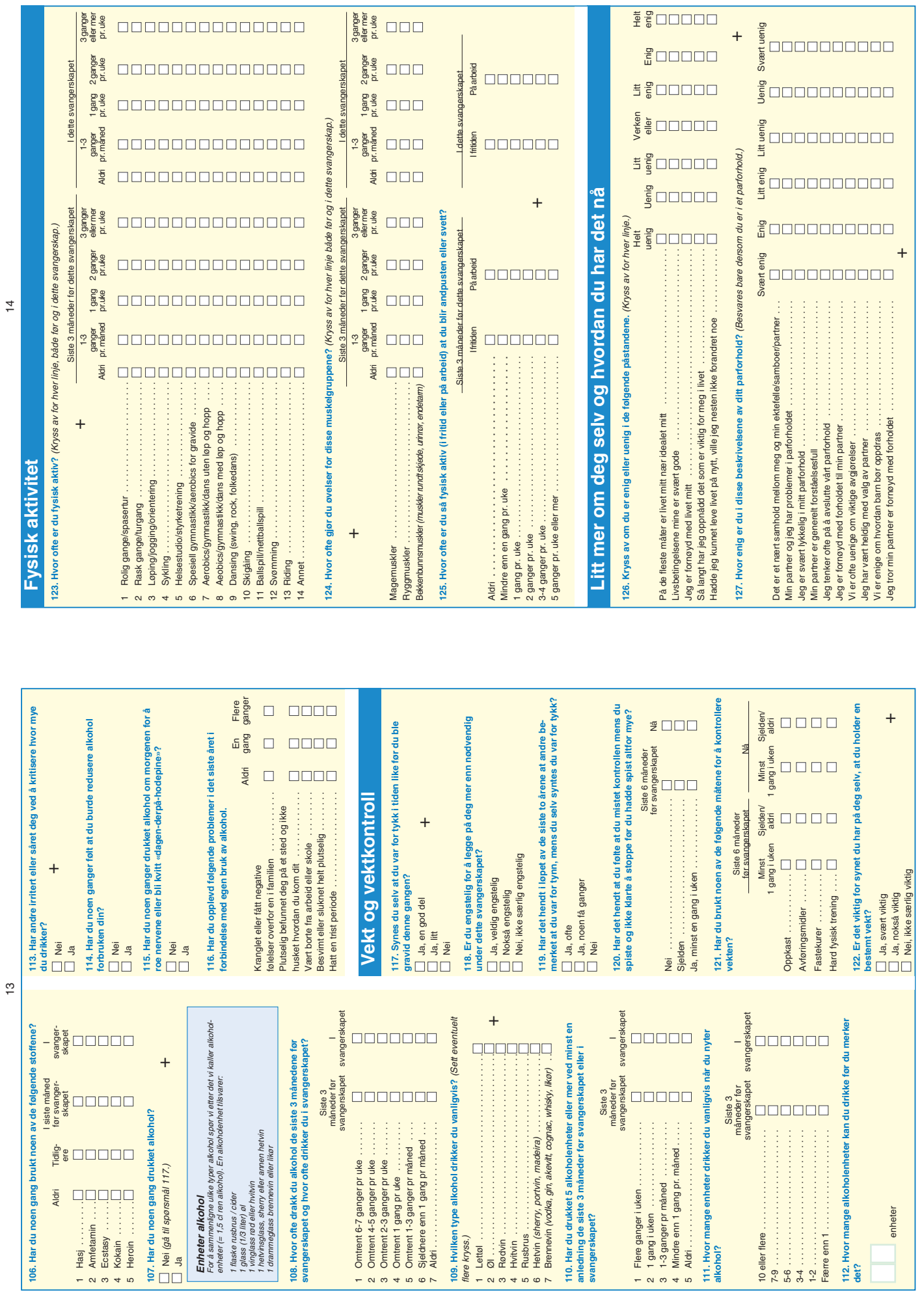

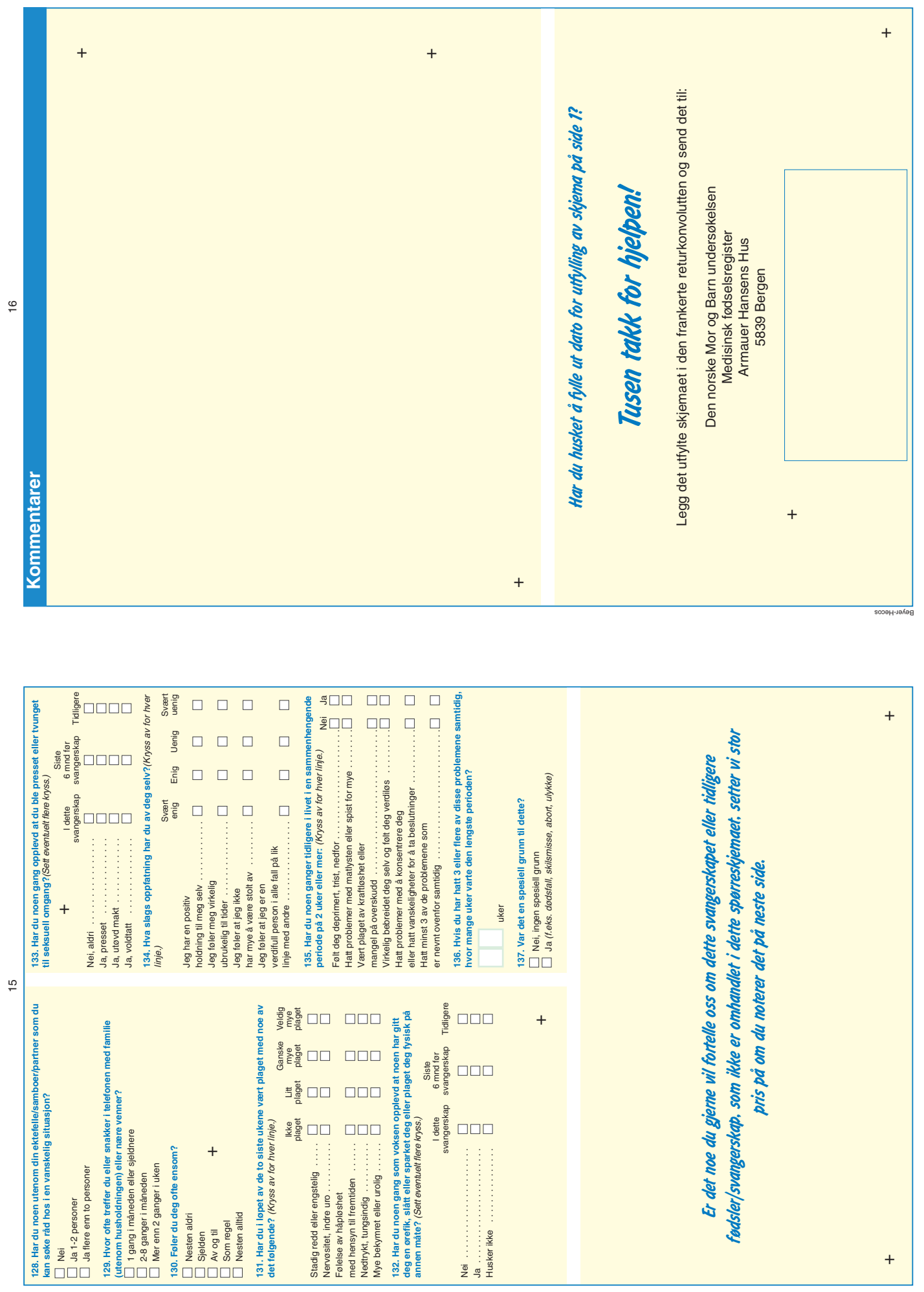

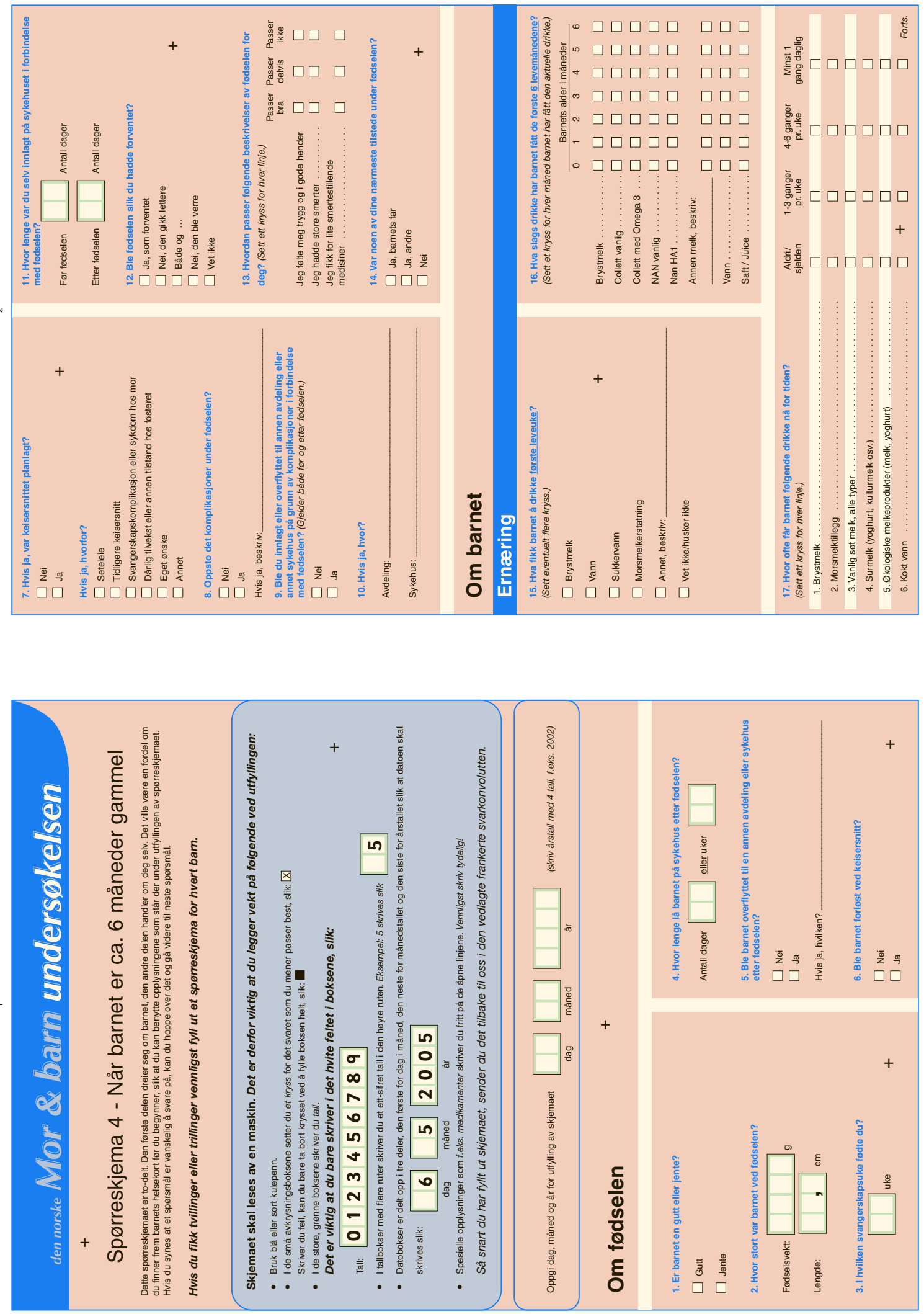


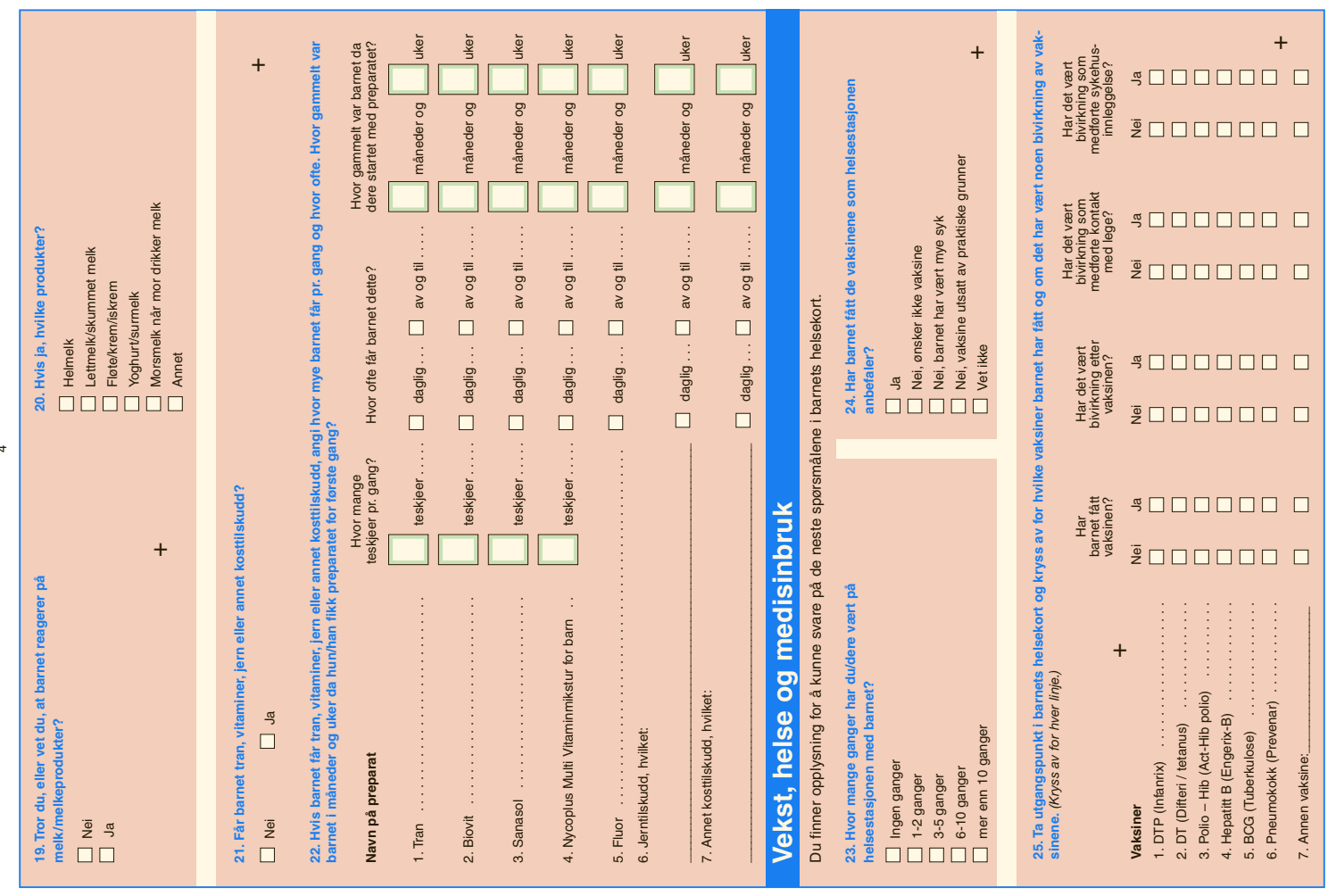

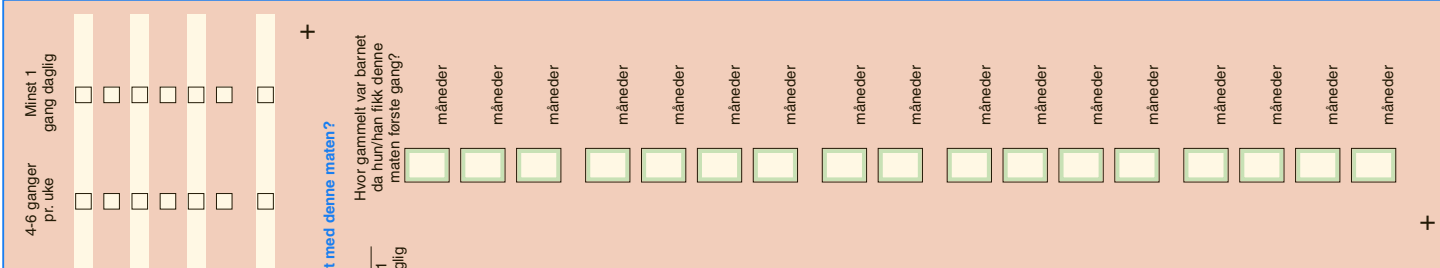

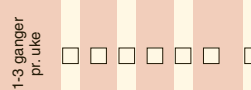

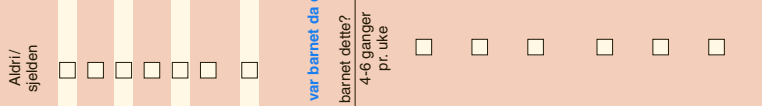

$+$ $\frac{z}{\frac{z}{4} \frac{\bar{\sigma}}{\frac{0}{0}}}$

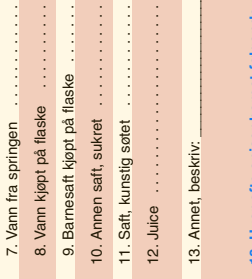

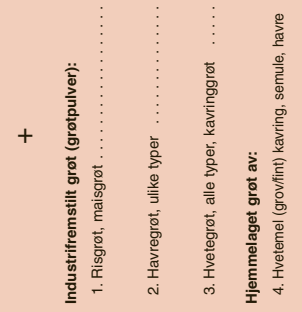

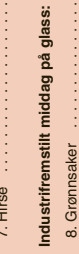

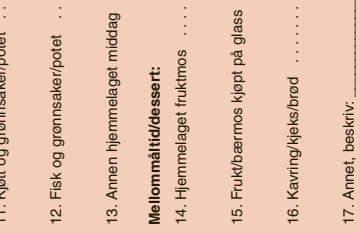



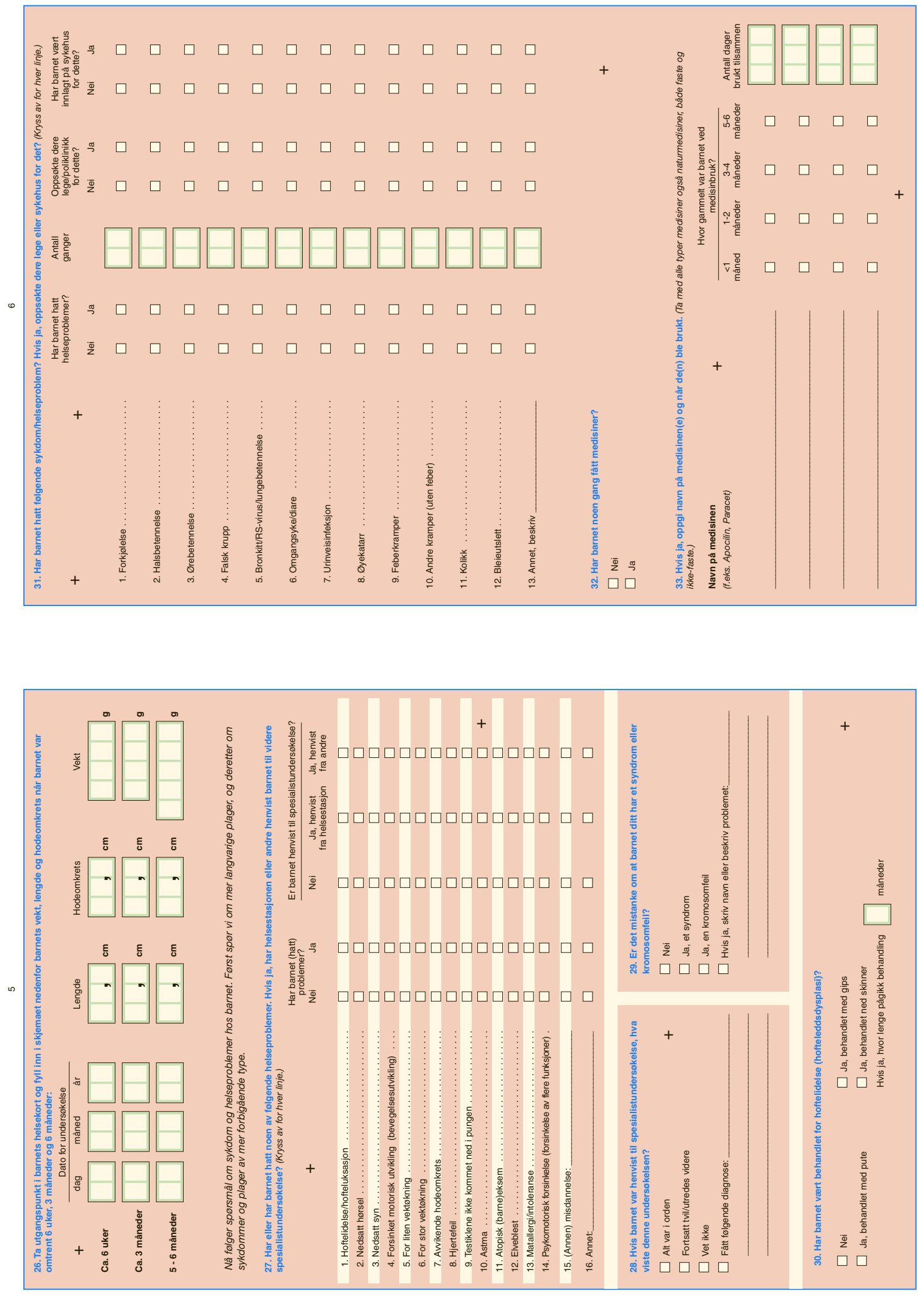

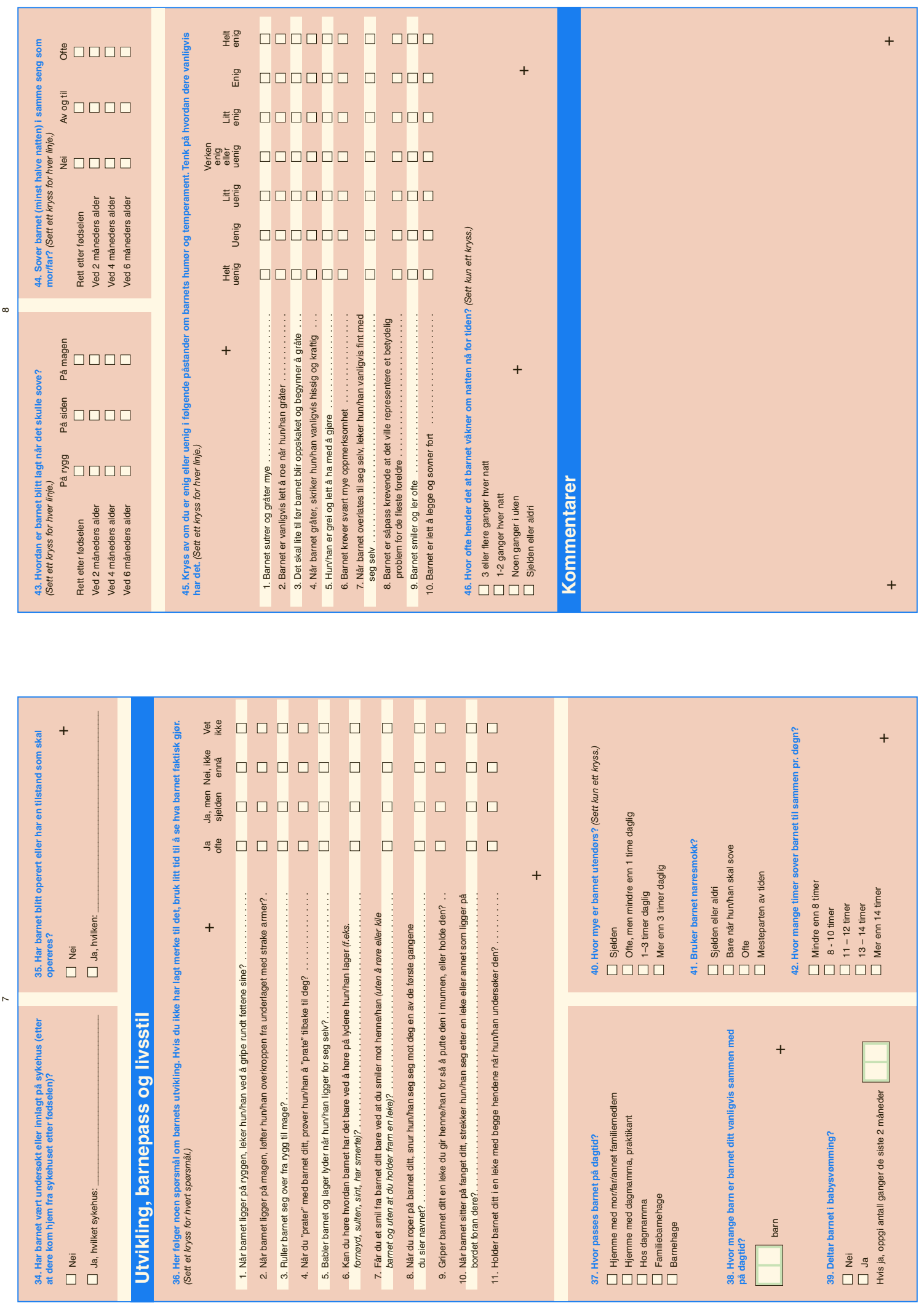

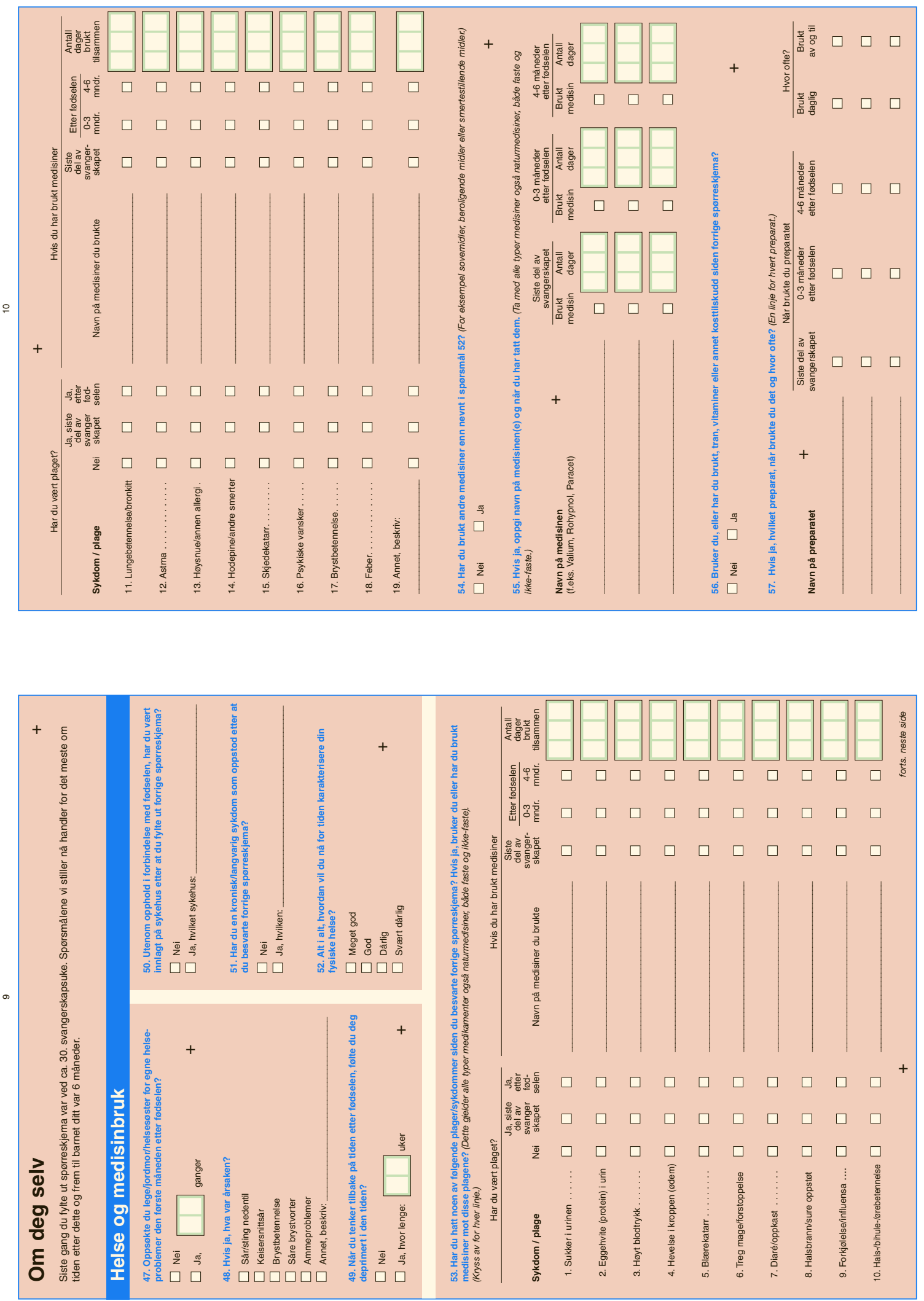

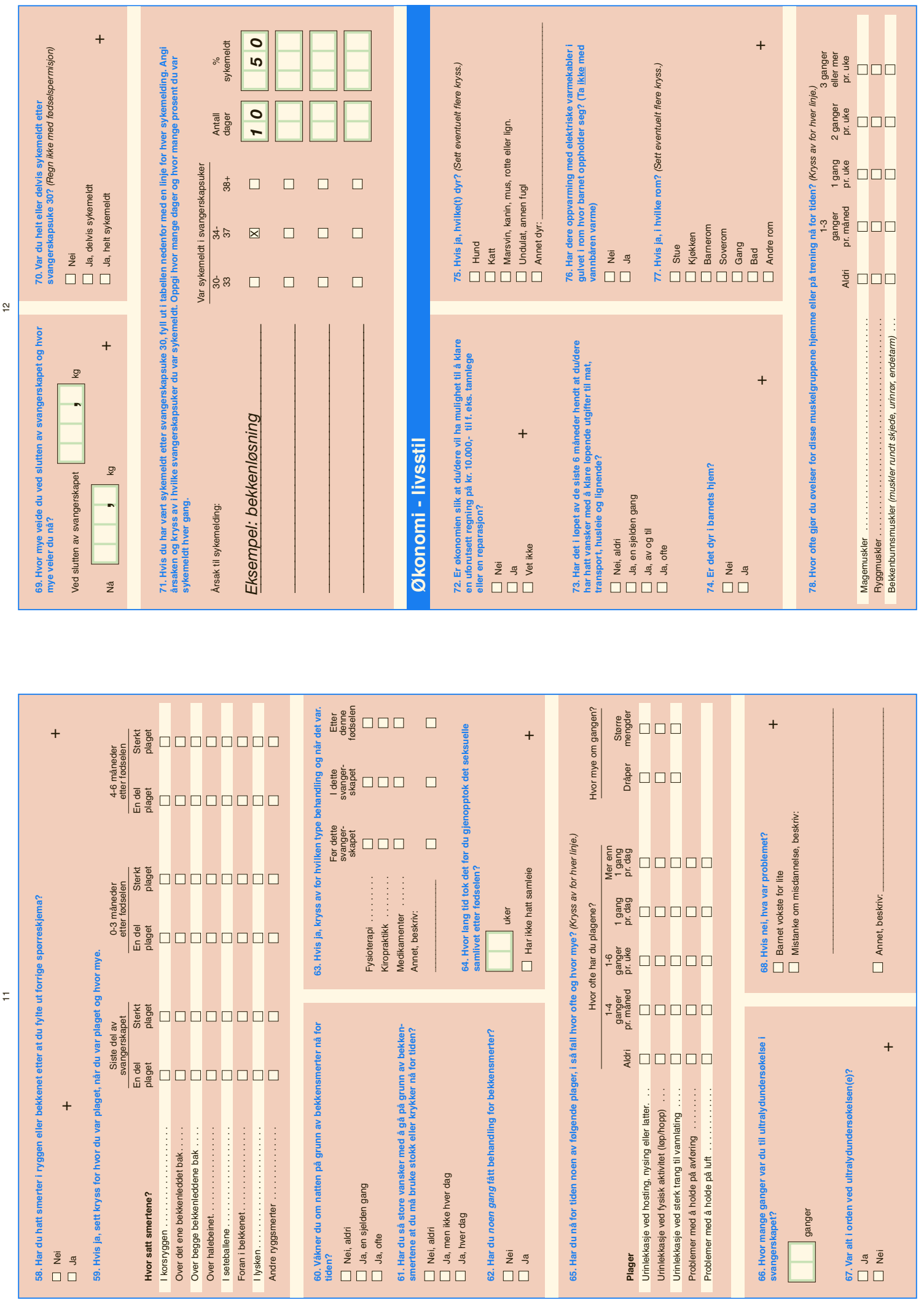

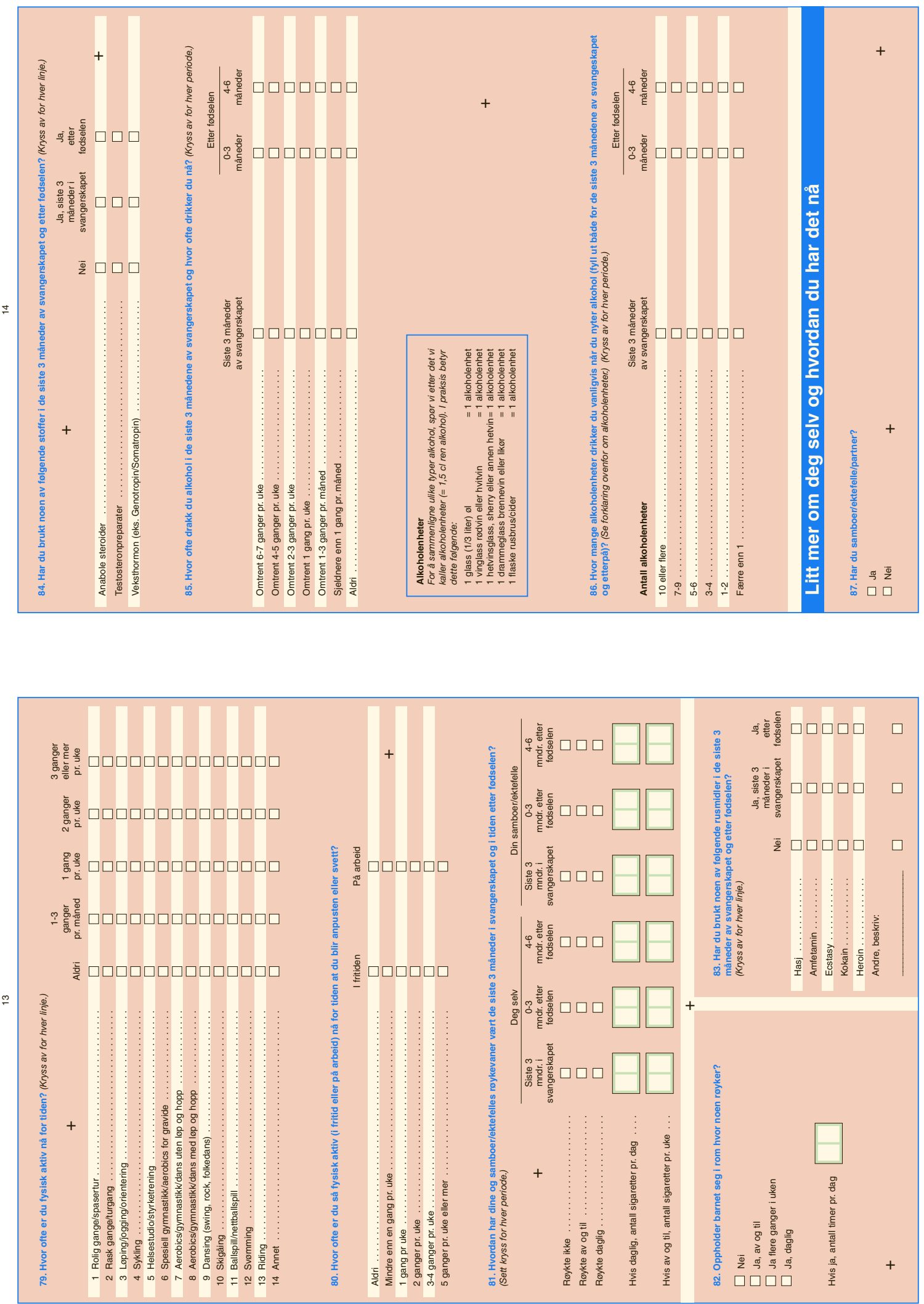


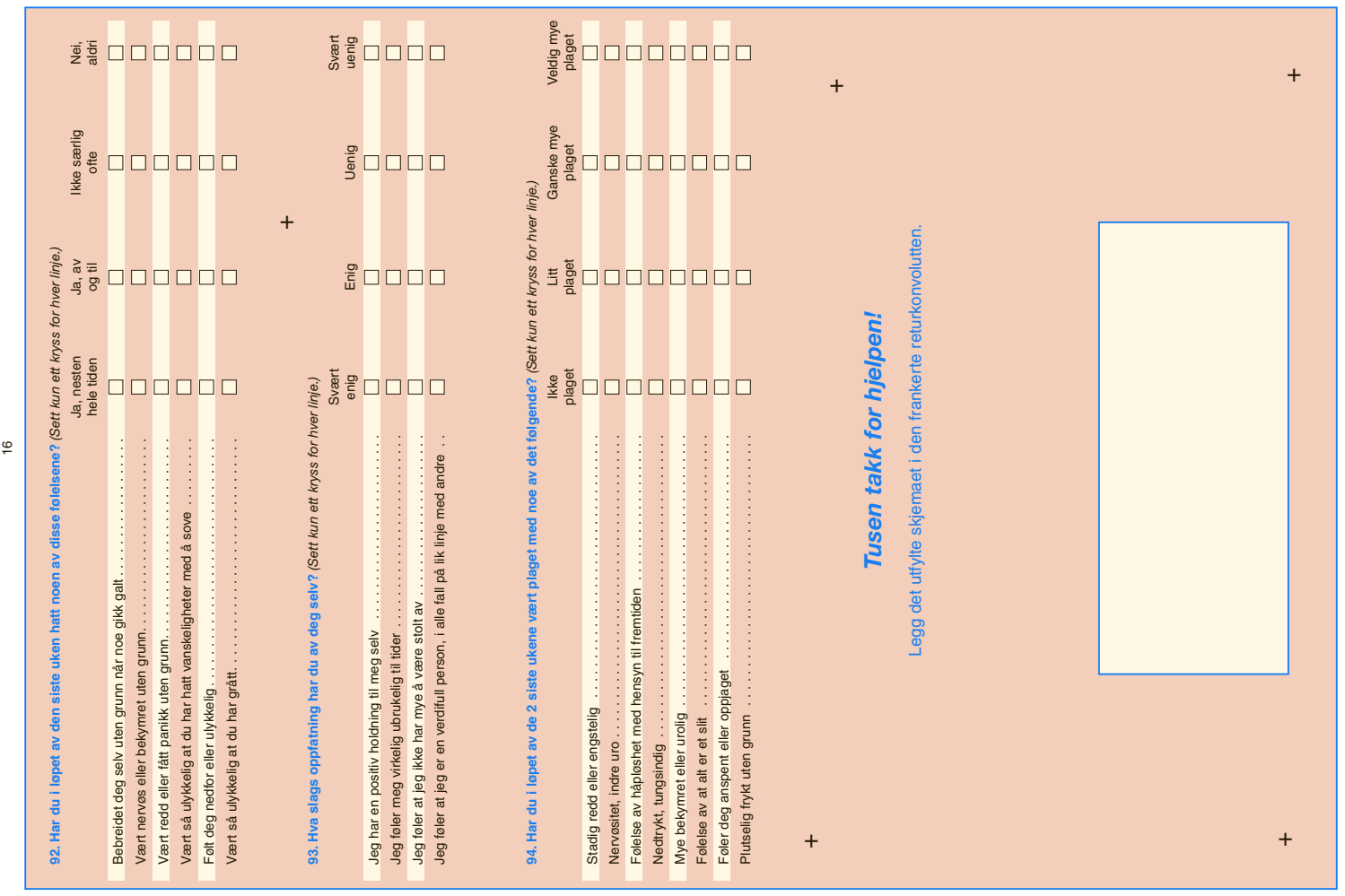

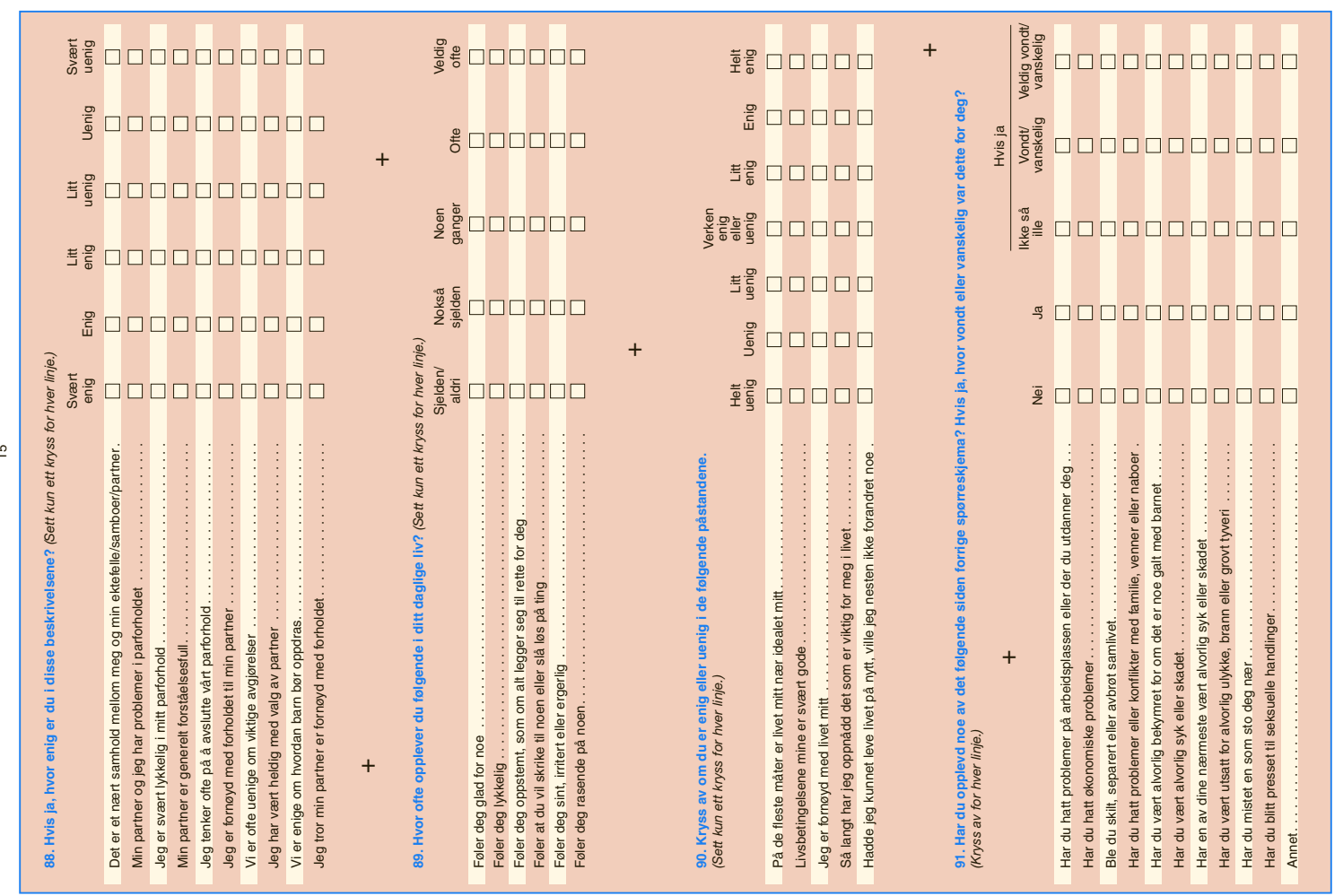



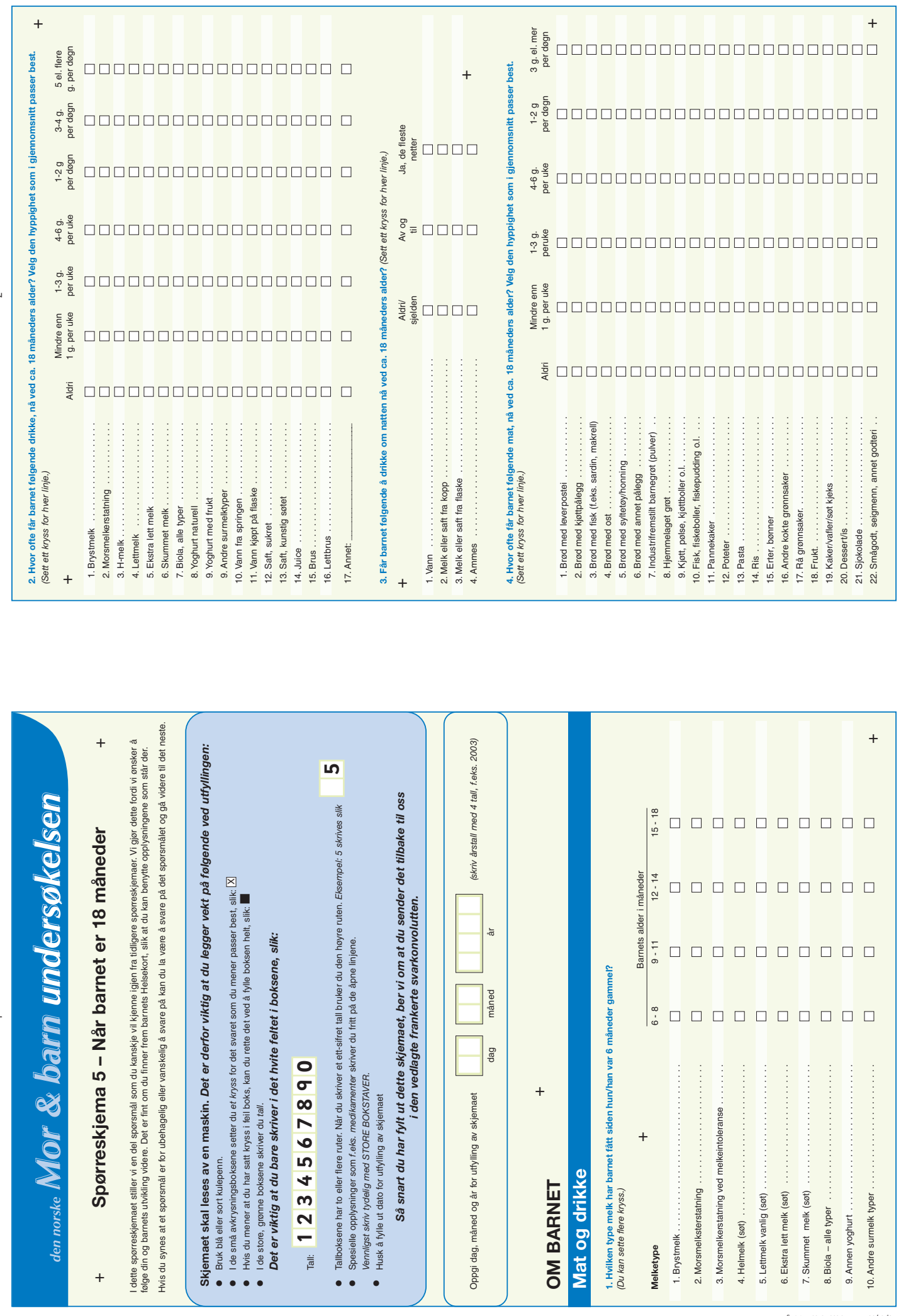

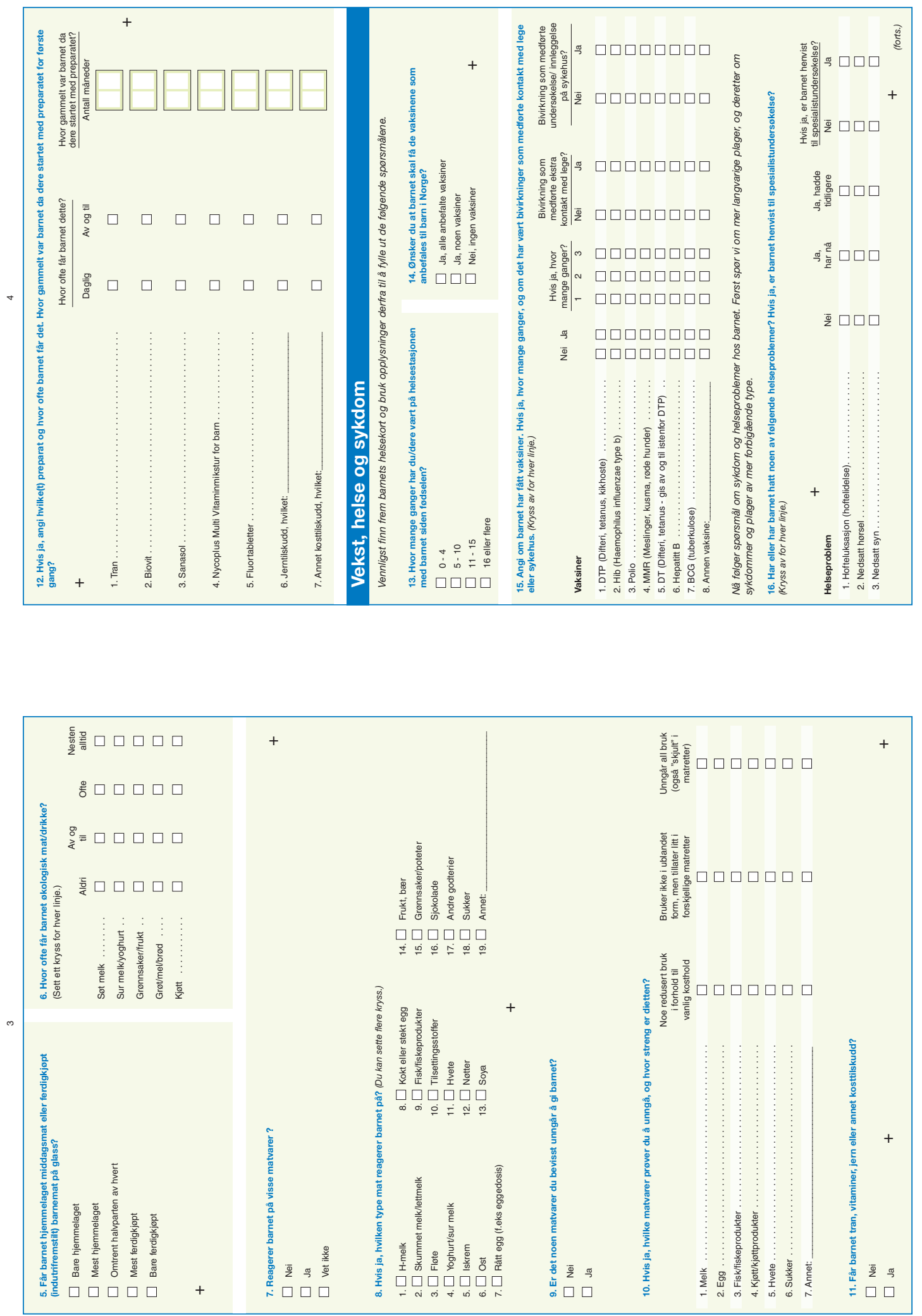

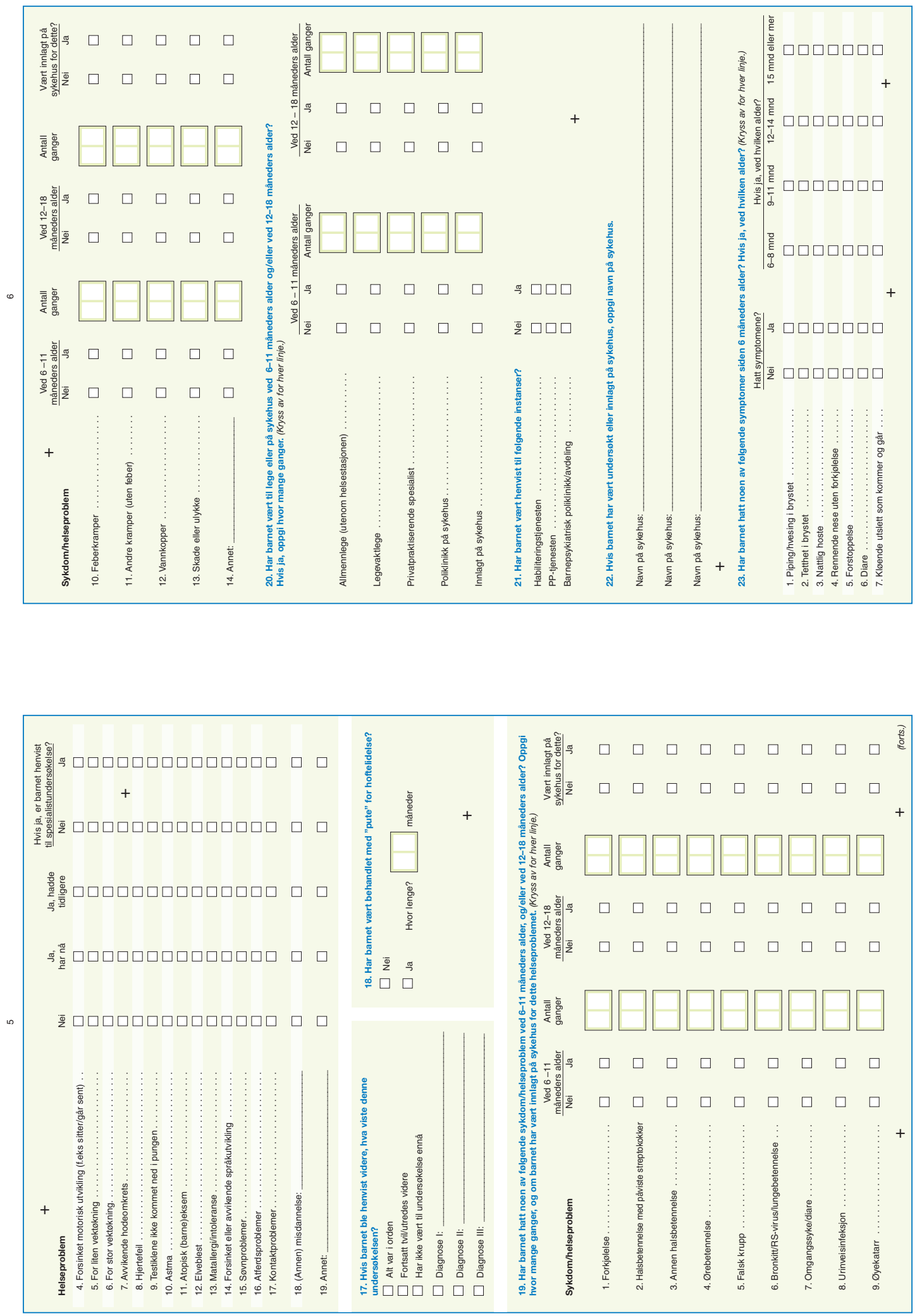

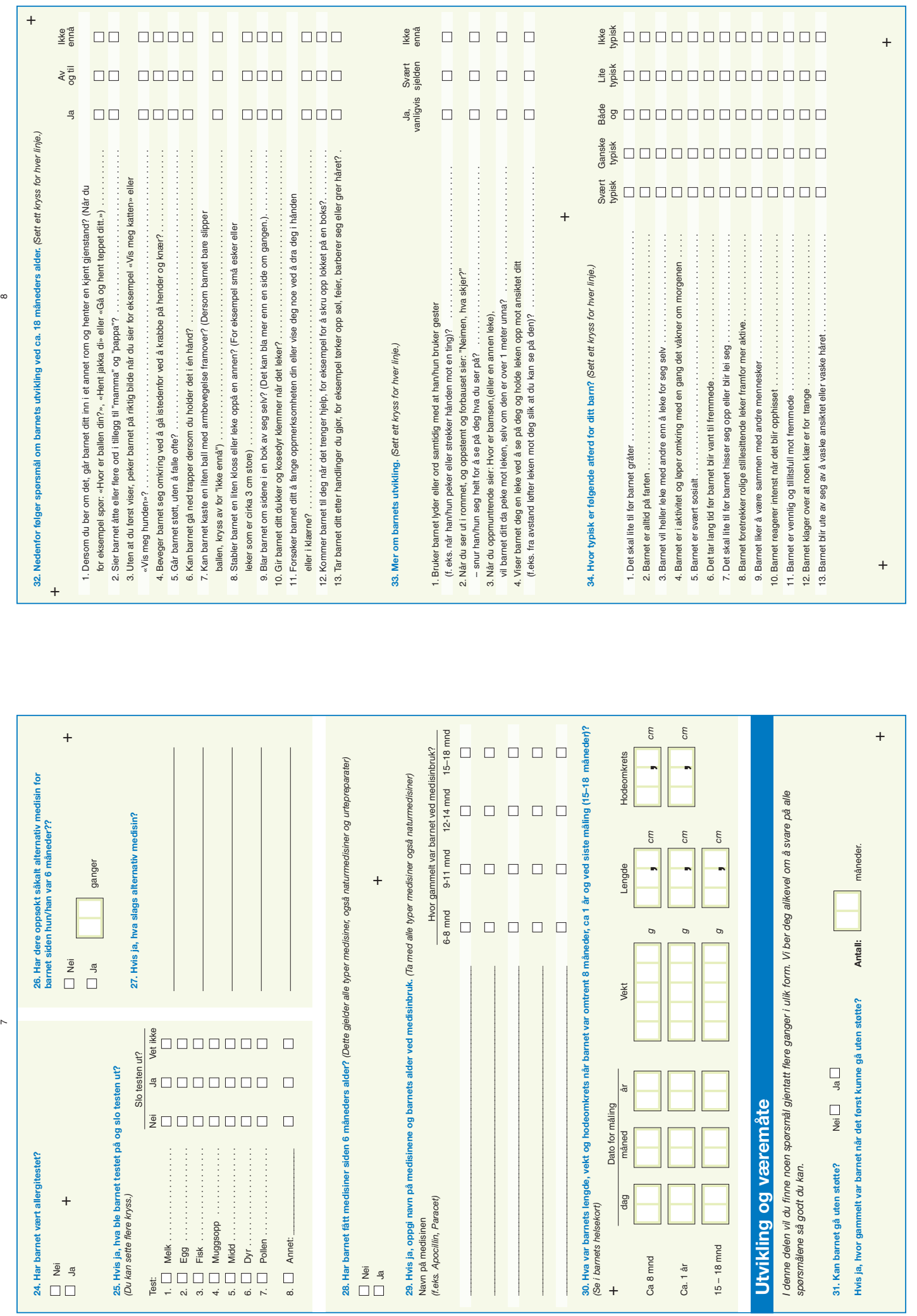

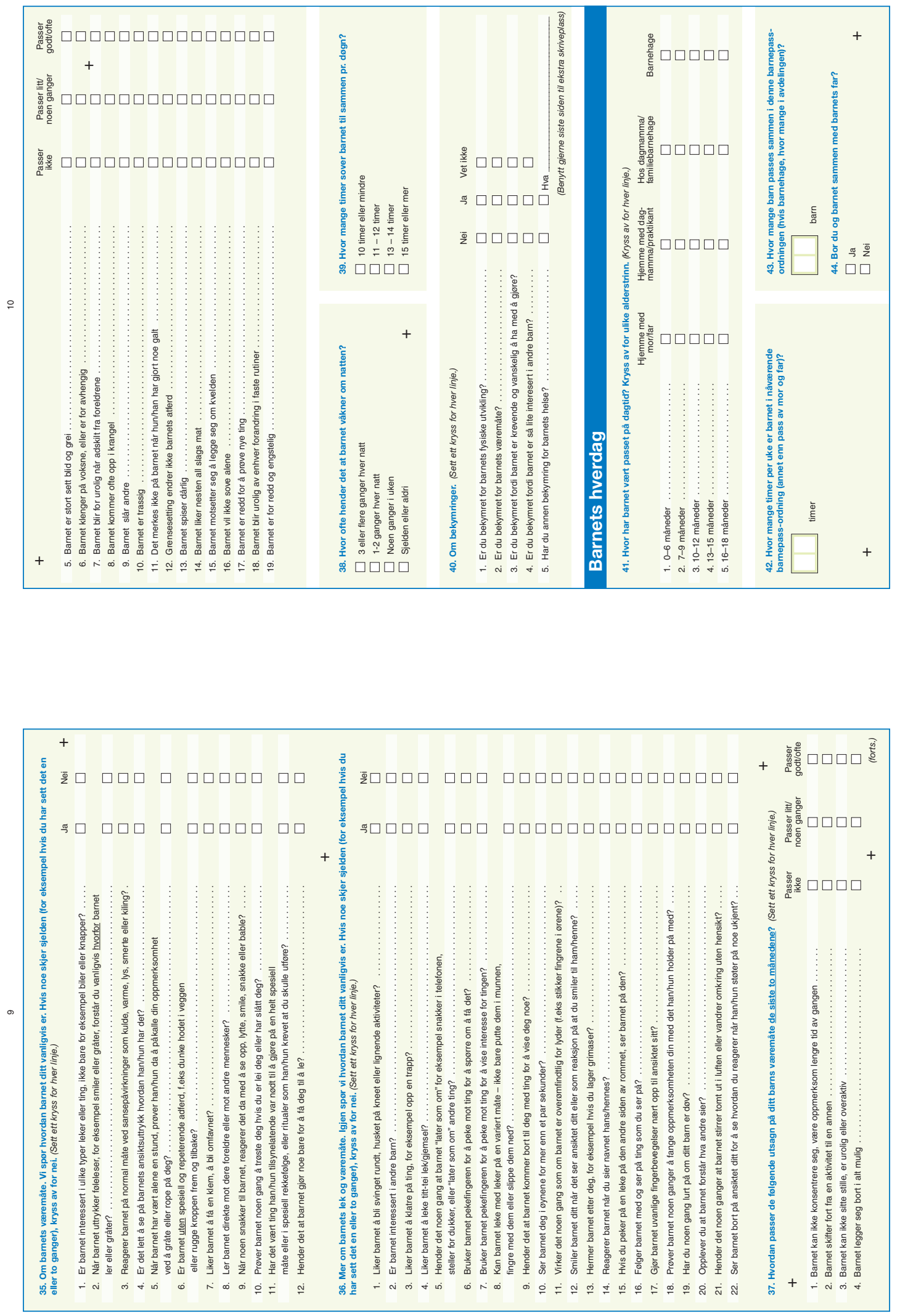

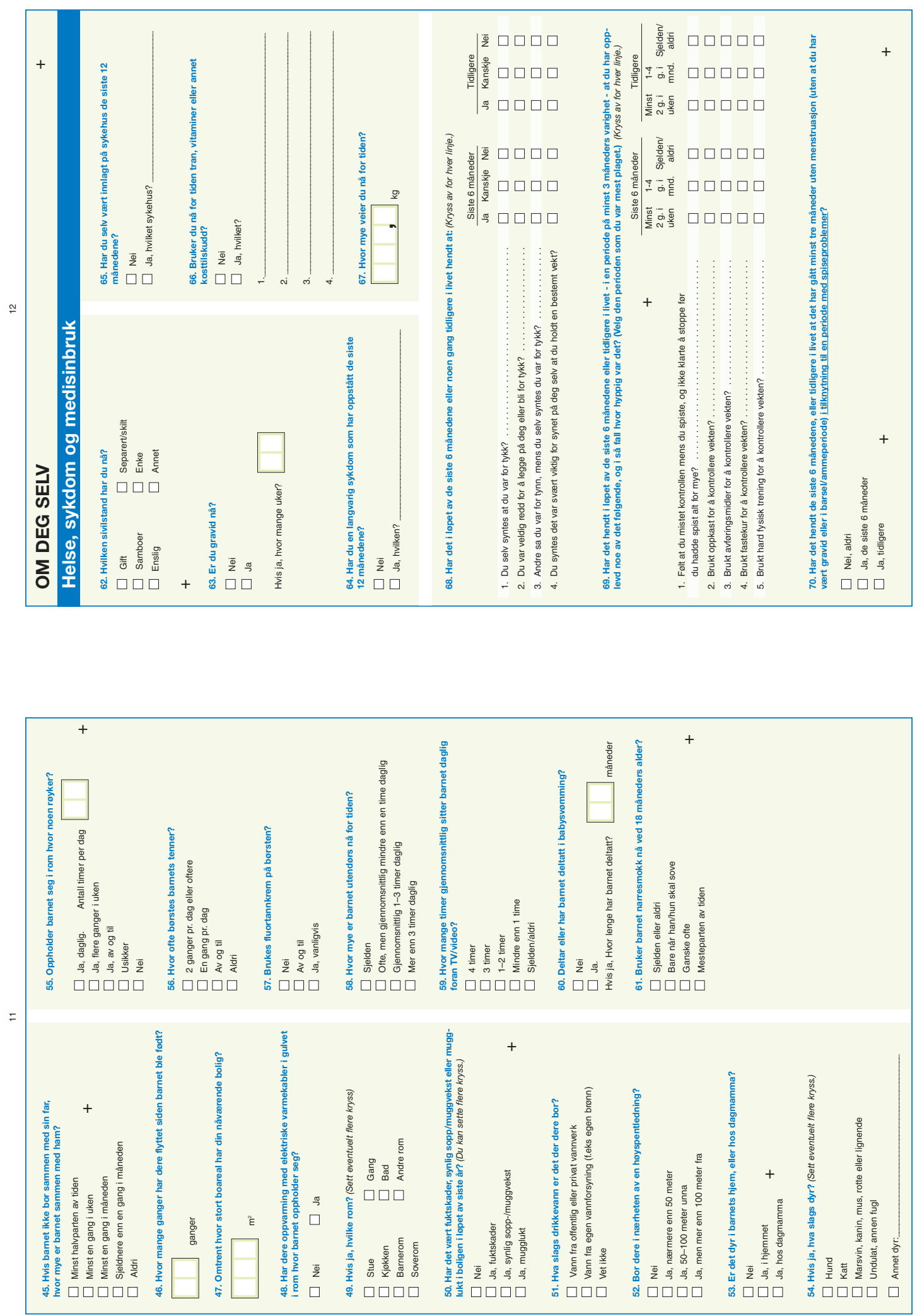

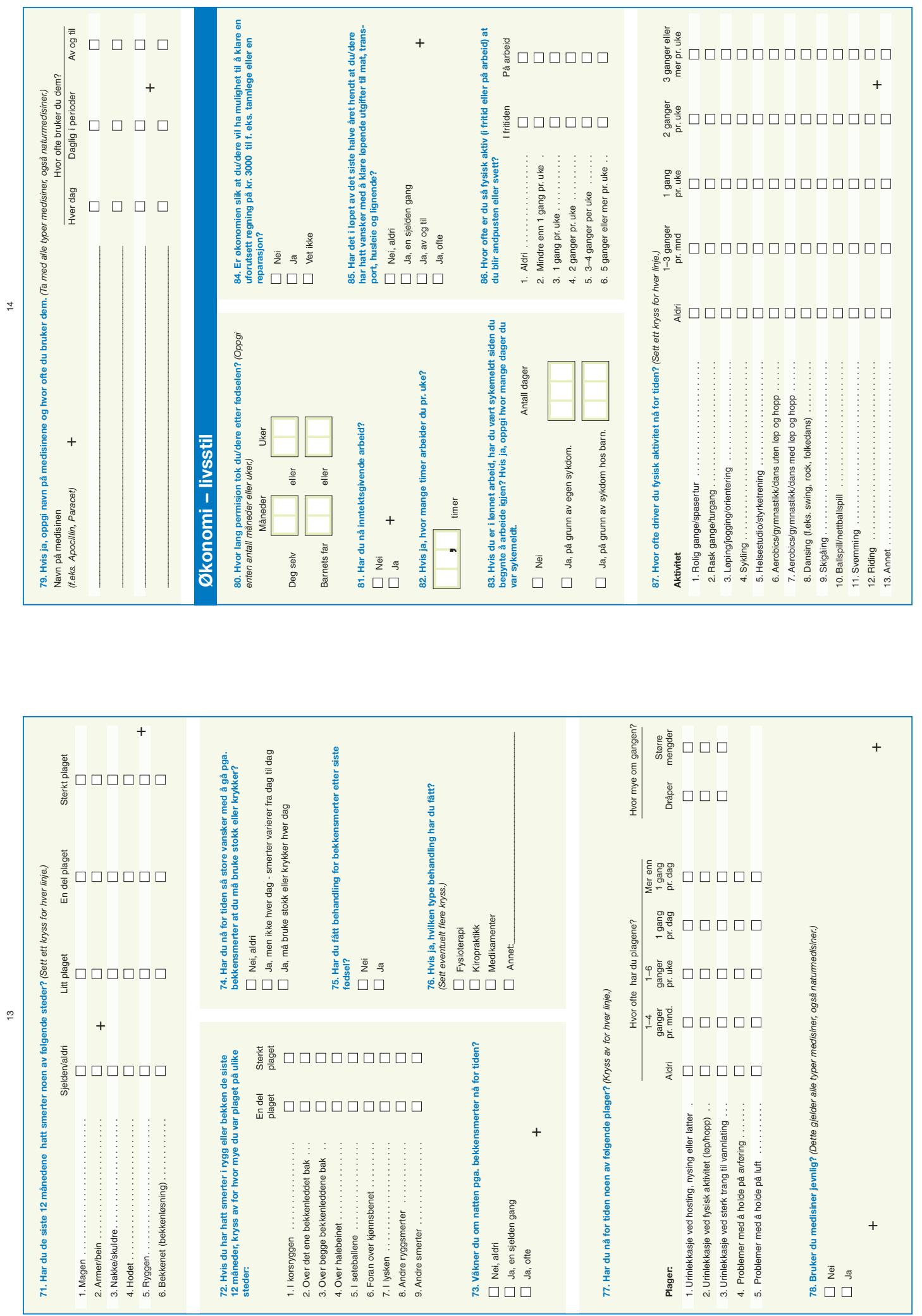


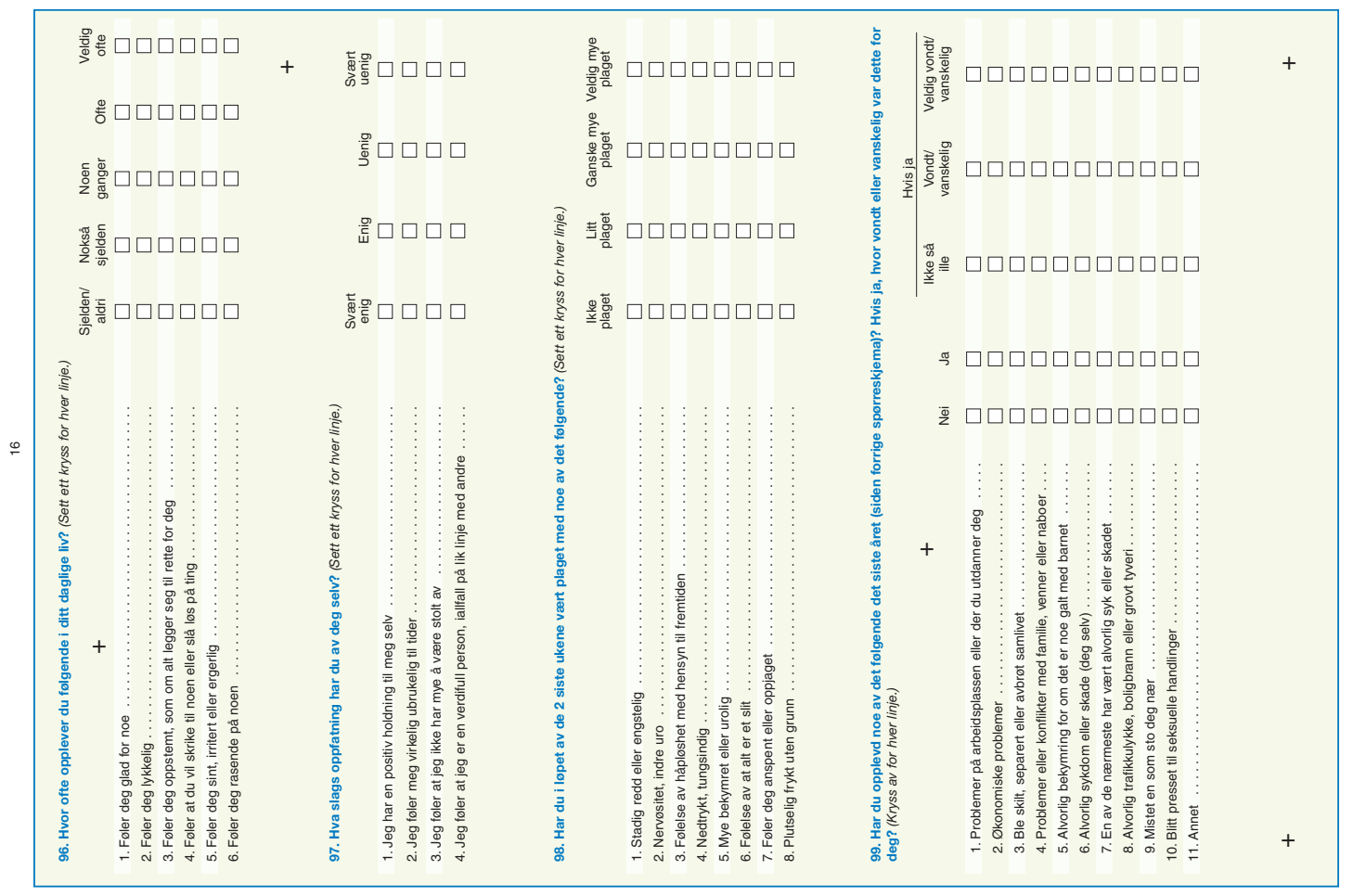

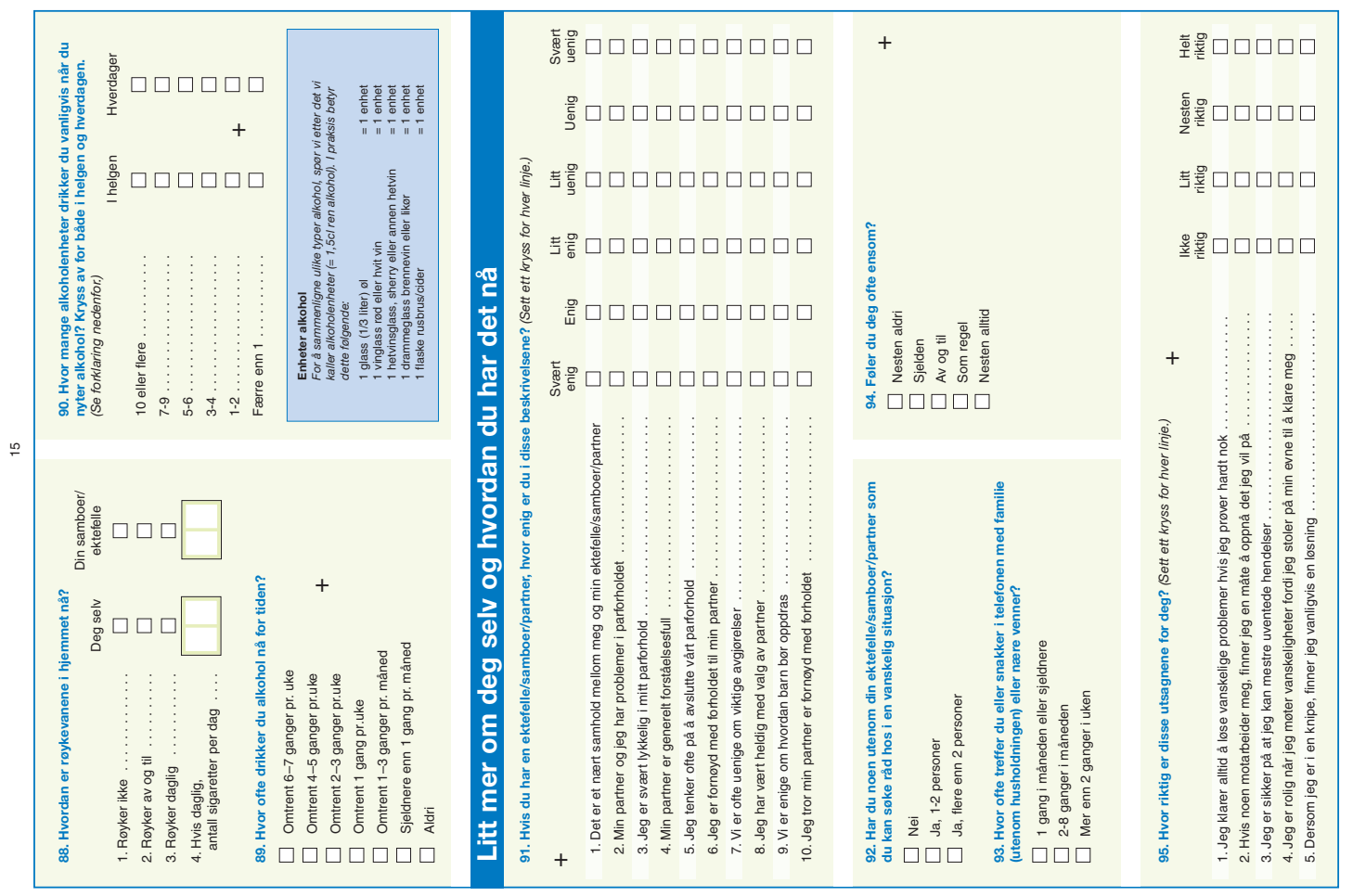



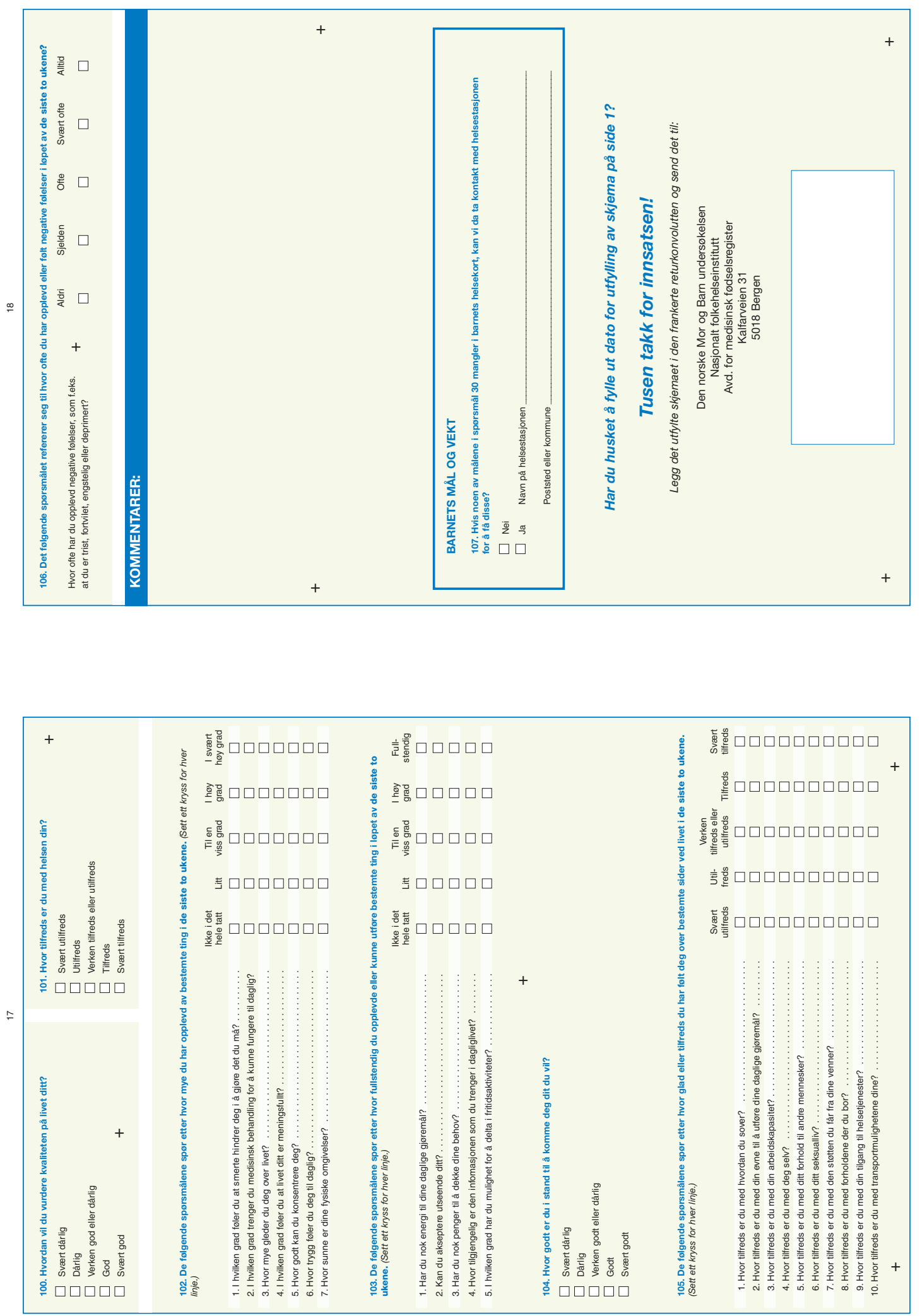

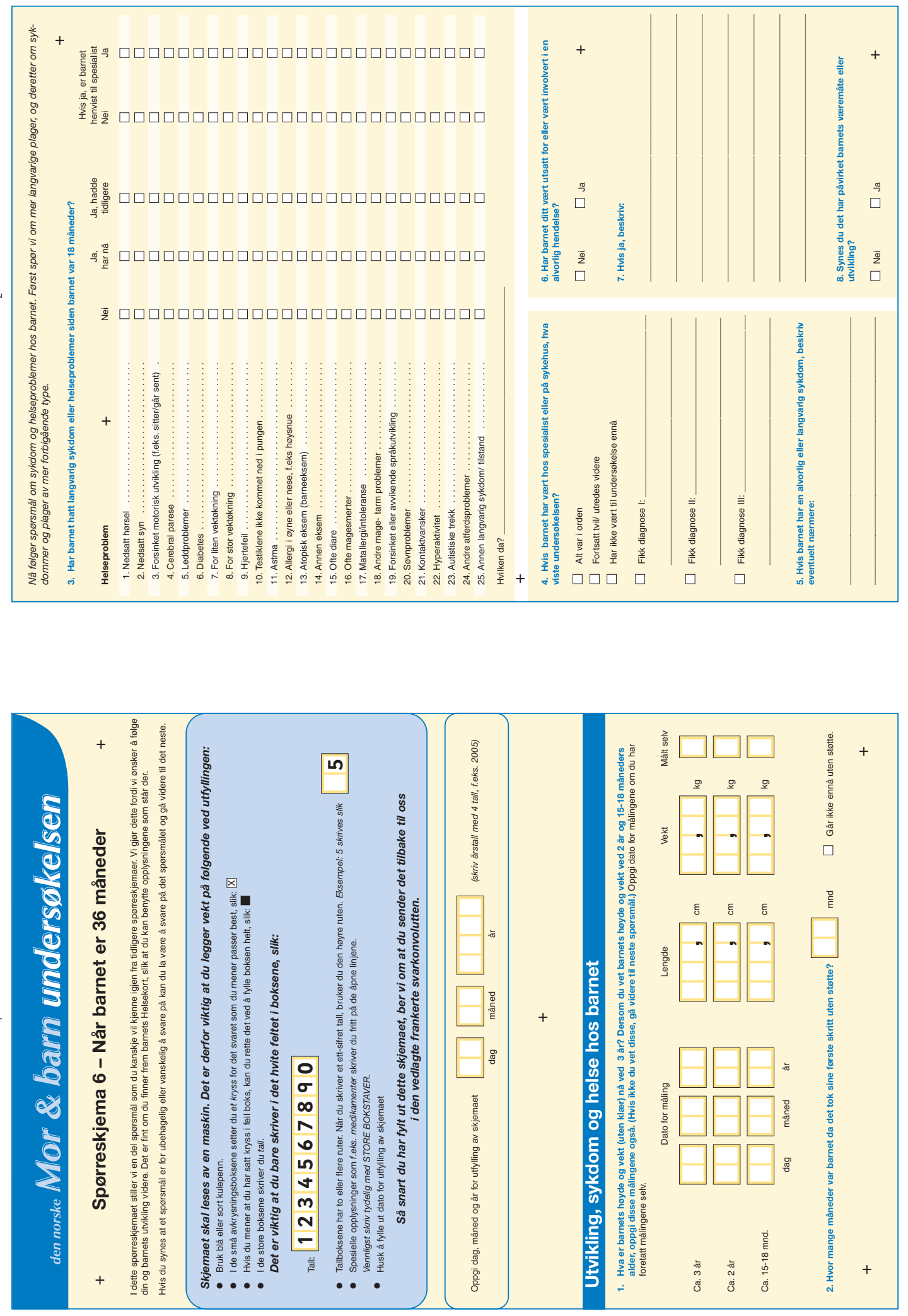

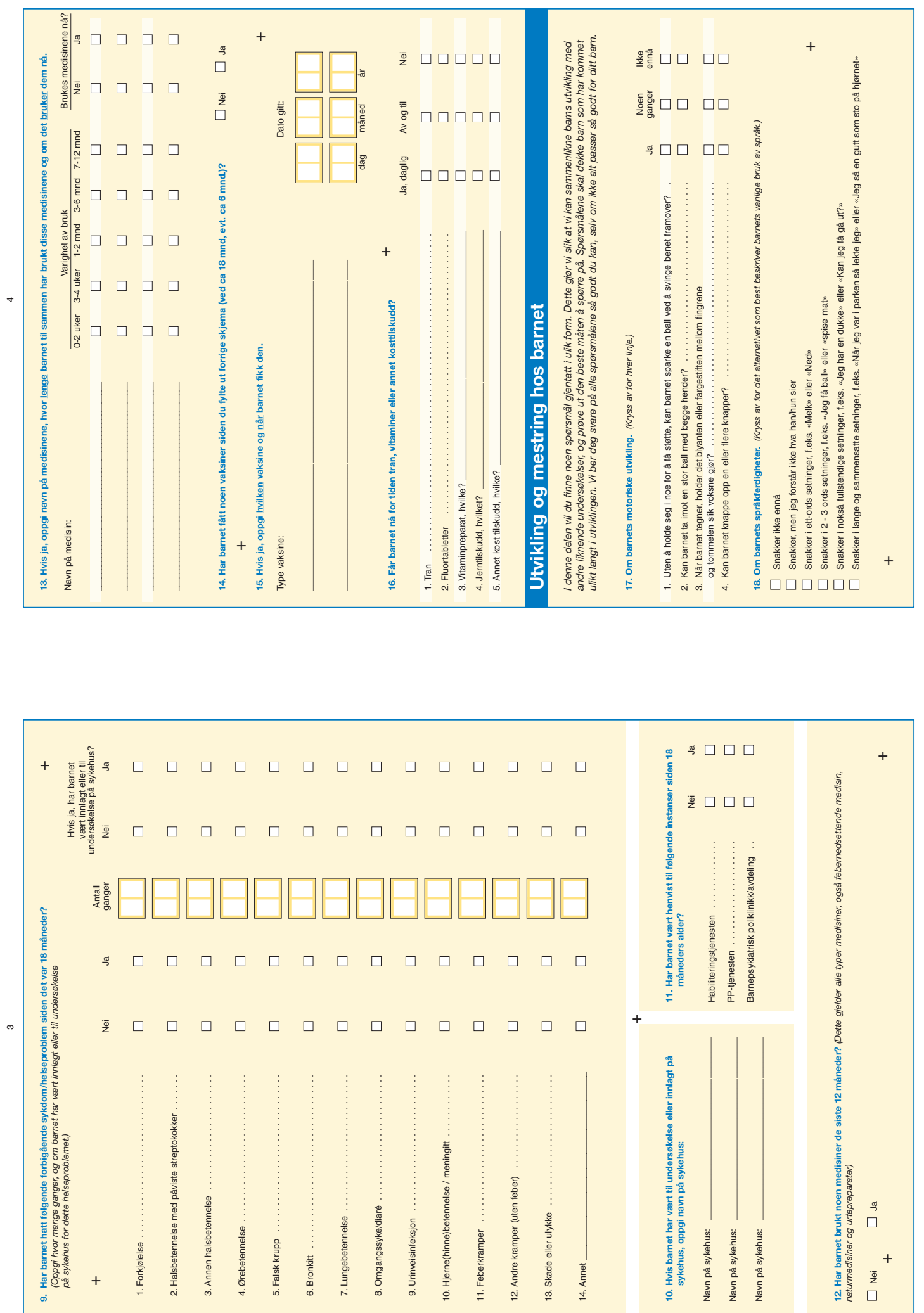


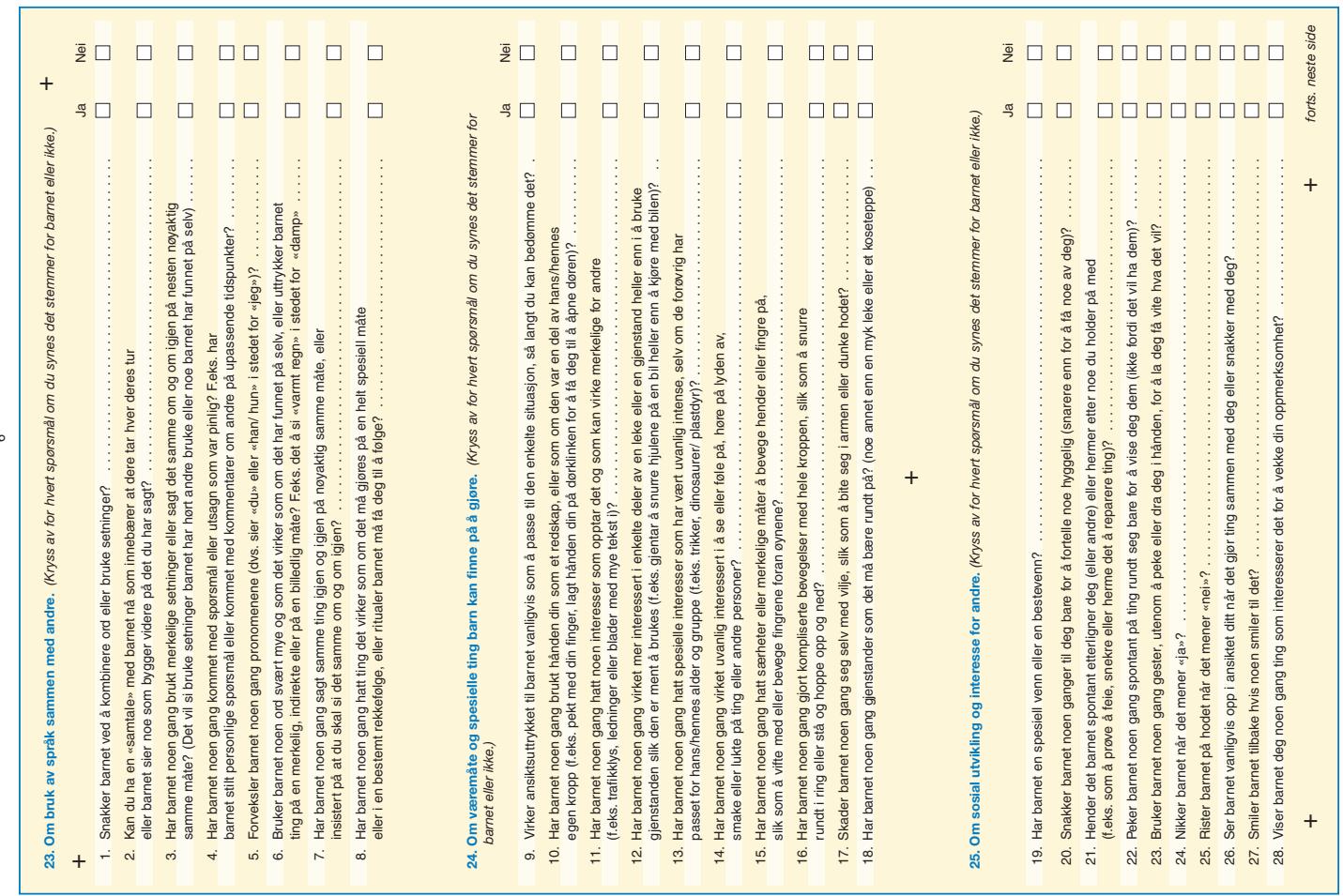

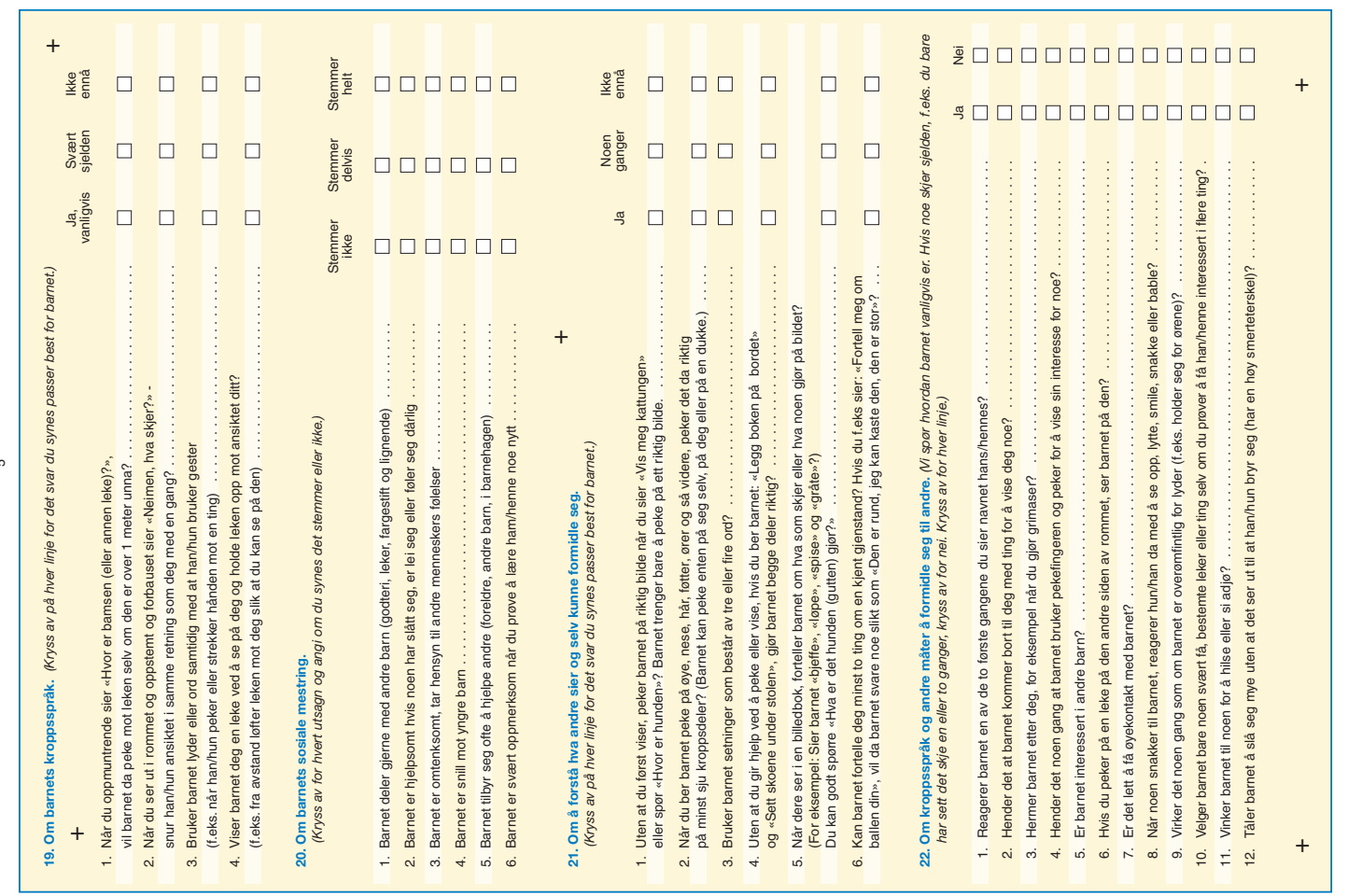




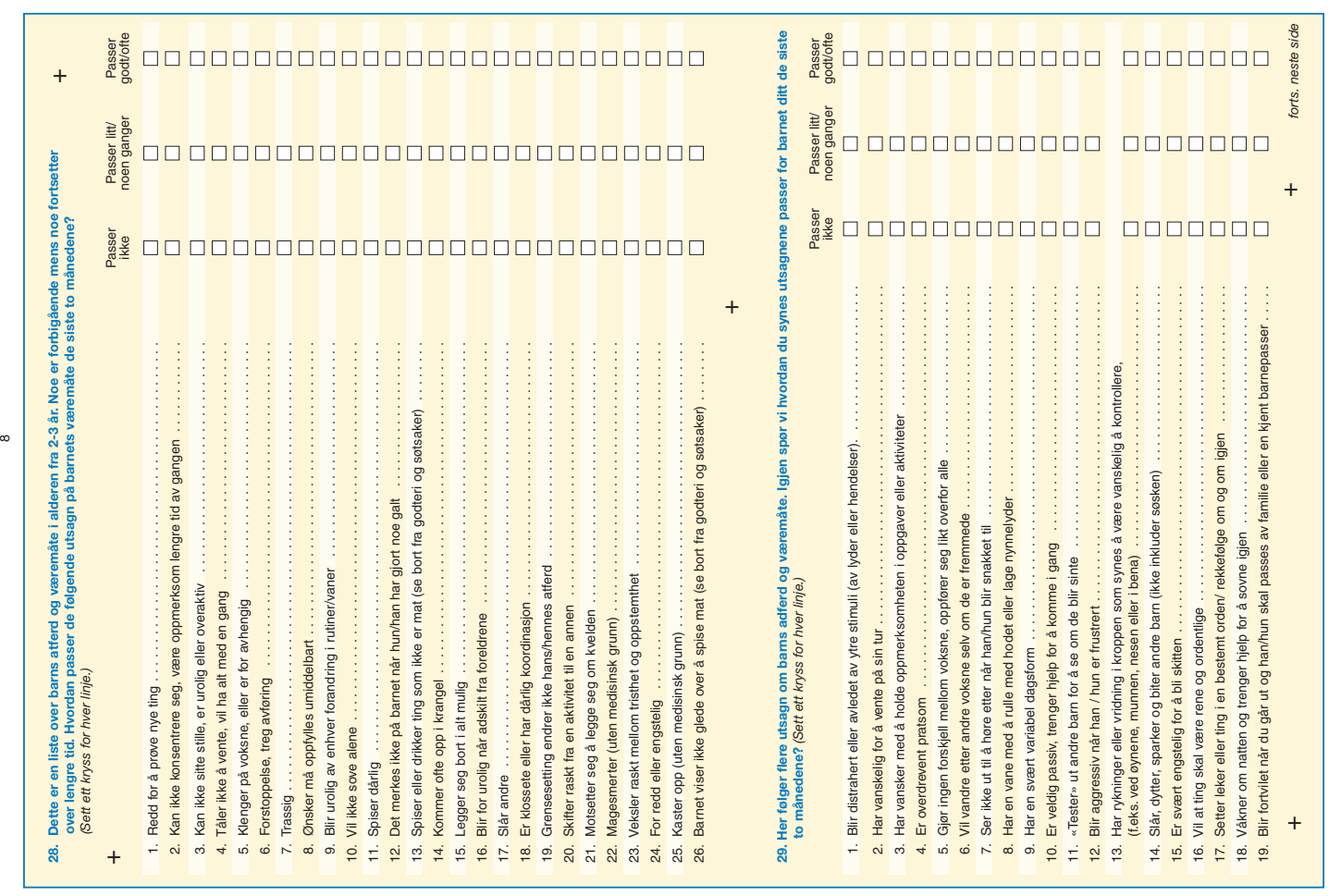

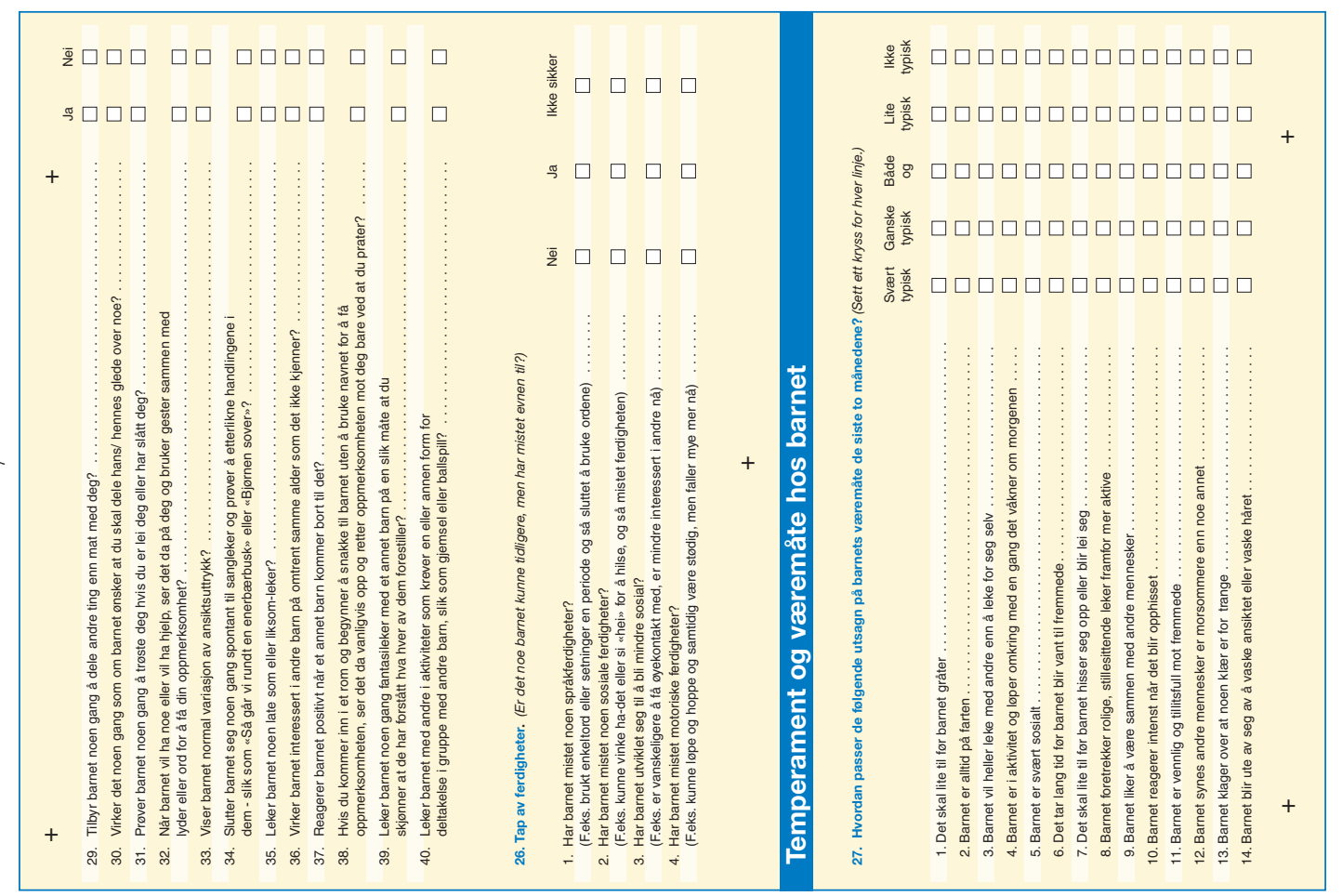




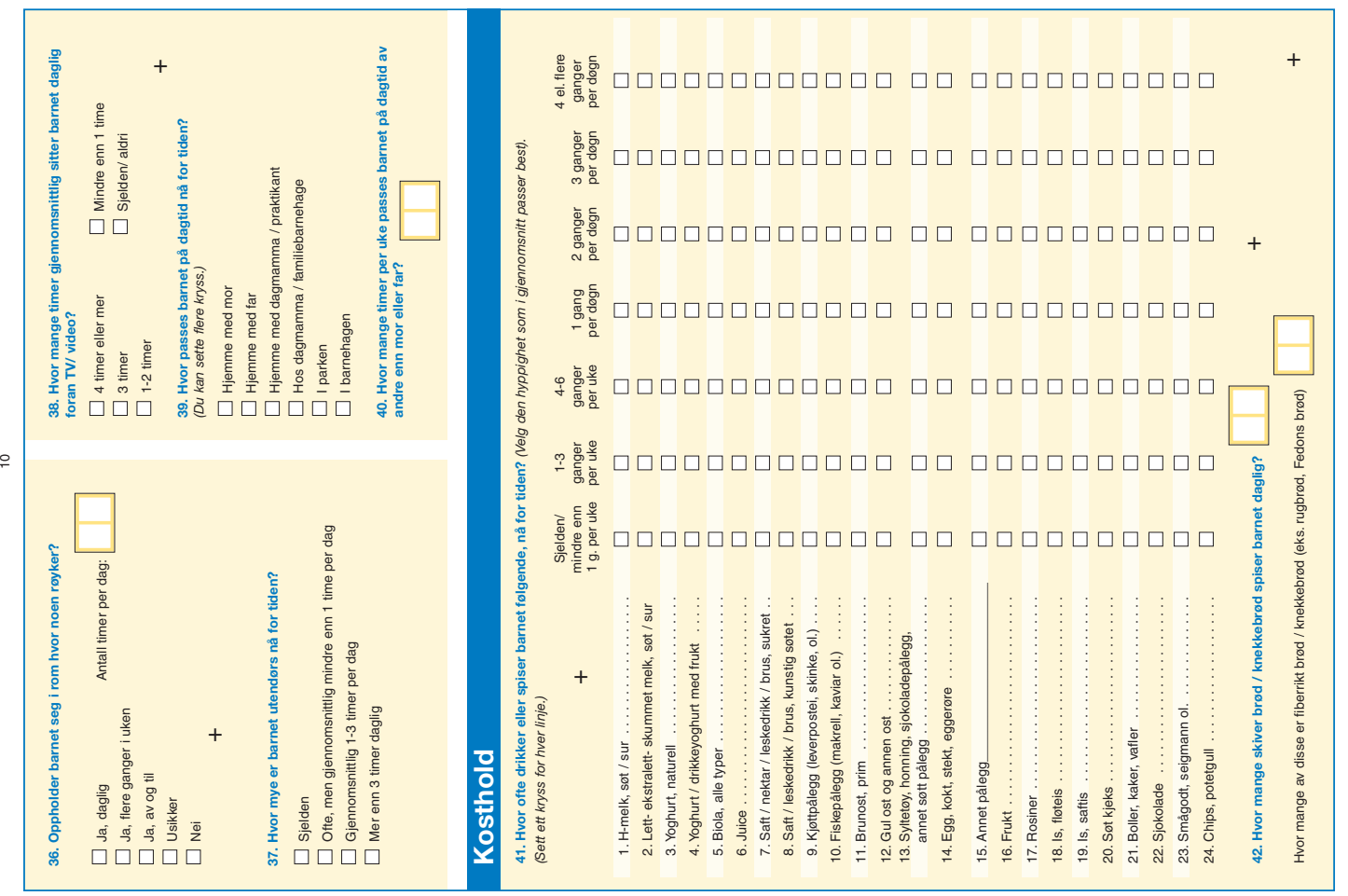

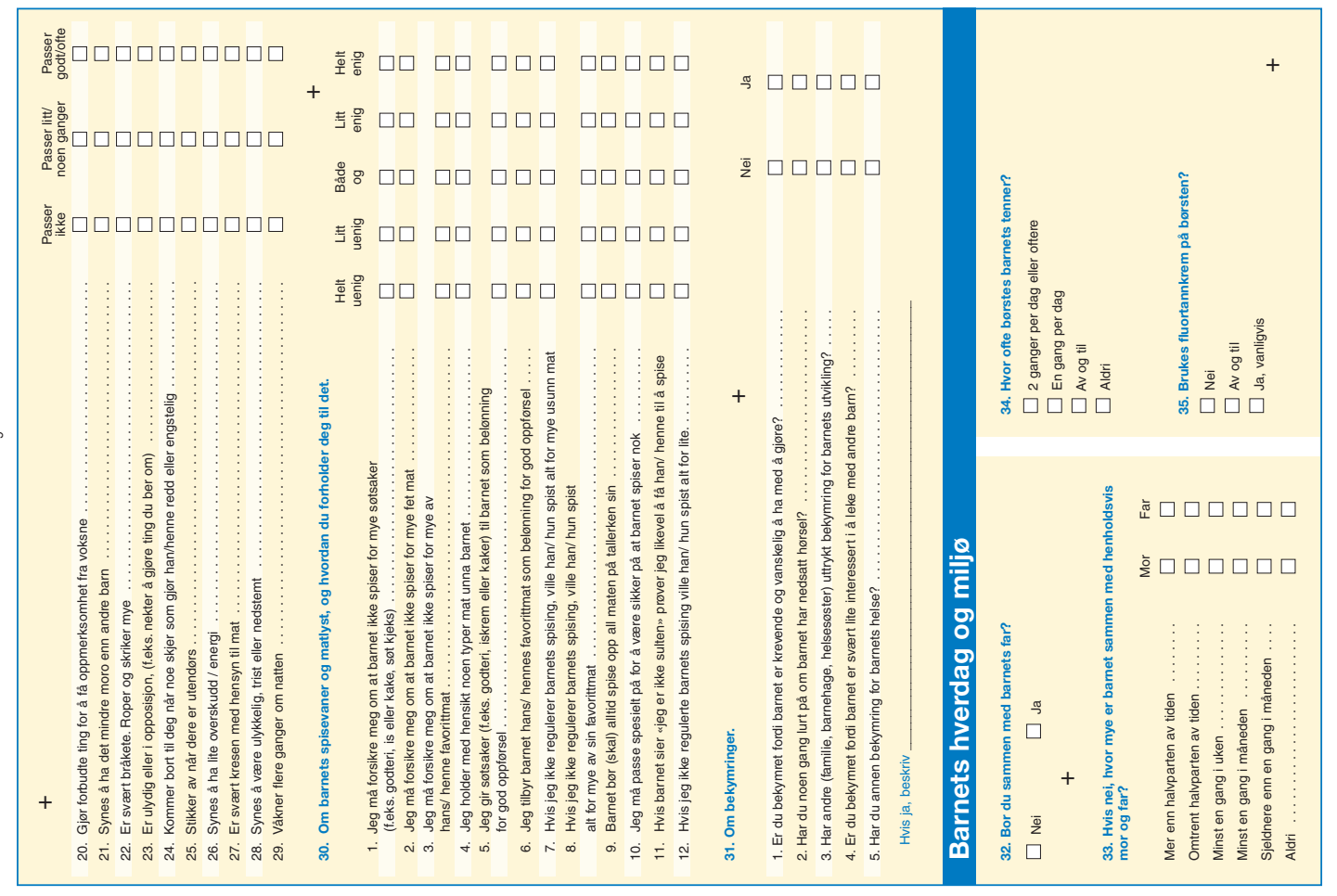



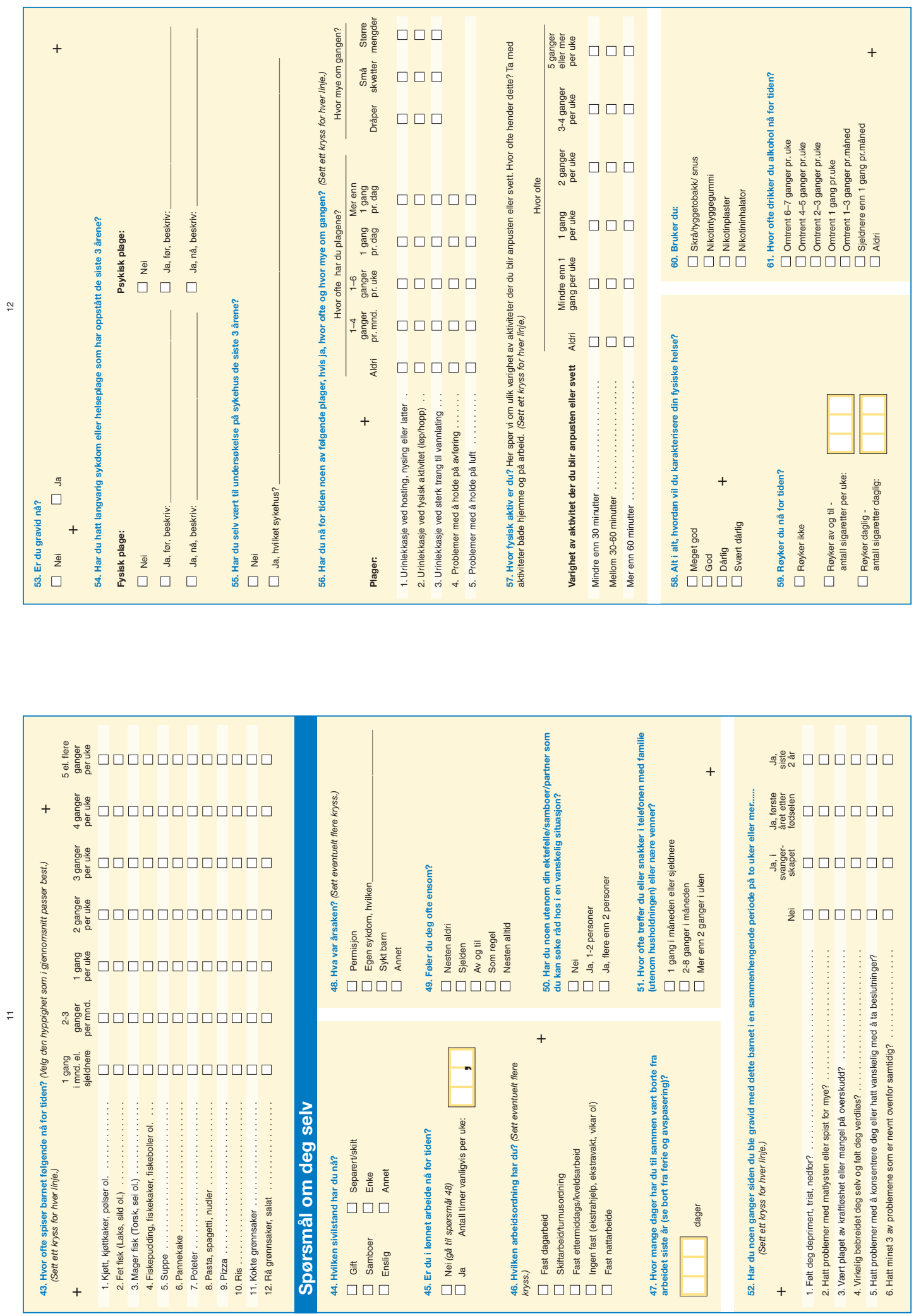


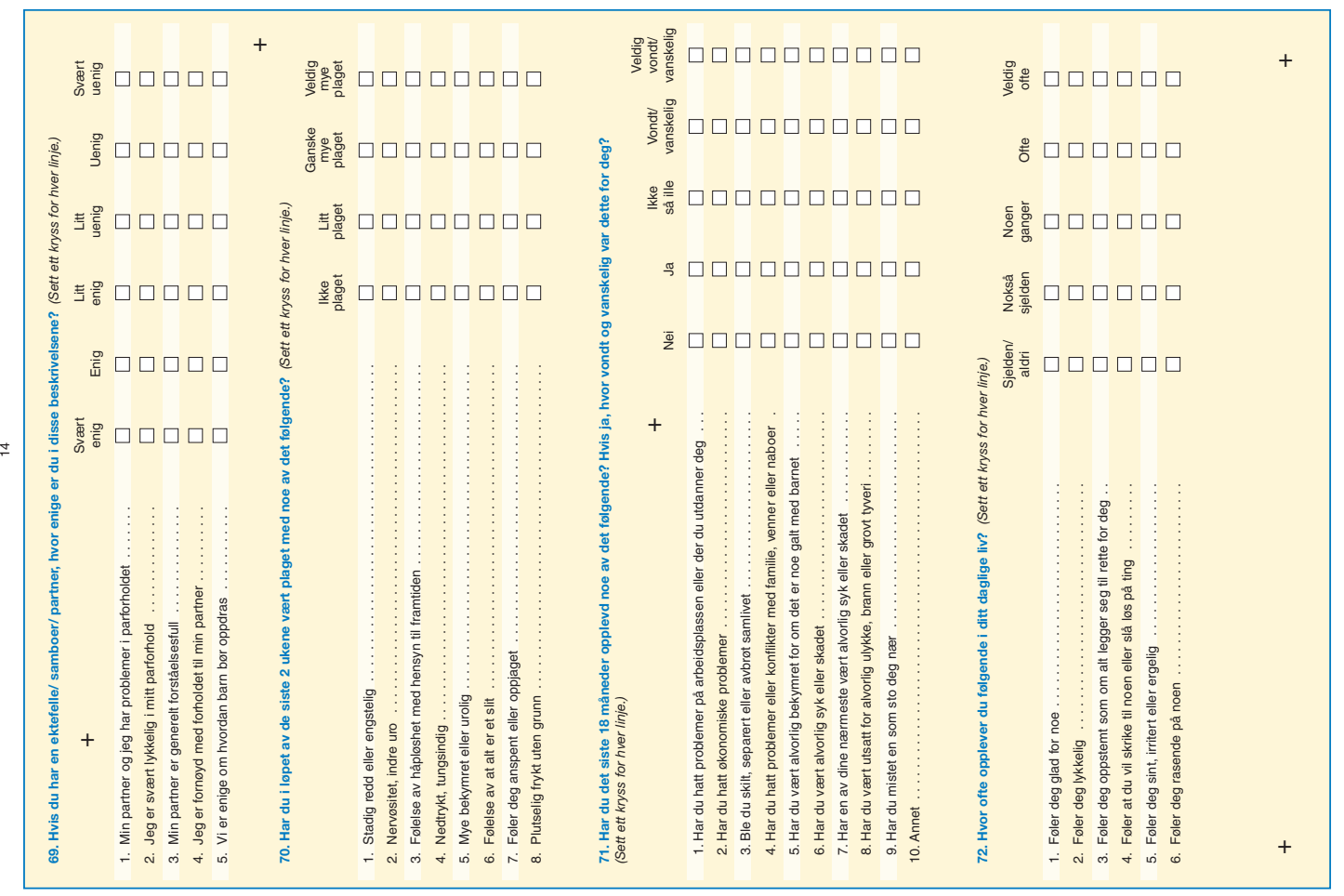

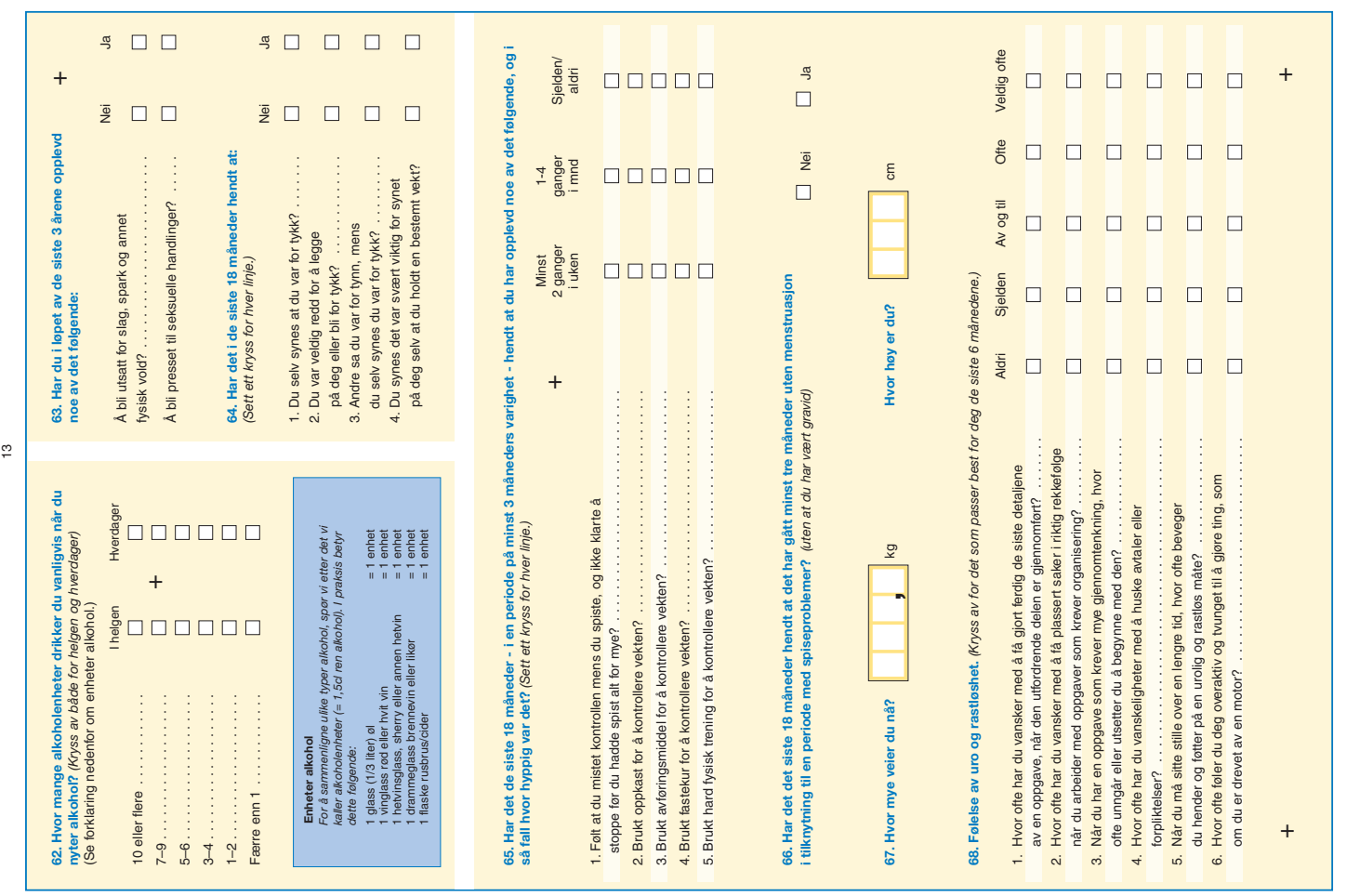




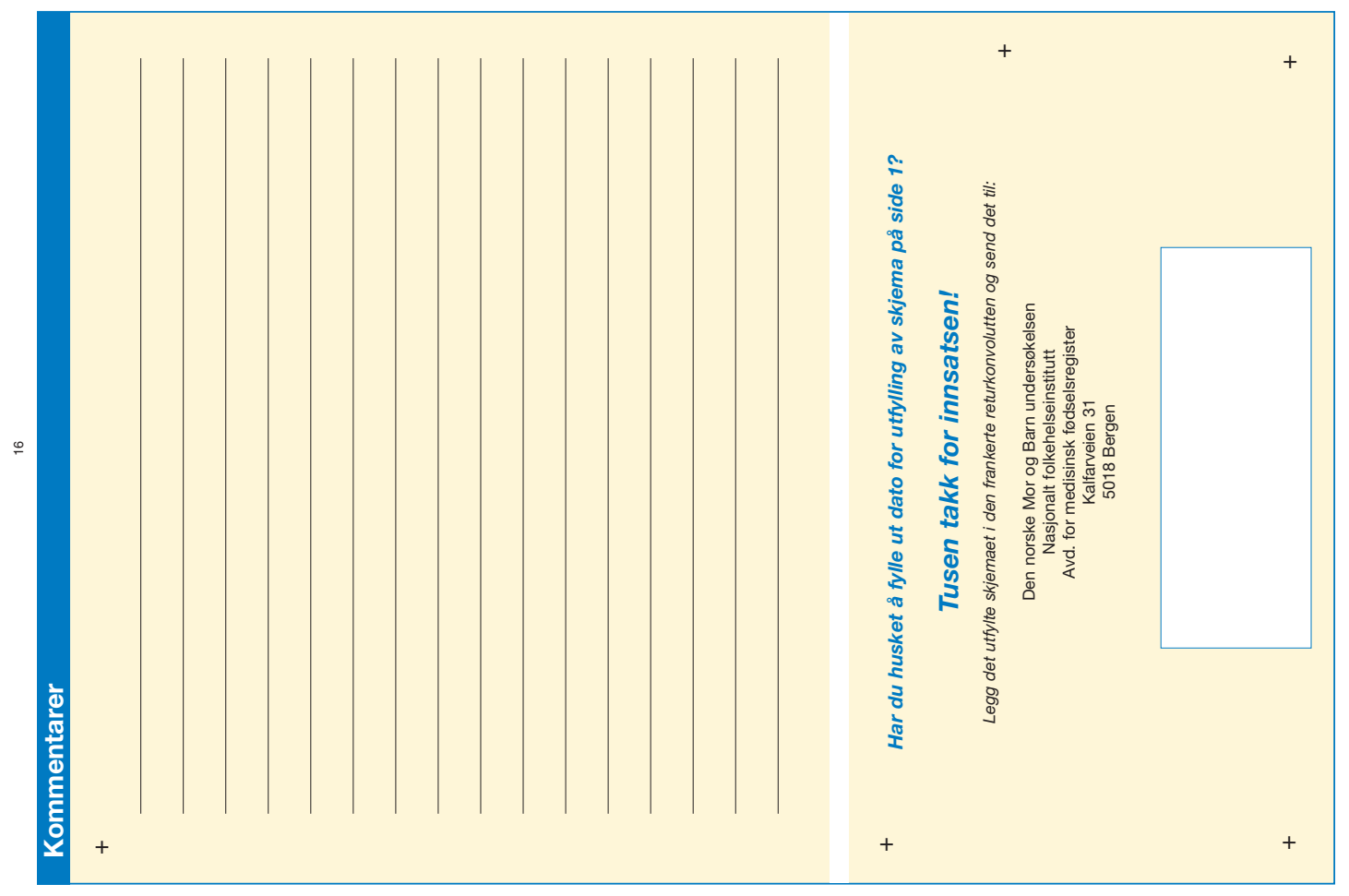

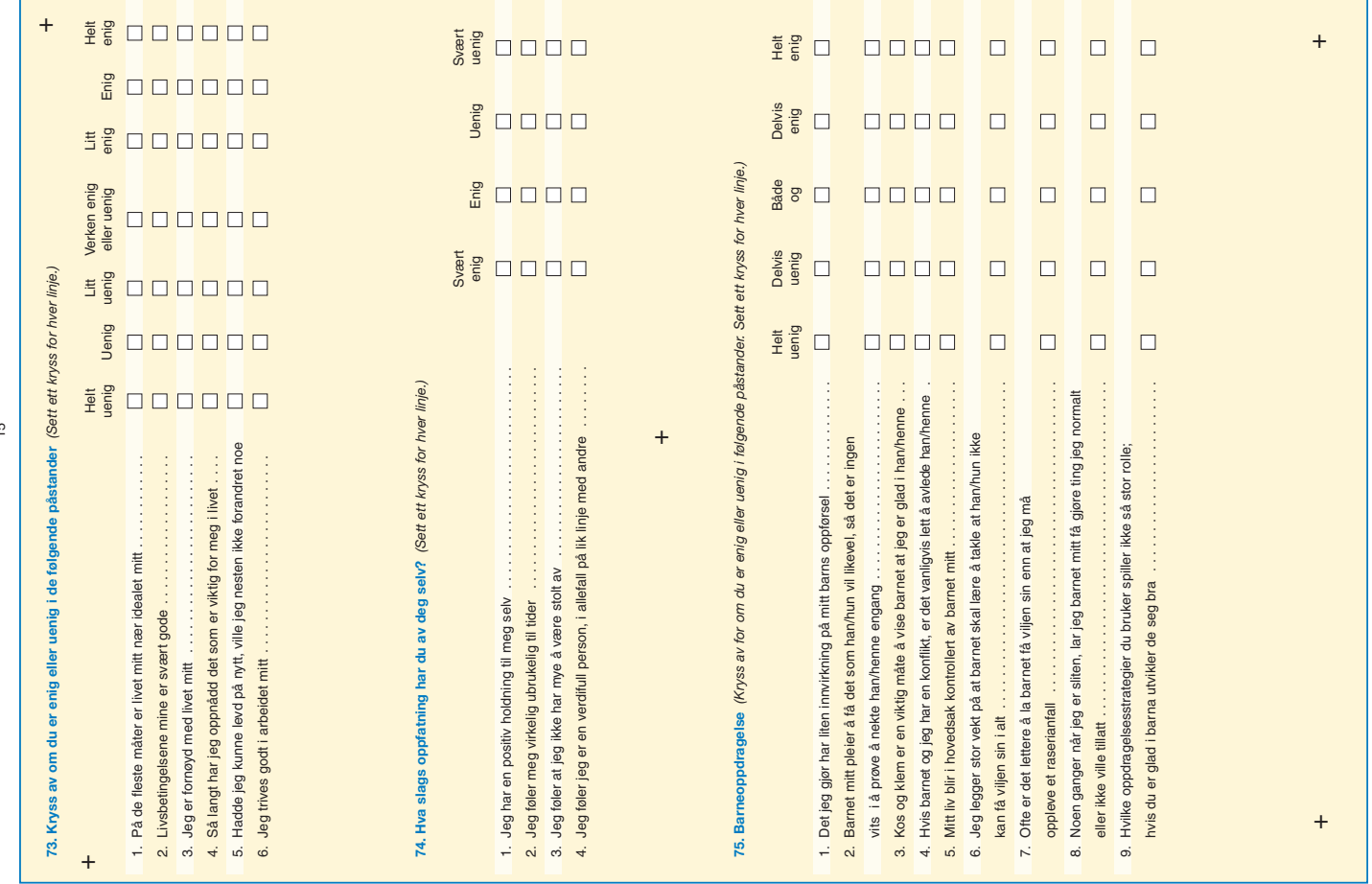


